\title{
Zur Grammatik (vor allem) konditionaler V1-Gefüge im Deutschen *
}

\author{
MARGA REIS \& ANGELIKA WÖLLSTEIN
}

\section{Abstract}

Standardly, verb-first (V1) conditionals are considered to be mere variants of wenn-conditionals; accordingly, left-peripheral V1-clauses are analyzed as embedded into the prefields of declarative apodosis clauses, just like their V-end counterparts. We challenge this view, proposing instead that dependent V1-clauses are syntactically unembeddedlunintegrated, and, consequently, that postposed declarative apodosis clauses are either V2declaratives with prefield ellipsis or V1-declaratives. We argue our case by presenting evidence that (i) wenn-clauses differ considerably from VIclauses in semantic distribution, (ii) unlike wenn-clauses, V1-clauses do not meet the criteria for syntactic embedding, (iii) the alternatives entailed by (ii) for the structural analysis of a postposed apodosis both have empirical support. As for a syntactic analysis of V1-structures suited to these findings, we argue that a CP adjunction analysis is currently the best option available. We also point out connections between the semantic restrictions on V1-conditionals and the semantics of V1-interrogatives that are suggestive of a common semantic core, which raises hope that our background vision (ultimately, all dependent $V$-to-C clauses are semantically licensed substitutes for genuine subordinates) may also be true for V1-clauses.

Keywords: V1-clauses, wenn-clauses, \pm integration, conditionals, concessives, polar interrogatives

* Die vorliegende Arbeit entstand im Rahmen des Projekts „Satzgefüge - Subordination - Parenthese“ (= Teilprojekt B15/SFB 441 Tübingen). Teile davon wurden projektintern wie -extern zur Diskussion gestellt an den Universitäten Potsdam und Hamburg (12/2007), auf der internationalen Tagung „Linguistic Evidence“/Tübingen (02/2008), und am ZAS Berlin (03/2008). Für produktive Kommentare und Kritik danken wir allen Teilnehmer(inne)n dieser Diskussionen, insbesondere Katrin Axel, Christian Fortmann, Manfred Krifka, Ewald Lang und Hubert Truckenbrodt. Besonderen Dank schulden wir darüber hinaus Rüdiger Christ, sowie zwei anonymen Gutachtern für gründliche Lektüre und zahlreiche daraus resultierende Verbesserungsvorschläge. 


\section{Worum geht's?}

Gegenstand der folgenden Überlegungen ist ein bemerkenswert unerforschtes Gebiet der deutschen Grammatik: die Struktur und Bedeutung von Gefügen mit unselbständigem V1-Satz, insbesondere in linksperipherer Stellung. Kanonische Beispiele sind Konditionalgefüge wie (1):

a. Regnet es, bleiben wir zu Hause.

(HdK 2003: 225)

b. Hätte ich mehr Zeit gehabt, hätte ich einen kürzeren Brief geschrieben.

(B. Pascal)

Diese scheinen völlig gleichbedeutend mit den konditionalen wenn-Gefügen in (2); allenfalls besteht ein stilistischer Unterschied, insofern wennSätze gesprochen und geschrieben das unmarkierte konditionale Ausdrucksmittel sind, während V1-Konditionale weitestgehend auf gehobene, schriftsprachliche Register beschränkt sind (s. Auer 2000).

a. Wenn es regnet, bleiben wir zu Hause.

b. Wenn ich mehr Zeit gehabt hätte, hätte ich einen kürzeren Brief geschrieben.

Dass V1-Gefüge wie (1) in der Tat bloß formale Varianten von wennGefügen sind, ist die - weitgehend stillschweigende - Communis Opinio der einschlägigen Literatur zum Deutschen (wie übrigens auch zur Alternation von V1- vs. if-clauses im Englischen). ${ }^{1}$ Von daher verwundert es nicht, dass ihnen traditionell die gleiche Gefügestruktur zugewiesen wird, wobei die wenn-Gefüge den Maßstab abgeben: Da es durchaus Gründe gibt, Fälle wie (2) für Einbettungsgefüge zu halten - was u.a. heißt: der linksperiphere wenn-Satz steht im Vorfeld eines (deklarativen) V2-Satzes -, wird Gleiches für V1-Gefüge angenommen (so explizit HdK 2003: 168, 202 u. a., Zifonun et al. 1997: 2252), also in etwa die Struktur (3). Auch hier gilt Analoges fürs Englische.

\section{Traditionelle Einbettungshypothese für konditionale V1-Gefüge im Deutschen:}

1. Vgl. u. a. Zifonun et al. (1997: 2313, 2349), Eisenberg (1999: 332-334), HdK (2003: 225); lediglich König \& Van der Auwera (1988: 116f.) verweisen auf einige Distributionsunterschiede. - Spezialliteratur zu deutschen V1-Konditionalen gibt es so gut wie nicht, und auch zum Englischen nur spärlich (Green 1980, Iatridou \& Embick 1994, Dancygier 1998: Kap. 7.3 [192-194]). 
[CP $\left[{ }_{C P} \text { Regnet es }\right]_{\mathbf{j}}\left[{ }_{C},\left[{ }_{C}\right.\right.$ bleiben $\left.{ }_{i}\right]$ [IP wir zu Hause $\left.\left.\left.\mathbf{t}_{\mathbf{j}} \mathbf{t}_{\mathrm{i}}\right]\right]\right]^{2}$ Protasis

Antecedens

Apodosis

Konsequens

Wir halten (3) für falsch und setzen ihr die Unintegriertheitshypothese $(\mathrm{H})$ entgegen:

(H) Linksperiphere V1-Nebensätze sind nicht in ihren Bezugssatz eingebettet/integriert, sondern mit ihm (quasi-)parataktisch ${ }^{3}$ verbunden.

(H) hat zwei klare strukturelle Implikationen, hier als Folgehypothesen (H1), (H2) formuliert:

(H1) Der linksperiphere V1-Satz ist kein Vorfeldelement, sondern unintegriert vorgeschaltet.

(H2) Das deklarative Zweitkonnekt in V1-Gefügen ist entweder ein V2Deklarativ mit (zu rechtfertigender) Vorfeld-Ellipse oder ein V1Deklarativ.

Wir werden im Folgenden argumentieren, dass (H1) - $(\mathrm{H} 2)$ empirisch so vieles für sich haben, dass $(\mathrm{H})$ gerechtfertigt bzw. zumindest äußerst ernst $\mathrm{zu}$ nehmen ist.

Der Nachweis von $(\mathrm{H})$ ist unser zentrales Anliegen. Allerdings ist er nicht nur Selbstzweck, sondern steht im Zusammenhang mit einer uns wichtigen, umfassenderen Hypothese, die an unselbständigen V2-Sätzen des Deutschen bereits gut bestätigt ist (s. Reis 1997, Truckenbrodt 2006), hier zusammengefasst als Semantische Substitutshypothese (SH):

(SH) Unselbständige V-in-C-Sätze (=V1-, V2-Sätze) sind keine ,geborenen' Nebensätze, sondern semantisch lizenzierte Substitute für V-End-Sätze bestimmten Typs.

Damit hat man sich allerdings auch den Nachweis bzw. zumindest die Plausibilisierung einer tief greifenden weiteren Implikation von (SH) aufgeladen, nämlich $(\mathrm{H} 3)$ :

2. Die Spur des V1-Satzes ist nur aus Praktikabilitätsgründen im MF lokalisiert. Zu Argumenten pro linksperipherer Basisgenerierung vs. Topikalisierung von if-Sätzen (z.T. übertragbar auf wenn-Sätze) s. Bhatt \& Pancheva (2006: 647 ff.).

3. ,(Quasi-)parataktisch' soll die Einordnung der V1-Gefüge zwischen echter (unintegrierter) Parataxe und (integrierten) Linksversetzungsstrukturen (Dass du gehst, das freut mich) vorläufig offen lassen. Zur Diskussion dieser Strukturfrage s. u. Abschnitt 6. 
(H3) V1-Nebensätze haben eine von wenn-Sätzen verschiedene Bedeutung, die sich in semantischen Restriktionen der gegenseitigen Austauschbarkeit manifestiert.

Da (H3), falls richtig, nicht nur (SH) stützt, sondern auch die traditionelle Strukturauffassung (3) der intuitiven Basis beraubt, beginnen wir unsere Argumentation pro (H) mit dem Nachweis von (H3) (Abschnitt 2). In Abschnitt 3 diskutieren wir sich daran anschließende semantische Fragen, die für (SH) bzw. (H) auch strukturell von Bedeutung sind. Anschließend argumentieren wir für die Richtigkeit von (H1) (Abschnitt 4). In Abschnitt 5 zeigen wir, dass die alternativen Ausprägungen von (H2) beide empirisch verteidigbar sind; eine Entscheidung zwischen ihnen ist derzeit nicht möglich, aber auch nicht nötig. Damit ist der Beweisgang für $(\mathrm{H})$ abgeschlossen. In Abschnitt 6 diskutieren wir, welche Gefügestruktur entsprechend $(\mathrm{H})$ und den dafür vorgebrachten Daten konditionalen V1-Gefügen zukommt. Abschnitt 7 resümiert die Ergebnisse.

Bevor wir beginnen, eine notwendige Vorbemerkung: Die Verfolgung der gerade genannten Ziele erfordert nicht nur, in beträchtlicher Breite auf die Syntax der V1-Gefüge einzugehen, sondern auch auf deren Semantik und Prosodie, all dies großteils vergleichend (mit wenn-Gefügen einerseits und selbständigen V1-Sätzen andererseits). Schon wegen des Umfangs des Vorhabens tun wir das in weitgehend unformaler Weise; auch hinsichtlich der Datenbasis bleibt es weitgehend bei (unseren) introspektiven Urteilen. Die Tücken eines solchen Vorgehens sind bekannt; von daher bleiben mit Sicherheit viele Wünsche in theoretischer wie empirischer Hinsicht offen. Dafür sei schon vorab als mildernder Umstand reklamiert, dass die Grammatik der V1-Gefüge bisher überhaupt kein Thema war, geschweige denn ein ernsthaft behandeltes. Wenn es durch unsere Arbeit dazu würde, hätten wir das linguistisch vielleicht Wesentlichste schon erreicht.

\section{Zu (H3): Restriktionen für die Austauschbarkeit von wenn- und V1-Sätzen}

Haben zwei formal vergleichbare sprachliche Mittel stets exakt gleiche Interpretation bzw. Funktion, ist das ein gutes Argument, sie auch strukturell gleich zu behandeln. Umgekehrt geht bloße Teilentsprechung eher mit struktureller Ungleichheit einher. Ein einschlägiges Beispiel sind die schon erwähnten V2-Nebensätze, die in vielen, aber nicht allen Umgebungen mit dass-Komplementen austauschbar sind und sich entgegen früherer Standardmeinung auch syntaktisch sehr verschieden verhalten (s. Reis 1997). Deshalb ist es ein zumindest suggestiv wichtiger erster 
Schritt auf $(\mathrm{H})$ hin, zu zeigen, dass wenn- und V1-Sätze nicht parallel distribuiert sind. Wir beschränken uns dabei im Wesentlichen auf wennbzw. V1-Sätze in linksperipherer Stellung.

\subsection{Hypothetische wenn-Konditionale}

Die zentrale Verwendung von wenn-Sätzen ist die hypothetisch-konditionale, d.h. der adverbiale wenn-Satz denotiert die Bedingungen $\mathrm{p}$, unter denen die Proposition q des Bezugssatzes wahr ist (s. Bhatt \& Pancheva 2006: 639). Kennzeichnend hierfür ist die Hinzufügbarkeit von dann. In dieser Verwendung sind wenn- und V1-Sätze im Allgemeinen ${ }^{4}$ frei austauschbar, gleich ob eine nichtepistemische Bedingung-Folge-Relation vorliegt (p ist Ursache für q), s. o. (1)-(2), hier wiederholt als (4)-(4'), oder eine epistemische (p ist Evidenz für q), s. (5)-(5'). Gleiches gilt für weitere (nichtfaktische) Abarten des hypothetischen Konditionals, ${ }^{5}$ auf die wir nicht näher eingehen.

(4) a. Wenn es regnet, (dann) bleiben wir zu Hause.

b. Wenn ich mehr Zeit gehabt hätte, (dann) hätte ich einen kürzeren Brief geschrieben.

(4') a. Regnet es, (dann) bleiben wir zu Hause.

b. Hätte ich mehr Zeit gehabt, (dann) hätte ich einen kürzeren Brief geschrieben.

(5) a. Wenn das Licht brennt, (dann) ist Paul zu Hause.

b. Wenn Paul nicht der Mörder war/ist, (dann) musste/muss es Tom sein.

(5') a. Brennt das Licht, (dann) ist Paul zu Hause.

b. War/Ist Paul nicht der Mörder, (dann) musste/muss es Tom sein.

Auch bei temporaler Schattierung des Konditionals scheint Austauschbarkeit gegeben, s. (6)-(6'); allerdings könnte das an den vereindeuti-

4. Auf gewisse semantische Einschränkungen der Austauschbarkeit auch in diesem Fall kommen wir in 3.1 zurück.

5. So für Optative (Wenn ich doch jünger wäre! / Wäre ich doch jünger!), die nach Rosengren (1993) elliptische Formen des hypothetischen Konditionals sind, sowie quasi-konditionale Idiome (wie wär's, wenn ..., vgl. Wie wär's, veranstalteten wir ein Wettrennen? [Ubu Rex, dt. Übers. S. 34] - ein Beleg, den wir C. Fortmann verdanken). - Auch sog. ,reduced conditionals“ (Schwarz 1998) und „adnominal conditionals“ (Lasersohn 1996), die auf Ausdruck der Bedingung-Folge-Relation beschränkt sind, lassen Austausch mit V1-Sätzen zu. Dass V1-Sätze z. T. weniger akzeptabel sind, scheint durch Interferenz unabhängiger Faktoren (z. B. erforderlicher Fokus auf wenn bei „reduced conditionals“, was bei V1-Konstruktion nicht erfüllbar ist) erklärbar. 
genden Adverbien gleich/stets liegen. Ohne diese tendiert u.E. V1 zur hypothetisch-konditionalen Lesart, vgl. (7)-(7'): Während für die wennSätze in (7) temporale Lesart - die einhergeht mit Geltung der im Antecedens genannten Betrachtzeit für das Konsequens (7a) bzw. mit nichtdeiktischer Perfekt-Lesart (,sobald'-Lesart) des Antecedens (7b) - das Naheliegende ist, sind die V1-Sätze in (7') gegenüber zeitlich unabhängiger Interpretation des Konsequens (7'a) bzw. deiktischer Perfekt-Interpretation $\left(7^{\prime} b\right)$ entschieden offener. ${ }^{6}$

(6) a. Wenn du heute Abend kommst, (dann) machen wir gleich den Kamin an.

(6') a. Kommst du heute Abend, (dann) machen wir gleich den Kamin an.

b. Regnete es, (dann) blieben wir stets zu Hause.

a. Wenn Karl heute Abend kommt, erzähle ich von den Plänen.

b. Wenn er die Aufgabe erledigt hat, können wir baden gehen.

a. Kommt Karl heute Abend, erzähle ich von den Plänen.

b. Hat er die Aufgabe erledigt, können wir baden gehen.

\section{2. ,Ergänzende` wenn-Sätze und wenn-Sätze nach Präferenzprädikaten}

In bestimmten Konstellationen fungieren wenn-Sätze als Prädikatsergänzungen, d. h. sie sättigen das von einem Prädikat in Subjekts- oder Objektsposition geforderte propositionale Argument, s. (8), woraus sich eine nicht-konditionale ,Komplement-Lesart' ergibt. Wie jedoch Fabricius-Hansen (1980) überzeugend argumentiert hat, sind diese wenn-Sätze nach wie vor syntaktisch-semantisch adverbiale Konditionale, ${ }^{7}$ was sich besonders bei Voranstellung der wenn-Sätze zeigt, s. (9): Hier ist obligatorisches es/das (als Vertreter eines dass-Satzes) die eigentliche Ergänzung, der adverbial-konditionale Status des wenn-Satzes entsprechend salient, was wiederum das dafür diagnostische dann und/oder so möglich macht.

6. Zu den Indizien für temporale vs. konditionale Lesart von wenn-Sätzen vgl. FabriciusHansen \& Saebø (1983); leider gehen sie auf V1-Antecedenten nicht ein. Der entscheidende Test unserer obigen Behauptung, dass diese primär hypothetisch-konditional zu interpretieren sind - eine Recherche von Belegen im Kontext -, steht noch aus.

7. Es liegt also nichtkanonische Argumentsättigung vor. Für eine Auflistung einschlägiger Parallelfälle s. Reis (1997). 
(8) a. Es ist meine Privatangelegenheit, wenn ich zum Beispiel mit Fräulein Renate befreundet bin.

(nach Fabricius-Hansen 1980: 160 f.)

b. Sie spürt, wenn er sie betrügt.

c. Sie würde spüren, wenn er nur aus Pflichtgefühl käme.

(9) a. Wenn ich zum Beispiel mit Fräulein Renate befreundet bin, (so/dann) ist das meine Privatangelegenheit.

b. Wenn er sie betrügt, (so/dann) spürt sie es/das.

c. Wenn er nur aus Pflichtgefühl käme, (so/dann) würde sie es/das spüren.

Von daher sollten ,ergänzende ‘ wenn-Sätze zumindest im Vorfeld mit V1Sätzen austauschbar sein, und das sind sie auch, vgl. (9'). Dass dies bei (8) nur marginal geht, vgl. (8'), liegt mit an der Nachstellung, die für indikativische V1-Konditionale unakzeptabel ist (s. u. 4.1.1).
a. *Es ist meine Angelegenheit, bin ich mit Fräulein Renate befreundet.
b. *Sie spürt, betrügt er sie.
c. ??Sie würde spüren, käme er nur aus Pflichtgefühl.

(9') a. Bin ich mit Fräulein Renate befreundet, (so) ist das meine Privatangelegenheit.

b. Betrügt er sie, (dann) spürt sie es/das.

c. Käme er nur aus Pflichtgefühl, (dann) würde sie es/das spüren.

Da u. E. aber auch nachgestellte konjunktivische V1-Sätze hier schlechter sind als gewöhnlich (s. ( $\left.8^{\prime} \mathrm{c}\right)$ ), ist wohl ebenso relevant wie die Tatsache, dass Nachstellung die syntaktisch-semantische Komplement-Interpretation der wenn-Sätze begünstigt, d. h. sie überlagert die hypothetisch-konditionale Interpretation so stark, dass der Austausch mit V1-Sätzen nicht mehr semantisch lizenziert ist. ${ }^{8}$

Im Wesentlichen analog verhalten sich die wenn-Sätze nach Präferenzprädikaten (die oft unter ,ergänzende ‘ wenn-Sätze subsumiert werden). Bei Voranstellung ist deren adverbial-konditionale Interpretation unabweislich und Austausch mit V1-Sätzen - allerdings mit klarer Präferenz für konjunktivische Gefüge - möglich (10)-(10'), bei Nachstellung, die zugleich die Komplementgeltung der wenn-Sätze forciert, ist dieser Aus-

8. Eine ähnliche Position wird von Zifonun et al. (1997: $2288 \mathrm{f}$.) vertreten. 
tausch so gut wie völlig zugunsten möglicher Substitution durch V2Sätze blockiert, ${ }^{9}$ s. (11)-(11').

(10) a. Wenn er dorthin zu Fuß geht, ist es/das besser.

b. Wenn du wegbliebst, wäre mir das lieber.

(10') a. ??Geht er dorthin zu Fuß, ist es/das besser.

b. Bliebst du weg, wäre mir das lieber.

(11) a. Es ist besser, wenn er dorthin zu Fuß geht.

b. Mir wäre lieber, wenn du wegbliebst.

(11') a. *Es ist besser, geht er dorthin zu Fuß. (aber: $\sqrt{ }$ Es ist besser, er geht dorthin zu Fuß.)

b. ?*Mir wäre lieber, bliebst du weg. (aber: $\sqrt{ }$ Mir wäre lieber, du bliebst weg.)

\subsection{Irrelevanzkonditionale und konzessive wenn-Sätze}

Irrelevanzkonditionale und konzessive Relation liegen nahe beieinander, sind aber an Fällen mit eindeutiger, distinktiver Einleitung wie (12) gut zu unterscheiden:

a. Konzessiv: Obwohl es regnet, gehen wir spazieren.

b. Irrelevanz-

konditional: $\mathrm{Ob}$ es regnet oder nicht, wir gehen spazieren.

König (1986, 1992) beschreibt sie wie folgt: Bei Konzessiven ist die Wahrheit der Protasis p wie der Apodosis q impliziert; ein konditionales Verhältnis besteht zwischen beiden nur insoweit, als ,wenn $\mathrm{p}$, dann normalerweise $\neg q^{6}$ implikatiert ${ }^{10}$ wird. Irrelevanzkonditionale hingegen drücken wie echte Konditionale primär die Folgebeziehung zwischen $\mathrm{p}$ und $\mathrm{q}$ aus, und implizieren auch nicht die Wahrheit von $\mathrm{p}$; dass $\mathrm{q}$ im Allgemeinen als wahr unterstellt ist, ist Folge des für Irrelevanzkonditionale konstitutiven Faktums, dass die Protasis einer Menge alternativer Propositionen $\mathrm{p}_{1}, \ldots, \mathrm{p}_{\mathrm{n}}$ entspricht (bei (12b) der Menge $\mathrm{p}, \neg \mathrm{p}$ ), und aus

9. Zu V2 nach Präferenzprädikaten s. Frank (1998). Die Beleglage gegen V1-Austausch bei Nachstellung ist eindeutig (s. auch Polikarpow 1996: 158); vereinzelte Prädikate, die V2- und (konjunktivische) V1-Substitution zulassen (so begrüßenswert, interessant, s. Kaufmann 1972: 60), sind wohl in primärer Interpretation keine Präferenzprädikate. (Zu deren semantischer Definition s. Frank 1998: Kap. 4; ihre o. a. Präferenz für konjunktivische Gefüge hängt mit ihrer semantischen Eigenart zusammen.)

10. Nach König (1986) ist das eine Präsupposition; dass das zu stark ist, wird in Zaefferers (1987: 276) - im Übrigen gleichsinnigen - Überlegungen zu Irrelevanzkonditionalen (bei ihm „Gleichsetzungskonditionale“) vs. Konzessiven gezeigt. 
jeder dieser Propositionen q folgt. Damit verbinden sich relativ leicht konzessive Implikaturen (es dürfte selten sein, dass aus $\mathrm{p}$ wie $\neg \mathrm{p}$ q folgt; ergo implikatiert etwa (12b) auf der Basis der Alltagsweisheit „,normalerweise: wenn es regnet (p), dann kein Spaziergang $(\neg q)$ “', dass wir spazieren gehen, obwohl es regnet).

In den uns interessierenden wenn-Fällen wird das gleiche Wortmaterial (wenn, dazu auch) zum Ausdruck beider Relationen benutzt, womit der lexikalischen Füllung von Protasis/Apodosis und dem Kontext von vornherein eine ungleich stärkere Rolle in der Vereindeutigung der Interpretation zukommt als bei (12). Wie erwartbar, führt das teilweise zu Verwischung der Grenzen, was auch die Austauschbarkeit mit V1-Sätzen tangiert.

Zunächst zu Irrelevanzkonditionalen: Bei diesen ist wenn auf den skalaren Subtyp ${ }^{11}$ beschränkt; das Auftreten von Irrelevanz- (wie konzessiven Implikatur-)Effekten lässt sich so gut wie ganz auf die Kombination mit Partikeln wie auch, selbst und lexikalisch ausgedrückten Grenzwerten ([nur] 1 Tropfen $X$, noch so sehr $Y$ ) zurückführen, die (skalar geordnete) Alternativenmengen induzieren, vgl. (13):

(13) a. Selbst/Auch wenn der Versuch missglückt war, gab er die Hoffnung nicht auf.

Selbst/Auch wenn der Versuch missglückt war, er gab die Hoffnung nicht auf.

b. Wenn man auch nur 1 Tropfen trinkt, ist man als Ex-Alkoholiker gefährdet.

c. Wenn es auch noch so sehr schüttet, er nimmt keinen Schirm mit.

Der Austausch mit V1-Sätzen ergibt auf den ersten Blick ein gemischtes Bild, vgl. (13'):

(13') a. *Selbst/*Auch war der Versuch missglückt, gab er die Hoffnung nicht auf.

*Selbst/*Auch war der Versuch missglückt, er gab die Hoffnung nicht auf.

b. Trinkt man auch nur 1 Tropfen, ist man als Ex-Alkoholiker gefährdet.

c. Schüttet es auch noch so sehr, er nimmt keinen Schirm mit.

11. Sog. universale und alternative Typen von Irrelevanzkonditionalen werden mit anderen Einleitern - insbesondere $w$ - ... immer-Phrasen, ob ... [oder nicht] - gebildet, vgl. König (1986, 1992). 
Die Unmöglichkeit von (13'a) ist jedoch unabhängig erklärbar: V-in-CSätze, also auch V1-Sätze, können generell nicht als syntaktischer Bezugsbereich für Fokuspartikeln fungieren (s. auch Abschnitt 4.4); eine Variante von (13'a) mit Binnenstellung von auch ist in Ordnung. ${ }^{12}$ Insofern kann man von der prinzipiellen Eignung von V1-Sätzen zum Ausdruck irrelevanzkonditionaler Beziehungen ausgehen. Unterstrichen wird das durch die Existenz einer V1-Variante zu irrelevanzkonditionalen so + Adjektiv-Verbletzt-Sätzen, vgl. (14)-(14'), auch wenn die V1-Variante an das Auftreten von mögen und/oder variantenspezifisches auch noch gebunden ist, vgl. (14'a) vs. (14'b, c), und insofern stark konstruktionelle Züge trägt (s. auch Zifonun et al. 1997: 2322 f.). ${ }^{13}$

(14) a. So vernünftig das zunächst (auch) klingt, ich habe meine Bedenken.

b. So vernünftig das zunächst (auch) klingen mag, ich habe meine Bedenken.

c. So gut ihm Nudeln (auch) schmecken, ich kann sie ihm nicht kochen.

(14') a. *Klingt das zunächst (auch) so vernünftig, ich habe meine Bedenken.

b. Mag das zunächst *(auch noch) so vernünftig klingen, ich habe meine Bedenken.

c. Schmecken ihm Nudeln *(auch noch) so gut, ich kann sie ihm nicht kochen.

Nun zu Konzessiven: Als konzessive wenn-Sätze gelten Fälle wie (15) (s. Zifonun et al. 1997: 2312 ff., dorther, leicht verändert, die Beispiele). Dabei gilt \pm adjazentes auch als obligatorisch:

(15) a. Wenn sie auch nicht unrichtig sind, treffen sie nicht im Ganzen die Chancen des demokratischen Weges.

a'. Wenn sie auch nicht unrichtig sind, sie treffen nicht im Ganzen die Chancen des demokratischen Weges.

b. Wenn der Versuch auch missglückt war, gab er die Hoffnung (doch) nicht auf.

b'. Wenn der Versuch auch missglückt war, er gab die Hoffnung (doch) nicht auf.

12. Darauf hat uns ein anonymer Gutachter aufmerksam gemacht.

13. Eine wenn-Variante zu (14') kann - entgegen der allgemein unterstellten Äquivalenz von wenn- und V1-Konstruktion - im Übrigen nicht auftreten, vgl. (14'b, c) vs. (i):

(i) a. ??Wenn das zunächst auch noch so vernünftig klingen mag, ...

b. ??Wenn ihm die Nudeln auch noch so gut schmecken, ... 
Ihre Konzessivität beruht darauf, dass die Protasis als faktisch (,wahr') interpretiert wird, ebenso die Apodosis. Dieser Unterschied zu Irrelevanzkonditionalen korreliert nach Zifonun et al. (1997: 2321) mit der unterschiedlichen Abfolge von wennlauch (auch > wenn bei Irrelevanzkonditionalen, wenn $>$ auch bei Konzessiven), was so kategorisch u. E. jedoch nicht stimmt: Wenn lexikalische Füllung oder auch Kontext keine skalare Interpretation zwingend nahe legt und/oder faktische Lesart begünstigt (z. B. durch Vergangenheitstempus, Einmaligkeit betonende Ausdrücke), erlaubt u. E. die auch wenn-Einleitung ebenfalls konzessive Interpretation. Ein durchaus schlagendes Beispiel ist das ,Minimalpaar ${ }^{6}$ $(15 \mathrm{~b}, \mathrm{~b}$ ') (wenn > auch) vs. (13a) (auch > wenn); zwar hat u. E. (15b, b') keine irrelevanzkonditionale Lesart, (13a) aber sehr wohl auch eine konzessive.

Wie dem auch sei, wenn-Sätze in konzessiver Interpretation sind nichts Ungewöhnliches. Dagegen sind, wie Zifonun et al. feststellen (1997: 2313), konzessiv interpretierbare V1-Sätze peripher und verlangen im Gegensatz zu entsprechenden wenn-Gefügen Elemente wie doch/dennoch in der Apodosis, die die konzessive Deutung forcieren, vgl. (15) vs. (15').

(15') a. *Sind sie auch nicht unrichtig, treffen sie nicht im Ganzen die Chancen des demokratischen Weges.

a'. *Sind sie auch nicht unrichtig, sie treffen nicht im Ganzen die Chancen des demokratischen Weges.

b. War der Versuch auch missglückt, gab er die Hoffnung *(doch) nicht auf.

(Zifonun et al. 1997: 2313)

b'. War der Versuch auch missglückt, er gab die Hoffnung *(doch) nicht auf.

Dass sie überhaupt vorkommen, ist wohl eher dem Umstand zu verdanken, dass in wenn-Fällen der Unterschied von irrelevanzkonditionaler vs. konzessiver Bedeutung mangels eindeutiger lexikalischer Verankerung noch geringer bzw. weit weniger salient ist als bei eindeutigeren Konstruktionsarten (s. etwa (12)); das erlaubt analogische Ausweitung der in irrelevanzkonditionaler Interpretation fest etablierten wenn-/V1-Alternation. Die Rolle vereindeutigender lexikalischer Mittel dabei bleibt noch zu untersuchen.

\subsection{Konfrontative/Adversative wenn-Sätze}

Im Falle der konfrontativen/adversativen Relation - die lexikalisch eindeutig vor allem durch während (neben wo(hin) gegen) ausgedrückt wird, vgl. (16) - ist die Asymmetrie genau umgekehrt: V1-Gefüge in konfrontativ-adversativer Interpretation sind unmarkiert (17), entsprechende 
wenn-Gefüge dagegen marginal und ,veraltet' (s. Zifonun et al. 1997: 2325), vgl. (17'). Das zeigt erneut, dass wenn- und V1-Gefüge nicht gleich verteilt sind.

(16) a. Während Öl früher zu billig war, ist es heute zu teuer.

b. Öl war früher zu billig, während es heute zu teuer ist.

a. Hatte Eddi früher nur Sinn für Mädchen, Fußball und Bier, (so) wurde in ihm durch die Übertragung von Verantwortung der Ehrgeiz geweckt [...].

b. War Öl lange Zeit zu billig, (so) ist es seit einiger Zeit zu teuer.

(17') a. Wenn Eddi früher nur Sinn für Mädchen, Fußball und Bier hatte, ?/*(so) wurde in ihm durch die Übertragung von Verantwortung der Ehrgeiz geweckt [...].

(Zifonun et al. 1997: 2325)

b. ?*Wenn Öl lange Zeit zu billig war, (so) ist es seit einiger Zeit zu teuer.

Die konfrontativ-adversative Relation ist klar nichtkonditional: Die verknüpften Propositionen sind beide faktisch, die unterstellte Relation zwischen ihnen ist die der Gegensätzlichkeit. Fragt man, unter welchen Umständen konfrontative vs. konditionale Lesart von V1-Gefügen auftritt, erscheint vor allem die Art des Gegensatzes zwischen den verknüpften Propositionen relevant. Dabei gibt es Unterschiede zwischen adversativen V1- und während-Gefügen, vgl. (18): Letztere sind mit Gegensätzen verschiedenster Art verträglich, solange die verknüpften Propositionen konsistent faktisch lesbar sind, das erklärt (18c) vs. (18c'). Dagegen verlangt adversative Interpretation von V1-Gefügen neben faktischer Lesbarkeit einen weiteren, etwa temporalen Kontrast der verknüpften Propositionen, der zudem ein gemeinsames Topik betreffen muss, s. (19a, b) vs. (19d); dass (19c) trotz des temporalen Kontrasts nur konditional zu deuten ist, liegt am Tempus, das keine konsistente faktische Interpretation der verknüpften Propositionen zulässt. Konditionale Lesart wiederum ist mit Gegensatzrelationen jeder Art verträglich, solange sich eine Bedingung-Folge-Beziehung plausibel unterstellen lässt, s. ebenfalls (19) - was bei rein statischen Gegensätzen und expliziter zeitlicher Dissoziation der verknüpften Propositionen unmöglich sein kann, s. (19b, d). Daraus ergibt sich das Muster \pm akzeptabler konditionaler vs. konfrontativer Lesarten zumindest der Beispiele in (19); mehr als ein erster Ansatz zur Beschreibung der distinktiven Bedingungen für konditionale vs. konfrontative Interpretation ist das jedoch nicht. ${ }^{14}$

14. Zum einen ist die Art des geforderten weiteren Kontrasts noch näher zu klären. So haben Fälle wie (i) trotz gleicher temporaler Verhältnisse wie in (19d) eine akzeptable (epistemisch) konditionale Interpretation. Auch ist nicht jeder temporale Kontrast per 
(18) a. Während Peter träge ist, ist Paul aktiv.

b. Während Paul körperlich träge ist, ist er intellektuell aktiv.

c. ??Während Paul in der Jugend träge ist, (so) ist er im Alter aktiv.

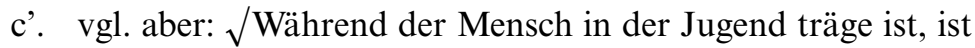
er im Alter aktiv.

d. Während Paul in der Jugend träge war, war/ist er im Alter aktiv.

(19) a. Ist Peter träge, (so) ist Paul aktiv.

(*konfrontativ, $\sqrt{\text { konditional) }}$

b. Ist Paul körperlich träge, (so) ist er intellektuell aktiv.

(??konfrontativ, ??konditional)

c. Ist Paul/der Mensch in der Jugend träge, (so) ist er im Alter aktiv.

(*konfrontativ, $\sqrt{ }$ konditional)

d. War Paul in der Jugend träge, (so) war/ist er im Alter aktiv.

( $\sqrt{\text { konfrontativ, }} ? / *$ konditional)

Trotzdem bleibt bemerkenswert, dass die konfrontative Interpretation von V1-Gefügen neben der konditionalen überhaupt Bestand haben kann, denn bei den vorher erörterten Fällen führte Abweichung von letzterer in der Regel zur Unakzeptabilität (die eher marginalen Ausnahmen in 2.2 und 2.3 erwiesen sich als unabhängig erklärbar). Wir kommen darauf in Abschnitt 3.3 zurück.

\subsection{Wenn-Relevanz- und -Metakonditionale}

Sog. Relevanzkonditionale unterscheiden sich von hypothetischen Konditionalen dadurch, dass die Protasis nicht spezifiziert, unter welchen Bedingungen die Apodosis wahr ist, sondern unter welchen Bedingungen sie adressaten- bzw. diskursrelevant ist (s. König \& Van der Auwera 1988: 110 und Bhatt \& Pancheva 2006: 671). Entsprechend ist die Apo-

se für konfrontative Interpretation ausreichend, vgl. (iia) vs. (iib). Offenbar ist zentral, dass ein deutlich markierter ,Phasen'-Kontrast vorliegt. Das passt auch zu dem einem unserer Gutachter zu verdankenden Beispiel (iii), das die Notwendigkeit einer generelleren Fassung des erforderlichen Phasen-Kontrastes und einer Präzisierung des hier relevanten Topikbegriffs illustriert.

(i) War Paul am 31. 3. in Hamburg, (so) war/ist er am 2. 4. in Dresden.

(ii) a. ??War Paul am 31.3. guter Laune, war er am 1. 4. weniger gut gelaunt.

b. War Paul am 31. 3. noch guter Laune, war er am 1. 4. schon weniger gut gelaunt.

(iii) Ist die Aussagenlogik noch leicht zugänglich, (so) bietet die Prädikatenlogik schon einige Fallstricke. 
dosis-Proposition unabhängig von der Protasis, und im deklarativen Fall stets als wahr behauptet. Trotzdem hat die Protasis konditionalen Bezug, nämlich auf den zu interpolierenden Sprechakt, dessen Proposition die Apodosis anzeigt (daher auch die Bezeichnung, Sprechakt-Konditional'). Typisches formales Kennzeichen, allerdings kein völlig obligatorisches, ist die positionelle ,Unintegriertheit' der Protasis, s. (20); auf ihr Verhältnis zu prosodischer Unintegriertheit kommen wir in 2.6 zurück.
a. Wenn Peter anruft - ich erwarte ihn im Café Einstein.
b. Wenn ich ehrlich bin - darüber habe ich noch nicht nachge- dacht.
c. Wenn du meine Meinung hören willst - die Aktien steigen bald.
c'. Wenn du meine Meinung hören willst, steigen die Aktien bald. ${ }^{15}$

Wie Günthner (1999) gezeigt hat, erfüllen Relevanzkonditionale eine Reihe sehr verschiedener Diskursfunktionen. Für unsere Zwecke ist das jedoch unerheblich, denn in keiner Funktion sind Relevanzkonditionale durch V1-Gefüge realisierbar, vgl. (20'): ${ }^{16}$

$\left(20^{\prime}\right) \quad$ a. *Ruft Peter an - ich erwarte ihn im Café Einstein.

b. *Bin ich ehrlich - darüber habe ich noch nicht nachgedacht.

c. *Willst du meine Meinung hören - die Aktien steigen bald.

c'. *Willst du meine Meinung hören, steigen die Aktien bald. ${ }^{17}$

Gleiches gilt für sog. Meta-Konditionale ${ }^{18}$ in denen die Ausdrucksform des ebenfalls wahrheitswertunabhängigen Bezugssatzes konditional kommentiert wird: Auch hier sind nur wenn-Realisierungen möglich, V1-Realisierungen nicht, vgl. (21) vs. (21'):

a. Sue hat mich ihrem Mann - wenn man ihn noch so nennen darf - vorgestellt.

b. Paul repariert Auspüffe - wenn das der richtige Plural ist.

15. Zur prosodischen Bedingtheit der Stellungsvariante (20c') s. Vandergriff (1997: 264).

16. Zum Ausnahme-Fall der V1-sollte-Konditionale s. u. Abschnitt 3.4.

17. Beide V1-Varianten sind in relevanzkonditionaler Interpretation ungrammatisch. Suggestiverweise hat die V1-Variante (20c') die voll akzeptable, aber pragmatisch unwahrscheinliche Lesart, dass das Antecedens den Grund für das Konsequens bezeichnet, was zur u. a. semantischen Einschränkung von V1-Sätzen passt.

18. Diesen Typ hat u.W. erstmals Dancygier (1998: 93 ff.) an englischen Beispielen ausführlich behandelt. 
(21') a. *Sue hat mich ihrem Mann - darf man ihn noch so nennen - vorgestellt.

b. *Paul repariert Auspüffe - ist das der richtige Plural.

\subsection{Austauschbarkeit von wenn- mit V1-Sätzen und, \pm Integriertheit ${ }^{\star}$}

Mit 2.5 ist der Vergleich zwischen wenn- und V1-Nebensätzen vorläufig abgeschlossen. Bevor wir ihn auswerten, möchten wir zeigen, dass Unterschiede in \pm Integriertheit des wenn-Satzes für die Austauschbarkeit mit V1-Sätzen per se nicht ausschlaggebend sind.

Nebensätze (=NS) sind genau dann in ihren Bezugssatz integriert, wenn sie eine Strukturstelle in diesem belegen, d.h. in diesen ,inkorporiert`/,eingebettet' sind (s. König \& van der Auwera 1988, Reis 1997). Für \pm Integration linksperipherer NS verwenden König \& van der Auwera (1988: 102 ff.) eine rein positionelle Diagnostik: Liegt in Deklarativen ,V2' vor, d. h. der NS steht direkt vor dem Finitum, ist NS integriert (22a), liegt ,V3' vor, d. h. der NS steht vor der (nichtresumptiv gefüllten) präverbalen Position, ist NS unintegriert (22b).

a. Wenn ich mich eile, krieg ich noch den Zug.

b. Wenn Paul anruft, ich krieg noch den Zug.

Dass positionelle (Un-)Integriertheit in Fällen wie (22) mit prosodischer (Un-)Integriertheit korreliert, ist bekannt: In (22a) bilden Protasis und Apodosis eine prosodische Einheit, der eine einzige Fokus-HintergrundGliederung entspricht, in (22b) sind sie separate (und als solche markierte) prosodische Einheiten, der separate Fokus-Hintergrund-Gliederungen entsprechen. ${ }^{19}$ Diese Korrelation gilt jedoch nicht 1:1: Zwar impliziert , $\mathrm{V}^{6}$ ' auch prosodische Unintegriertheit im o. a. Sinn, und prosodische Integriertheit im o. a. Sinn auch ,V2', aber die jeweilige Umkehrung gilt nicht, da prosodisch unintegrierte NS sehr wohl in ,V2'-Stellung auftreten. In 5. haben wir Anlass, das breiter auszuführen, hier sei nur auf die bereits angeführten Fälle verwiesen: Linksperiphere konfrontative, konzessive und relevanzkonditionale NS sind stets prosodisch unin-

19. Zentral ist, dass integrierte Gefüge mit einer FHG auskommen können, während unintegrierte Gefüge separate FHGs haben müssen. Da der Unterschied dadurch verwischt werden kann, dass auch ein integriertes Gefüge, d. h. eine FHG, in mehrere Akzentphrasen zerlegt wird (s. Uhmann 1991), was bei längeren Teilsätzen fast unvermeidlich ist, müssten stichhaltige experimentelle FHG-Überprüfungen auf \pm prosodische Integriertheit auf möglichst kurzen Teilsätzen aufgebaut sein. Dass klar positionelle Unintegriertheit (,V3“) prosodische Separierung verstärkt, scheint durchaus möglich. (Darauf könnten die Spektrogramme von ,V3'- vs. ,V2'-Konditionalen hindeuten, die wir einem unserer Gutachter verdanken.) 
tegriert, egal ob V1 oder durch wenn oder andere Subjunktionen (während, obwohl) eingeleitet, Gleiches trifft auf die mit (13c), (14) illustrierten Formtypen von Irrelevanzkonditionalen zu. Aber nur letztere verlangen die ,V3'-Konstruktion, während die anderen für ,V2' offen sind, wenngleich in unterschiedlichem Maß: Bei Relevanzkonditionalen ist fakultatives ,V2' marginal, d. h. Fälle wie (20c') sind an besondere Fokusmuster gebunden (s. Vandergriff 1997); bei Konzessiven scheinen die ,V2'- und ,V3'-Variante durchweg mehr oder minder gleichberechtigt, vgl. (15); bei während-Konfrontativen (16) ist , V2'-Konstruktion obligatorisch.

Von daher scheint uns dringend geboten, (i) zwischen Unintegriertheit als tief liegender struktureller Eigenschaft, die sich durch Besonderheiten auf mehreren sprachlichen Ebenen manifestiert (syntaktische, prosodische, aber auch semantische und entsprechend pragmatische, s. Reis 1997), und eben diesen Manifestationen klar zu unterscheiden, (ii) nicht vorschnell von 1:1-Korrelationen zwischen diesen Manifestationen (die ins grammatische Netzwerk je verschieden eingebunden sind) auszugehen. Das schließt Teilkorrelationen nicht aus, so die hier offenkundige zwischen gewissen semantischen Relationen und ( \pm obligatorischer) (Un-) Integriertheit oder die o. a. Implikation ,V3 $>$ prosodische Unintegriertheit, lässt aber auch die z. T. weit reichende gegenseitige Unabhängigkeit der relevanten Faktoren hervortreten.

In unserem Fall befördert das die zentrale Einsicht, dass die Distribution von V1-NS, insbesondere ihre Austauschbarkeit mit wenn-Sätzen, rein semantisch bedingt ist. Ihre grundsätzliche Unabhängigkeit von (stets prosodisch nachweisbarer) \pm Integriertheit zeigt sich daran, dass V1-Sätze sowohl zweifelsfrei integrierte wenn-Sätze (Konditionale wie (4)-(5)) als auch zweifelsfrei unintegrierte wenn- und andere Sätze (Konfrontative und Irrelevanzkonditionale) substituieren können. Ihre grundsätzliche Unabhängigkeit von ,V2 ${ }^{\text {‘ }}$ vs. ,V3'-Position zeigen nicht nur Fälle wie (15'b), sondern vor allem die ,V3'-Variante hypothetisch-konditionaler Gefüge wie (23), deren initiale wenn-Sätze problemlos mit V1Sätzen austauschbar sind (23'), dies unter Beibehaltung des von unintegrierter Stellung ausgelösten pragmatisch-stilistischen Effekts.

$(23)^{20}$ a. Wenn das mein Hund wäre, er bekäme keinen Zucker.

b. Wenn du Hilfe bräuchtest, ich bliebe den ganzen Nachmittag zu Hause.

20. Die Beispiele (23a, b) entstammen König \& van der Auwera (1988: 114) bzw. (verändert) Köpcke \& Panther (1989: 687). Wie man Kaufmann (1972: 26) entnehmen kann, ist (23a) ein Beleg aus P. Bichsel (Die Jahreszeiten, S. 61). 
(23') a. Wäre das mein Hund, er bekäme keinen Zucker.

b. Bräuchtest du Hilfe, ich bliebe den ganzen Nachmittag zu Hause.

Zweifellos sind bereits die, V3'-wenn-Gefüge à la (23) markiert, d. h. weit seltener als die integrierte Variante und auch offenbar stärker beschränkt, nämlich auf nicht-epistemische, konjunktivische ${ }^{21}$ Fälle. Auf diese Restriktionen wie auch den (23) - (23') eigenen Effekt können wir hier jedoch nicht eingehen. Betont sei nur nochmals das hier allein Wesentliche: \pm Austauschbarkeit von wenn- und V1-Sätzen ist maßgeblich von der semantischen Beziehung zwischen Protasis und Apodosis abhängig, und dabei von \pm Integriertheit der wenn-Protasis unabhängig.

\subsection{Fazit}

Wie 2.1-2.5 zeigt, haben wenn-Sätze eine weit breitere Distribution als V1-Sätze: wenn-Gefüge können hypothetisch-konditionale, irrelevanzkonditionale, konzessive, relevanzkonditionale Beziehungen ausdrücken, sowie als Metakonditionale und in gewissen Kontexten als Komplemente fungieren. V1-Gefüge sind diesbezüglich auf den Ausdruck der Bedingung-Folge-Relation beschränkt, wie sie im zentralen Fall der hypothetischen Konditionale, aber auch bei Irrelevanzkonditionalen vorliegt (die Abweichungen davon, s. 2.2 und 2.3, sind unabhängig erklärbar bzw. marginal). Abweichend ist der konfrontativ-adversative Fall (2.4), insofern er einerseits nichtkonditional ist, andererseits die V1-Realisierung eindeutig die Oberhand über die nur marginal mögliche wenn-Realisierung hat. Diese nichtkonditionale ,Neben'-Bedeutung von V1-Gefügen steht zwar auf den ersten Blick einer einheitlichen Bedeutungsbeschreibung für (unselbständige und selbständige) V1-Sätze im Wege (s. dazu Abschnitt 3), unterstützt aber das an dieser Stelle allein wichtige Fazit, dass die Distribution von wenn- vs. V1-Sätzen verschieden ist und dabei offenkundig von der Art der auszudrückenden semantischen Relation abhängt.

Mit anderen Worten: (H3) ist gerechtfertigt: V1-Substitution für wennSätze ist semantisch lizenziert. Damit ist der traditionellen Strukturannahme (3) für konditionale V1-Gefüge der intuitive Boden entzogen und der erste Schritt auf $(\mathrm{H})$ hin getan.

21. König \& van der Auwera (1988: 114) erklären die Beschränkung auf konjunktivische ,V3'-wenn-Gefüge damit, dass die V2-Apodosis via Konjunktiv II schon unabhängig Abhängigkeit signalisiere und deshalb separat assertierbar sei (i. E. die generelle Voraussetzung für ,V3'-Konstruktion). Das erklärt aber per se nicht den Ausschluss epistemischer Lesarten für Fälle wie * Sähe man weiße Segel, sie hätten gesiegt (vs. Sähe man weiße Segel, hätten sie gesiegt). 


\section{3. (Weitere) Hinweise auf eine eigene Strukturbedeutung von V1-Sätzen}

Das Ergebnis von Abschnitt 2 wirft die Frage auf, wie sich die unterschiedliche Distribution von wenn- vs. V1-Nebensätzen erklärt. Da sie offenbar semantisch bedingt ist, liegt die Annahme nahe, dass V1-Sätze eine Strukturbedeutung haben, die Substitution für/durch wenn-Sätze bzw. gleiche Interpretation nur in bestimmten Kontexten zulässt. Aber was genau ist diese Strukturbedeutung? Dieser Frage gehen wir in 3.1 und 3.2 nach, indem wir weitere semantische Unterschiede zwischen wenn- und V1-Gefügen im zentralen Bereich der hypothetischen Konditionale nachweisen. Da sich hier suggestive Parallelen zu selbständigen V1-Interrogativen auftun, ist das zugleich Evidenz für die Hintergrundhypothese (SH). In 3.3 sichern wir diese Überlegungen ab, indem wir die Bezüge zwischen eingeleiteten Konditionalen und Interrogativen vergleichend betrachten. 3.4 vervollständigt die semantische Diskussion durch Betrachtung eines Sonderfalls.

\subsection{Eingrenzung der V1-kompatiblen konditionalen Relation}

Die weitere Eingrenzung geschieht durch Betrachtung der von wenn- und V1-Gefügen ausgedrückten Relationen im Hinblick auf die möglichen Wahrheitswerte von Konsequens und Antecedens und deren gegenseitiger Abhängigkeit.

Wie oben gezeigt, erlauben wenn- im Gegensatz zu V1-Gefügen bei wahrem Gesamtsatz, dass der Wahrheitswert des Konsequens unabhängig vom Antecedens stets, wahr' ist - man denke an Konzessive bzw. Relevanzkonditionale. Ebenso erlauben sie, dass der Wahrheitswert des Antecedens feststeht, so bei der bisher nicht erwähnten ,faktiven' Variante hypothetischer Konditionale (oft auch 'premise' oder 'echoic conditionals' genannt, s. Haegeman 2003: 319, 2006: 1656), vgl. (24). V1-Sätze hingegen lassen das nicht zu, vgl. (24'); entsprechend sind sie mit Elementen wie ohnehin, wie ihr sagt, etc., die diese Lesart erzwingen, unverträglich. ${ }^{22}$

(24) a. Wenn ihr ohnehin schon Bescheid wisst, warum fragt ihr noch?

b. Wenn also die Lehrer wie ihr sagt so schlecht sind, muss man die Ausbildung ändern. (nach Haegeman 2003: 319)

22. Vgl. die auf Korpusauswertung beruhende Aussage Kaufmanns 1972, bei faktiven Antecedenten (bei Kaufmann Sätze, die das Merkmal [+existent] tragen) sei „Initialstellung der finiten Verbform [...] ausgeschlossen" (Kaufmann 1972: 11). Leider sagen die weiteren Arbeiten, die ausführlicher auf faktive Konditionale eingehen (Hermodsson 1977, Fabricius-Hansen \& Saebø 1983, Metschkova-Atanassowa 1983), dazu nichts, enthalten allerdings auch keinen einzigen faktiv-konditionalen V1-Beleg. 
c. Wenn ihr schon so lange bleibt, könnt ihr auch mithelfen.

d. Wenn er angeblich so schlau ist, warum ist er dann nicht reich?

(24') a. ?/*Wisst ihr ohnehin schon Bescheid, warum fragt ihr noch?

b. ??Sind also die Lehrer wie ihr sagt so schlecht, muss man die Ausbildung ändern.

c. ?*Bleibt ihr schon so lange, könnt ihr auch mithelfen.

d. *Ist er angeblich so schlau, warum ist er dann nicht reich?

Einen analogen Gegensatz finden wir bei Konditionalen mit Ex falso quodlibet-Interpretation, in der aus der offensichtlichen Falschheit des Konsequens die Falschheit des Antecedens, d. h. ein feststehender Wahrheitswert, erschlossen werden kann bzw. soll. Bei wenn-Antecedens ist diese Lesart ohne Weiteres möglich (25), bei V1-Antecedens ist sie mehr oder minder schlecht; jedenfalls ist die rein hypothetisch-konditionale Interpretation die stark präferente, vgl. (25').

(25) a. Wenn diese Frau die Zarentochter war, bin ich die Tochter von Queen Victoria.

b. Wenn der dir das Geld zurückzahlt, flanier ich nackt über die Kö.

c. Wenn Meier ihm das abnimmt, fress ich 'nen Besen.

(25') a. ??War diese Frau die Zarentochter, bin ich die Tochter von Queen Victoria.

b. ??Zahlt der dir das Geld zurück, flanier ich nackt über die Kö.

c. ??Nimmt Meier ihm das ab, fress ich 'nen Besen. (,,?? jeweils in der Ex falso quodlibet-Interpretation)

V1-Konditionalgefüge sind also offenbar auf Konstellationen beschränkt, in denen (i) die Wahrheit des Konsequens von der Wahrheit des Antecedens abhängt ( $\Rightarrow$ hypothetische Konditionale), (ii) der Wahrheitswert des V1-Antecedens in der thematisierten Welt offen ist. ${ }^{23}$

Das passt gut zur Semantik von V1-Entscheidungs-Interrogativen: Zum einen beinhaltet diese nach Standardmeinung ebenfalls die Offen-

23. Das gilt auch für irreale Konditionale (mit Konjunktiv II): Wie von Fintel (1999) zeigt, kommt kontrafaktische Lesart der Antecedensproposition durch Implikatur zustande (s. auch Abschnitt 3.2). 
heit des Wahrheitswerts der Frageproposition, ${ }^{24}$ zum andern bildet der positive Wert ebenfalls die Grundlage der Fortsetzung, d.h. der Antwort. ${ }^{25}$ Das ist nicht nur historisch suggestiv (s. dazu schon Behaghel 1928: 636, 783), es gibt auch gewisse Hoffnung, dass man eine einheitliche Semantik für V1-Sätze im Deutschen spezifizieren kann. Das gibt (SH) weiteren Auftrieb, und ermöglicht, last but not least, auch eine Lösung für ein zentrales Folgeproblem unserer Strukturhypothese $(\mathrm{H})$ (s. dazu u. Abschnitt 3.3).

\subsection{Implikaturunterschiede bei konjunktivischen wenn- vs. V1-Konditionalen}

Ein weiteres suggestives Indiz ergibt sich bei Betrachtung der kontrafaktischen Implikatur von konjunktivischen wenn- vs. V1-Konditionalen. Dass hier lediglich eine Implikatur vorliegt, zeigt sich an Beispielen, in denen der Wahrheitswert des Antecedens (und entsprechend des Konsequens) in der aktualen Welt durchaus offen und entsprechend möglicherweise wahr ist. Das klassische Beispiel hierfür ist (26a), aber zumindest für die Offenheit der Antecedensproposition lassen sich durchaus leicht weitere Beispiele finden, vgl. (27).

(26) a. If Jones had taken arsenic, he would have shown just exactly those symptoms, which he does in fact show.

(Anderson 1951: 37, zitiert nach von Fintel 1999: 29)

b. Wenn Jones Arsen genommen hätte, hätten sich genau die Symptome gezeigt, die sich tatsächlich zeigen.

(27) a. Wenn Peter um 5 Uhr gefahren wäre, könnte er es noch bis zur Party schaffen.

b. Wenn Paul das Gift etwa erst um 12 Uhr eingenommen hätte, könnten wir ihn noch retten.

24. Ein anonymer Gutachter hält das angesichts rhetorischer Fragen für strittig - u. E. zu Unrecht, da der rhetorische Effekt bei (bzgl. rhetorizitätserzeugender/-verstärkender Mittel wie präfinites schon u. a.) unmarkierten V1-Interrogativen rein pragmatisch zustande kommt. Dass dieser auf der Basis der angenommenen Bedeutung von Entscheidungsinterrogativen herleitbar sein muss (wie übrigens auch die Besonderheiten von monologischen, Prüfungs- und pädagogischen Fragen) und das Probleme aufwirft, ist eine andere Sache. ( $\mathrm{Zu}$ einem attraktiven Herleitungsversuch s. Truckenbrodt 2004.)

25. M. Krifka, dem wir diesen zweiten Punkt verdanken (p. M.), hat gleichzeitig darauf hingewiesen, dass dies zwar der üblichen Fragesemantik widerspreche, die $\mathrm{p} / \neg \mathrm{p}$ in Frage wie Antwort als gleich gute Alternativen behandelt, aber mit der Wirklichkeit übereinstimme. (D.h. Entscheidungsfragen p? wären nicht als ,p oder $\neg$ p? zu modellieren, sondern grob gesagt als ,p wahr?'). 
c. Wenn Tim sich mal mehr als gewöhnlich beeilt hätte, gäbe es keine Probleme.

d. [Mit einer 3 im Examen wäre ich durchaus zufrieden.] Aber wenn Tom eine 2 erreicht hätte, wäre ich natürlich noch zufriedener.

Für all diese Fälle sind Kontexte vorstellbar, in denen der Wahrheitswert der (stets in der Vergangenheit liegenden) Antecedens-Proposition nicht feststeht, für (26) etwa eine Argumentation dafür, dass Jones tatsächlich Arsen einnahm, ${ }^{26}$ für (27) die Abwägung situationsrelevanter, im Konsequens thematisierter Alternativen, die vom Wahrheitswert des Antecedens abhängen (wird Peter pünktlich sein oder nicht?, kann man Paul noch retten oder nicht?, wird es Probleme geben oder nicht?, wie zufrieden werde ich mit Toms Note sein können?).

Was solche Fälle für uns interessant macht, ist die Beobachtung von Iatridou \& Embick (1994: 200 f.), dass die kontrafaktische Implikatur bei konjunktivischen if-Konditionalen weit weniger fest ist als bei entsprechenden V1-Konditionalen. ${ }^{27}$ Ihres Erachtens lässt sie sich bei ersteren, im Gegensatz zu letzteren, sogar direkt streichen, vgl. ihre hier in (28) wiedergegebenen Beispiele:

(28) a. If he had broken his leg in his childhood, which, in fact, he did, he would have exactly this type of scar.

a'. Wenn er als Jugendlicher sein Bein gebrochen hätte, (?\#was er tatsächlich hat), hätte er genau eine solche Narbe.

b. \#Had he broken his leg in his childhood, which, in fact, he did, he would have exactly this type of scar.

b'. Hätte er als Jugendlicher sein Bein gebrochen, (?\#was er tatsächlich hat), hätte er genau eine solche Narbe.

Dieses Beispiel bzw. die Annahme leichter - und dabei unterschiedlich leichter - Streichbarkeit ist u. E. nicht völlig überzeugend (deshalb das ,$?^{\circ}$ in den deutschen Übersetzungen $\left.\left(28 \mathrm{a}^{\prime} / \mathrm{b}^{\prime}\right)\right)$. Aber der Unterschied scheint trotzdem real: Erstens führen Iatridou \& Embick (1994: 200) überzeugende Korpus-Evidenz dafür an, dass konjunktivische V1-Konditionale, anders als if-Konditionale, nur dann vorkommen, wenn das

26. So von Fintel (1999: 29), der darauf hinweist, dass es dann ,self-defeating [wäre] to presuppose that the hypothesis is false."

27. Es gelingt Iatridou \& Embick (1994) nach eigener Überzeugung allerdings nicht, diesen speziellen Kontrast aus ihrer Deutung des generellen Unterschieds zwischen if- und V1Konditionalen abzuleiten (Iatridou \& Embick 1994: 201). (Zur Kritik an dieser Deutung s. u. $4.4 \mathrm{f}$.). 
Antecedens aus Diskurs oder Weltwissen als falsch bekannt ist, aber nie in Kontexten, wo der Wahrheitswert des Antecedens nicht in dieser Weise gesichert ist. Zweitens gibt es Beispiele, auch fürs Deutsche, bei denen der interpretative Unterschied u. E. weit klarer herauskommt, vgl. die auf $(27 \mathrm{c}, \mathrm{d})$ aufbauenden Kontraste in (29): 28
a. Wenn Tim sich mehr als gewöhnlich beeilt hätte, gäbe es keine Probleme.
a'. Hätte Tim sich mehr als gewöhnlich beeilt, gäbe es keine Probleme.
b. Wenn Tom das Examen mit 2 bestanden hätte, wäre ich noch zufriedener.
b'. Hätte Tom das Examen mit 2 bestanden, wäre ich noch zu- friedener.

Auf den ersten Blick ist das ein problematisches Faktum, scheint doch die größere Festigkeit der kontrafaktischen Implikatur bei V1 nicht zu dem Ergebnis von $3.1 \mathrm{zu}$ passen, dass V1-Konditionale Antecedenten mit offenem Wahrheitswert fordern. Aber auf den zweiten Blick hat es sein Gutes: Es scheint eine weitere Parallele zu V1-Interrogativen abzugeben, bei denen Konjunktiv Plusquamperfekt so gut wie immer mit kontrafaktischer Interpretation verbunden ist, ${ }^{29} \mathrm{vgl}$. (30):
a. Hätte sich Tim (unter Umständen X,Y,Z) mehr als gewöhn- lich beeilt?
b. Hätte Tom (bei einem anderen Prüfer) das Examen mit 2 bestanden?

Der Zusammenhang ist nicht so direkt wie der in 3.1 hergestellte, insofern die V1-Interrogative in (30) nicht dem Antecedens, sondern einem ganzen konditionalen Gefüge entsprechen; dabei entspricht die Frage-

28. Unsere eigenen Intuitionen haben wir bisher nur durch Befragungen von ca. einem Dutzend anderer Linguisten abgesichert (dies unter Vorschlag von Kontexten wie den zu (27c, d) knapp skizzierten), aber die Ergebnisse waren so stabil, dass wir den Kontrast für ein bei aller Subtilität robustes Faktum halten.

29. Es gibt auch Fälle, in denen äußerlich entsprechende V1-Interrogative nicht kontrafaktisch sind, vgl. (i) im Kontext einer Diskussion etwa über den (immer noch umstrittenen) Ort der Varusschlacht.
(i) Hätte die Schlacht an einem Ort wie diesem stattfinden können?
U.E. hängt das mit dem Auftreten von Modalverben im Konjunktiv Plusquamperfekt zusammen, die mit einer potentialen Konstruktion gleichwertig sind - (i) ist ja gleichbe- deutend mit: Kann/konnte die Schlacht an einem Ort wie diesem stattgefunden haben?; wir können dem aber hier nicht weiter nachgehen. 
proposition dem Konsequens (mit mehr oder minder explizit angedeutetem Antecedens). Wie dieser Unterschied zwischen konjunktivischen und indikativischen Entscheidungs-Interrogativen, der sich auch in \pm konditionaler Bedingtheit der Antworten spiegelt, genau zu fassen ist, können wir (in jeder Lesart von können) nicht klären. Klar scheint uns aber, dass ein Zusammenhang zwischen V1-Interrogativen wie (30) und konditionalen V1-Gefügen wie (29) besteht, insofern ein kontrafaktisches Konsequens immer auf ein kontrafaktisches Antecedens schließen lässt, d.h. die typische Kontrafaktizität konjunktivischer V1-Interrogative wie (30) entspricht genau der (nur) für konjunktivische V1-Konditionalgefüge typischen Kontrafaktizität.

Dieses Ergebnis unterstreicht einmal mehr, dass sich wenn- und V1Konditionale semantisch unterscheiden; ebenso stützt es die in Abschnitt 3.1 hergestellte Verbindung zwischen V1-Konditionalen und V1-Interrogativen, und den ihr dort zugemessenen argumentativen Wert.

\subsection{Eingeleitete vs. uneingeleitete Konditionale und Interrogative}

Will man wie wir die Verwandtschaft zwischen V1-Konditionalen und V1-Interrogativen dazu nutzen, einen relevanten Unterschied $\mathrm{zu}$ wennKonditionalgefügen zu begründen, ist auch zu fragen, wie man es mit der ebenfalls beschworenen Beziehung zwischen eingeleiteten Konditionalen und Interrogativen hält (s. zusammenfassend Bhatt \& Pancheva 2006: 653 ff.). Nur dann, wenn diese im Wesentlichen nicht der von V1 gestifteten Beziehung vergleichbar ist, hat unser diesbezügliches Argument pro (H) und $(\mathrm{SH})$ Bestand.

Die Nähe von eingeleiteten Konditionalen und Interrogativen ist sprachübergreifend durch viele etymologische Verbindungen zwischen konditionalen Subjunktionen und interrogativen Komplementierern zweifelsfrei belegt (s. Traugott 1985). Die Verbindung läuft aber in entscheidender Weise anders herum als im V1-Fall: Es ist nicht so, dass die eingeleiteten Konditionale auf die Semantik der entsprechenden Interrogativformen beschränkt sind, sondern dass eingeleitete Interrogative semantisch mit dem Bedeutungsspektrum eingeleiteter Konditionale überlappen; das kann zur Benutzung gleicher Formtypen im Überlappungsbereich führen bzw. diese semantisch lizenzieren. Die Verhältnisse im Deutschen wie auch im Englischen belegen das deutlich, wobei die eingeleiteten Entscheidungsinterrogative hier besonders interessieren:

Im Gegenwartsdeutschen ist das der - in der Regel unselbständige $o b$-Interrogativsatz. Formal überlappt er mit Konditionalen nur im Bereich der Irrelevanzkonditionale; dabei sorgen obligatorisches ,V3 bei deren Erstposition, prosodische Unintegriertheit in jeder Position, sowie 
der Zwang zum Ausdruck einer Alternative für Unterscheidbarkeit, vgl. $(31)-(32)$ :

(31) a. Ob es an Ostern regnet (oder nicht), möchten viele gern wissen.

b. Ob es an Ostern regnet (oder schneit), ist mir egal.

a. Ob es an Ostern regnet *(oder nicht), wir machen eine Wanderung.

b. $\mathrm{Ob}$ es an Ostern regnet *(oder schneit), wir machen eine Wanderung.

Worin die semantische Verwandtschaft besteht, die gleiche Ausdrucksform lizenziert, hat Zaefferer deutlich gemacht (1987: $262 \mathrm{ff}$.), gleichzeitig aber keinen Zweifel an der semantischen Divergenz gelassen (s. Zaefferer 1987: 279-281). Ebenso wenig sind (formungleiche) hypothetische wennKonditionale mit $o b$-Interrogativen bedeutungsgleich, da erstere nur die positive Alternative thematisieren, letztere aber - anders als selbständige V1-Interrogative (s. o. Abschnitt 3.1, Fn. 25) - die zu entscheidende Alternative (d. h. $o b p$ bedeutet klar ,p oder $\neg$ p', s. dazu auch Eckardt 2007).

Im Englischen gibt es eine salientere Überlappung, insofern der konditionale Marker if den Interrogativ-Komplementierer whether (der genau dt. $o b$ entspricht) genau dann ersetzen kann, wenn die Geltung der positiven Alternative im Vordergrund steht (Bolinger 1978, Eckardt 2007: $455 \mathrm{ff}$., letztere mit Hinweisen auf gegenwärtige Aufweichungen dieser Restriktion), vgl. (33).

a. Please tell me if you want to marry me.

b. Please tell me whether you want to marry me.

(Bolinger 1978, zitiert nach Eckardt 2007: 457)

Das markiert natürlich einen offensichtlichen Überlappungsbereich zwischen durch if-Sätze ausdrückbarer konditionaler und polar-interrogativer Bedeutung - was unsere o. a. Feststellung sehr direkt bestätigt: Die Bedeutung interrogativer if-Sätze ${ }^{30}$ ist auf die (bzw. eine Teil-)Bedeutung konditionaler if-Sätze zurückzuführen, nicht umgekehrt.

Der semantische Unterschied zwischen wenn- und V1-Konditionalen wird also auch durch die Unterschiedlichkeit der Beziehung zu Entscheidungsinterrogativen bestätigt: Nur V1-Konditionale haben im Wesentli-

30. $\mathrm{Zu}$ Distribution und Struktur interrogativer if- vs. whether-Sätze, s. Adger \& Quer (2001), für deutsche Analoga Öhl (2007). 
chen die Semantik ihrer interrogativen Pendants, den (stets selbständigen) V1-Interrogativen. Das ist weitere Bestätigung für (H3) wie auch für $(\mathrm{SH})$. Auch für $(\mathrm{H})$ ist der Befund von Abschnitt 3.3 relevant, da er - falls sich die quasi-parataktische Strukturannahme für konditionale V1-Gefüge als richtig erweist - zumindest ansatzweise eine Erklärung erlaubt, wieso das V1-V1-(Oberflächen-)Muster trotzdem ${ }^{31}$ stets als Konditionalgefüge (pace konfrontative Gefüge) interpretiert wird: Was wir hier vor uns haben, ist ,grammatikalisierter Diskurs' (so Reich 2009 für einen vergleichbaren Fall), d.h. die Diskursrelation zwischen Entscheidungsfrage und (aus der in der Regel unmarkiert vorausgesetzten ja-Antwort) gezogenen Folgerungen, vgl. (34), spiegelt sich in der Antecedens-Konsequens-Relation von V1-Konditional-Gefügen. ${ }^{32}$
a. Sucht er eine Stelle? Dann wird er sich über das Angebot freuen.
b. Hättest du morgen Zeit für mich? Dann würde ich dir die Sache schildern.

Bleibt eine Nachbemerkung zu konfrontativen V1-Gefügen, deren stets faktische Erstkonnekte ja nicht zur einheitlichen Bedeutungsbeschreibung von selbständigen V1-Interrogativen und V1-Konditionalen passen. Hier gehen wir vorerst davon aus, dass eine faktische bzw. deklarative ,Nebenbedeutung' von V1-Sätzen vorliegt, die allerdings ihr Pendant bei selbständigen V1-Sätzen hat - neben V1-Interrogativen als V1Haupttyp gibt es auch V1-Deklarative. Ob die Wunschvorstellung erfüllbar ist, Haupt- und Nebenbedeutung, sei es insgesamt oder nur im unselbstständigen Fall, auf einen gemeinsamen Nenner zurückzuführen, muss dahingestellt bleiben.

\subsection{Nachbemerkung zu einem Sonderfall: sollte-V1-Konditionale}

Die bisherige Diskussion wurde anhand indikativischer und konjunktivischer Beispiele von V1-Konditionalen geführt. Den semantischen Teil

31. Dass konditionale Interpretationen mit Parataxe verträglich sind, ist bekannt (s. u. a. Haiman 1983, 1986). Jedoch ist die konditionale Interpretation nicht die einzig mögliche, vgl. koordinierte V2-Gefüge wie [Damit das klar ist:] Ich seh dich noch einmal dort und du fliegst raus. vs. [Damit das klar ist:] Ich lade ihn ein und ihr sprecht mit ihm. Dass das bei Pseudo-Imperativen (Hau zu und ich hau zurück!) anders ist, liegt wohl an der obligatorischen Potentialis-Interpretation des imperativen Erstkonnekts.

32. S. dazu auch die erhellende vergleichende Diskussion des möglichen Diskursursprungs konditionaler V1-Gefüge im Deutschen bei Van den Nest (i. E.) und Hilpert (i. E.). Einen anderen Weg gehen Bhatt \& Pancheva (2006: $653 \mathrm{f}$.). Ihnen zufolge ist die Beziehung zwischen Interrogativen und Konditionalen zwar prinzipiell indirekt, andererseits formulieren sie eine sehr direkte Generalisierung über deren Zusammenhang: ,,[42] Interrogative adjuncts are interpreted as conditionals“ (Bhatt \& Pancheva 2006: 653). 
abschließend, wollen wir auf die Besonderheit von sollte-Konditionalen wie (35) eingehen.

a. Wenn das zutreffen sollte, kündige ich.

b. Sollte das zutreffen, kündige ich.

Der sich darin manifestierende Gebrauch von sollte ist ,idiosynkratisch“ (Glas 1984: 86), d. h. auf Konditionale beschränkt. Nach Welke, der sich relativ ausführlich mit dieser Variante befasst (1965: $98 \mathrm{f}$.), hat konditionales sollte keine eigene deskriptive, sondern nur „unterstützende Funktion“, nämlich „den hypothetischen Charakter, der dem Bedingungssatz eigen ist, stärker hervorzuheben" (Welke 1965: 99). Das trifft das Verhältnis zwischen (35) und den sollte-losen indikativischen Gegenstücken (36) recht gut; ebenso passt dazu, dass sollte faktive Lesart der Antecedens-Proposition ausschließt, egal ob sie in Gegenwart, Vergangenheit oder Zukunft angesiedelt ist, vgl. (37).
a. Wenn das zutrifft, kündige ich.
b. Trifft das zu, kündige ich.
a. Wenn er kleiner sein sollte, ist das nicht schlimm.
Sollte er kleiner als 1.70 sein, ist das nicht schlimm.
b. Wenn ich ihn beleidigt haben sollte, bedaure ich das. Sollte ich ihn beleidigt haben, bedaure ich das.
c. Wenn er ihn morgen treffen sollte, habe ich nichts dagegen. Sollte er ihn morgen treffen, habe ich nichts dagegen.

Da ,Hervorhebung des hypothetischen Charakters' leicht zur Implikatur führt, dass die Antecedens-Proposition $\mathrm{p}$ in sollte-Konditionalen weiter von der Realität entfernt ist als in den sollte-losen Pendants, ${ }^{33}$ ist zu fragen, wie sich sollte-Konditionale hinsichtlich dieser ,Entfernungsskala' (= Wahrscheinlichkeitsskala für $\mathrm{p} / \neg \mathrm{p}$ ) nicht nur $\mathrm{zu}$ indikativischen, sondern auch zu konjunktivischen Konditionalen wie (38) verhalten.

a. Wenn das zuträfe, würde ich kündigen.

b. Träfe das zu, würde ich kündigen.

Kaufmann (1972: 11 f., 18 f.) lokalisiert sie auf dieser Skala zwischen indikativischem und konjunktivischem Typ, hebt aber hervor, die spezifi-

33. S. auch die Diskussion der sog. ,future less vivid'-Implikatur (die Wahrheit der Antecedens-Proposition ist weniger wahrscheinlich als ihre Falschheit) und deren Auslöser bei Iatridou (2000: 234). 
sche Leistung von sollte sei eine andere als die von bloßem Indikativ oder Konjunktiv II, nämlich die, eine Bedingung explizit ,als möglicherweise erfüllbar" (Kaufmann 1972: 19) zu charakterisieren. Welke (1965) sagt Analoges (mit explizitem Verweis, dass sollte die dem Konjunktiv II eigene ,mittelbare Negation“ nicht besitze); als zusätzliche Stütze führt er an, dass sollte-Konditionale in der Regel Indikativ im Konsequens aufweisen (s. Welke 1965: 99).

Die Analyse von konditionalem sollte muss sicher viel weiter getrieben werden, sowohl was das Verhältnis zum Modalverb sollen bzw. dessen epistemischen und futurischen Abarten angeht, als auch die Verbindung des sollte zugeschriebenen stärker hypothetischen Charakters mit der ihm gleichfalls zugeschriebenen Fokussierung möglicher Erfüllbarkeit. ${ }^{34}$ Was man aber schon jetzt sagen kann, ist, dass sollte in etwa das Gleiche leistet wie falls: falls ist ebenfalls auf die Einleitung strikt hypothetischer Konditionale beschränkt und schließt kontrafaktischen Gebrauch aus; oft werden falls-Konditionale zusätzlich durch sollte markiert (Zifonun et al. 1997: 2281). Insbesondere verweist falls via seine wörtliche Bedeutung ,für den Fall dass ...' genau wie sollte explizit auf die Möglichkeit der Realisierung der Antecedens-Proposition.

Das erklärt u. E. einleuchtend, warum sollte-V1-Konditionale in einem Kontext lizenziert sind, in dem einfache V1-Konditionale es nicht sind, nämlich bei gewissen Relevanzkonditionalen, vgl. (39a) vs. (39b). Relevanzkonditionale setzen offenbar voraus, dass die mögliche Realisierung der Antecedens-Proposition explizit mit ausgedrückt wird, was durch falls, wenn und eben auch sollte eingeleitete Antecedenten leisten (39bd), bloße V1-Sätze dagegen nicht.
a. *Ruft Peter an - ich bin im Café Einstein.
b. Sollte Peter anrufen - ich bin im Café Einstein.
c. Falls Peter anruft - ich bin im Café Einstein.
d. Wenn Peter anruft - ich bin im Café Einstein.

Mit anderen Worten, (39b) widerspricht nicht den zentralen Feststellungen in Abschnitt 2, sondern bestätigt nur aus anderer Perspektive, dass Anreicherung durch overte Markierung des Bedingungscharakters zu Distributionsunterschieden führen kann. ${ }^{35}$

34. Hierzu gehört auch eine vergleichende Untersuchung mit englischen should-Konditionalen (s. hierzu Nieuwint 1989, Dancygier 1998: 192f.), die jedenfalls auf den ersten Blick den deutschen sollte-Konditionalen völlig parallel scheinen.

35. Ein anonymer Gutachter verweist darauf, dass es auch V1-Relevanzkonditionale mit Konjunktiv II gebe, vgl. (i):

(i) Hättest du Durst gehabt - es wäre Bier im Kühlschrank gewesen.

Beispiele wie (i) sind zweifellos besser als (39a), aber u. E. schlechter als (39b). Da auch Konjunktiv II den Bedingungscharakter overt markiert, passt das einerseits zur o.a. Erklärung der Zulässigkeit von (39b). Andererseits macht es erneut deutlich, dass die 


\section{Zu (H1): Syntaktische Unterschiede zwischen wenn- und V1-Konditionalen: Argumente für die Unintegriertheit des V1-Antecedens}

Mit dem Nachweis von (H3), der nur partiellen Austauschbarkeit von V1- und wenn-Sätzen, ist der erste Schritt weg von der traditionellen Einbettungshypothese (3) für V1-Konditionale getan. Im Folgenden zeigen wir, dass auch die syntaktische Distribution von V1- und wenn-Sätzen verschieden ist, und argumentieren, dass die Art der Unterschiede für (H1) spricht: Der linksperiphere V1-Satz ist kein Vorfeldelement, sondern der Apodosis unintegriert vorgeschaltet, s. (40).

$$
\text { [CP [CP Regnet es] [CP [C bleiben } \left.\left.\left.{ }_{\mathrm{i}} \text { [IP wir zu Hause } \mathrm{t}_{\mathrm{i}}\right]\right]\right]
$$

Dazu überprüfen wir die topologische Distribution von V1- vs. wennSätzen (4.1) und deren Verhalten unter weiteren diagnostischen Kriterien für syntaktische (Un-)Integriertheit, insbesondere hinsichtlich Bezugssatzellipse (4.2), Bindung (4.3), Auftreten von skopusfähigen Ausdrücken, Korrelaten und Resumptiva (4.4) sowie Fokus-Hintergrund-Gliederung (4.5), mit einem u. E. klaren Ergebnis: Wenn-Sätze erfüllen die Kriterien für syntaktische Integriertheit, V1-Sätze nicht.

\subsection{Stellungsunterschiede}

\subsubsection{Initial- und Finalstellung}

Nach Greenbergs Wortstellungsuniversale 14 (1963: 66) geht in konditionalen Gefügen das Antecedens dem Konsequens in allen Sprachen normalerweise voraus. Andererseits sind in vielen Sprachen beide Abfolgen möglich (s. Bhatt \& Pancheva 2006: 646), so auch im Deutschen. Für V1- und wenn-Konditionale gilt das aber nicht in gleicher Weise: Während wenn-Sätze initial wie final stehen, präferieren V1-Sätze Initialstellung bei Weitem und im indikativischen Fall praktisch absolut, was schon Iatridou \& Embick (1994: 192) für Konditionale wie (41) angemerkt haben und Axel \& Wöllstein (2008) in einer Korpusanalyse bestätigen. ${ }^{36}$ Ebenfalls bestätigt wird der Einfluss des Verbmodus durch die

Rolle des Verbmodus für die Grammatik der V1-Konditionale weit genauer reflektiert werden müsste, als es hier geschieht.

36. In den syntaktisch annotierten Baumbanken TIGER und TüBaD/Z (insgesamt 80.000 Datensätze) wurden 1288 wenn-Sätze und 292 V1-Sätze in folgender Distribution gefunden: $8 \%$ der V1-Sätze treten in Nachstellung auf vs. $81 \%$ der wenn-Sätze. Dabei zeigt sich auch ein qualitativer Kontrast: Alle nachgestellten V1-Sätze sind konjunktivisch; bei wenn-Sätzen gibt es diesbezüglich keine Restriktion. - Eine weitere Korpusanalyse (Axel \& Wöllstein 2008), basierend auf den COSMAS-Subkorpora St. Galler Tagblatt (23.-26. 4. 97) und Vorarlberger Nachrichten (2. 7. 97), zeigte dagegen keine Präferenz für Nachstellung von wenn-Sätzen: Von 301 Fällen waren 122 voran-, 117 nachgestellt. 
stets indikativischen V1-Typen (42)-(43); hier ist so gut wie nur Initialstellung zulässig.
Konditionalltemporales V1
a. *Er schläft ein, liest er.
b. ??/*Er schläft ein, muss er ihm lange zuhören.
c. ??Er schlief stets ein, musste er einer Predigt zuhören.
d. ?Er schliefe ein, müsste er einer Predigt zuhören.
e. Er wäre eingeschlafen, hätte er der Predigt noch länger zu- hören müssen.

Konfrontatives $V 1$
* Ärzte verdienen heute zu viel, verdienten sie früher zu wenig.

Irrelevanzkonditionales $V 1$

??Er gab (*doch) die Hoffnung nicht auf, war der Versuch auch missglückt.

Für uns zentral interessant sind die Verhältnisse bei V1-Konditionalen, da nur sie mit integrierten wenn-Sätzen alternieren. Dass deren Nachstellung - im Gegensatz zu wenn-Sätzen - großteils schlecht ist, ist jedoch nicht notwendig grammatischen, sondern eher Verarbeitungs- bzw. Verständlichkeitsgründen geschuldet. Ausschlaggebend für die Akzeptabilität von $(41 \mathrm{~d}$, e) ist u. E., dass Verbmodus eine wichtige Rolle bei der Lizenzierung bzw. dem Erkennen der semantischen Abhängigkeit des V1-Satzes spielt: Konjunktiv signalisiert interpretative Abhängigkeit, Indikativ nicht, es sei denn, Stereotype über Ursachen-Folge-Beziehungen kommen zu Hilfe, vgl. $(41 \mathrm{~b}, \mathrm{c}) .{ }^{37}$ Die in der Regel ikonische Abbildung der zeitlichen Abfolge von Protasis und Apodosis in indikativischen V1Gefügen erscheint von daher eher als eine Verständnis sichernde Maßnahme, die nicht per se auf einen tief greifenden strukturellen Unterschied zu wenn-Gefügen schließen lässt. Ein i.e.S. syntaktisches Argument für (H1) geben sie nicht ab.

Argumentativ unerheblich, wenngleich aus anderen Gründen, sind auch die Verhältnisse bei Medialstellung von V1- und wenn-Konditionalen: Beide lassen sie ohne Einschränkung zu (44), sind dabei aber stets intonatorisch abgesetzt. (Das Gleiche beobachten Bhatt \& Pancheva 2006: 645 fürs Englische.) Aber das heißt nichts anderes, als dass sich V1- und wenn-Konditionale wie alle anderen (korrelatlosen) Adverbial-

Dies relativiert das vorige Ergebnis und lässt vermuten, dass der Unterschied stilistischen Gründen und solchen der Textsorte geschuldet ist.

37. Zu Konjunktiv als Abhängigkeitszeichen s. auch Fabricius-Hansen (1997) und Fabricius-Hansen \& Saebø (2004). 
sätze im Deutschen verhalten, die nicht nur in klar parenthetischer präfiniter Position wie in (44a), sondern auch im Mittelfeld (44b) stets prosodisch unintegriert auftreten. ${ }^{38}$ Wie dann nicht anders zu erwarten, sind indikativische und konjunktivische V1-Sätze medial auch gleich gut, vgl. (44a, b) mit (44c, d).

(44) a. Die Berliner Schauspielerin Alice Treff, will man Eingeweihten glauben/wenn man Eingeweihten glauben will, wird heute 85 Jahre.

(MMM/106.15201: Mannheimer Morgen, 4. 6. 91)

b. Petra Roth muss also, will sie etwas in Gang setzen / wenn sie etwas in Gang setzen will, mit wechselnden Mehrheiten regieren.

c. Ypsilanti, würde sie die Regierung anstreben, müsste mit den Linken koalieren.

d. Ypsilanti müsste, würde sie die Regierung anstreben, mit den Linken koalieren.

\subsubsection{Rechtsperiphere Stellung und VP-abhängige Topikalisierung}

Ein weiteres Stellungskriterium für (Un)Integriertheit von Sätzen ist deren mögliches Vorkommen vor zweifelsfreien Nachfeldkonstituenten (Reis 1997: 127 f.). Können rechtsperiphere Sätze etwa vor restriktiven Relativsätzen stehen, die auch nachgestellt zweifelsfrei eingebettet/integriert sind, sind auch diese als eingebettet/integriert zu werten; können sie es nicht, weist das auf unintegrierte Position ,außerhalb' des Bezugssatzes hin. Analoges gilt für die Möglichkeit, rechtsperiphere Sätze mit VP-Teilen des Bezugssatzes mit zu topikalisieren: Geht das, ist auf VPinterne bzw. an VP unmittelbar adjungierte Position für den betreffenden Satz zu schließen und damit auf Einbettung/Integration; geht es nicht, muss der nachgestellte Satz an eine höhere Strukturposition ,außerhalb des Bezugssatzes adjungiert sein.

Bhatt \& Pancheva (2006: 648) weisen nun anschließend an Iatridou (2000) darauf hin, dass nachgestellte if-Sätze zwei mögliche Strukturpositionen einnehmen können, einmal unterhalb der Negation und einmal oberhalb, wie man an der entsprechenden Ambiguität solcher Sätze sieht, vgl. die ganz analogen deutschen wenn-Beispiele (45). ${ }^{39} \pm$ Betrof-

38. Darauf, ob dieses stets unintegrierte Mittelfeld-Vorkommen als ,parenthetisch` zu werten ist, können wir hier nicht eingehen.

39. Ein anonymer Gutachter weist darauf hin, dass die sog. I-Topikalisierung ggf. Einfluss auf den Erhalt der ,oberen' Lesart nehmen kann; das Argument wird jedoch dadurch nur auf bestimmte Intonationsvoraussetzungen relativiert, nicht entwertet. 
fenheit von Negation - wie von anderen Bereichsträgern im Bezugssatz - ist ein bekannt starkes Indiz für \pm Integriertheit (s. auch u. Abschnitt 4.4); d. h. in der zu Lesart (45b) korrespondierenden Strukturposition ist der wenn-Satz unintegriert. Dass bei entsprechender VP-Topikalisierung die ,obere' Lesart wegfällt, vgl. (46), unterstreicht die einschlägige Gültigkeit dieses positionellen Kriteriums.

(45) Sue ist nicht nett zu Tom, wenn er ihr viel zu tun gibt a. ... sondern wenn er sie dafür ordentlich bezahlt.

b. ... denn sie ist auch so schon überlastet. $\quad \begin{aligned} & (\neg>\text { wenn })^{40} \\ & (\text { wenn }>\neg)\end{aligned}$

(46) Nett zu Tom, wenn er ihr viel zu tun gibt, ist Sue nicht.

$(\neg>$ wenn; *wenn $>\neg)$

Genau wie weil-Sätze treten also rechtsperiphere wenn-Sätze in integrierter wie unintegrierter Position auf. Dagegen scheinen selbst konjunktivische V1-Sätze rechtsperipher nur unintegriert möglich, vgl. (47); der Ausschluss der ,integrierten' Interpretation ist robust. Wie von daher zu erwarten, sind auch die entsprechenden VP-Topikalisierungen schlecht(er) (48a); letzteres gilt auch dann, wenn kein skopusfähiges Element im Spiel ist $(48 b-d)$.

(47) Sue wäre nicht nett zu Tom, gäbe er ihr viel zu tun.

$$
\left(?^{*} \neg>\text { wenn; } \sqrt{ } \text { wenn }>\neg\right)
$$

(48) a. ??Nett zu Tom, gäbe er ihr viel zu tun, wäre Sue nicht.

b. ??Protestieren, käme wieder was dazwischen, würde man wohl müssen.

c. ??Zu Schaden, hätte der Blitz eingeschlagen, wären viele gekommen.

d. ??Getrauert, wäre Deutschland ausgeschieden, hätte ich schon.

Das lässt den Schluss zu, dass V1-Sätze strukturell stets höher positioniert und dabei unintegriert sind. Dass die VP-abhängigen Topikalisierungen (48) nicht völlig schlecht sind, und dies noch mehr für die Stellung von V1-Sätzen vor zweifelsfreien Nachfeldkonstituenten gilt, vgl. (49b, d), widerspricht dem nicht, da sich anders als bei sonstigen Vergleichspaaren (etwa \pm integrierten weil- oder $u m$-Verbletzt-Sätzen) die

40. Lesartenkennzeichnung nach Bhatt \& Pancheva (2006). In aussagenlogischer Notation entspricht (45a) $\neg(\mathrm{p} \rightarrow \mathrm{q}),(45 \mathrm{~b}) \mathrm{p} \rightarrow \neg \mathrm{q}$. 
Bedeutung hypothetischer Konditionale in integrierter vs. unintegrierter Konstruktion in nichts unterscheidet.

(49) a. Ihr hättet lauter Leute getroffen, die euch interessieren, wärt ihr gekommen.

b. ?Ihr hättet lauter Leute getroffen, wärt ihr gekommen, die euch interessieren.

c. Sie würde höher gewinnen als euch lieb wäre, würde sie kandidieren.

d. ?Sie würde höher gewinnen, würde sie kandidieren, als euch lieb wäre.

Das leistet konstruktioneller Kontamination in semantisch eindeutigen Positionen wie (48) - (49) Vorschub, die in Fällen wie (47), wo die rechtsperiphere Position relativ zum Bereichsträger zu echten Bedeutungsunterschieden führt, unterbleibt. Hinzu kommt in Fällen wie (49) die nie auszuschaltende Möglichkeit parenthetischen Einschubs am linken Nachfeldrand. Insofern kann man auf dem Hintergrund des klaren Unterschieds (45) vs. (46) in rechtsperipherer Stellung die z.T. signifikant schlechtere Bewertung von V1-Fällen wie (48)-(49) vs. ihren wenn-Pendants, s. (50)-(51), durchaus als Argument pro prinzipielle Unintegriertheit der V1-Konditionale werten.

(50) a. Protestieren, wenn wieder was dazwischen käme, würde man wohl müssen.

b. $\mathrm{Zu} \mathrm{Schaden,} \mathrm{wenn} \mathrm{der} \mathrm{Blitz} \mathrm{eingeschlagen} \mathrm{hätte,} \mathrm{wären}$ viele gekommen.

c. Getrauert, wenn Deutschland ausgeschieden wäre, hätte ich schon.

(51) a. Ihr hättet lauter Leute getroffen, die euch interessieren, wenn ihr gekommen wärt.

a' Ihr hättet lauter Leute getroffen, wenn ihr gekommen wärt, die euch interessieren.

b. Sie würde höher gewinnen als euch lieb wäre, wenn sie kandidieren würde.

b'. Sie würde höher gewinnen, wenn sie kandidieren würde, als euch lieb wäre.

\subsection{Bezugssatzellipsen}

Wie von Iatridou \& Embick (1994: 197) fürs Englische und Niederländische und unabhängig davon von Reis (2000: 217) fürs Deutsche beobach- 
tet, können eingeleitete Konditionale als elliptische Antworten fungieren, nicht aber V1-Sätze, vgl. (52a) vs. (52b).

[Unter welchen Umständen würden Sie einen Bentley kaufen?]

a. Wenn ich Millionär wäre.

b. *Wäre ich Millionär.

U. E. ist das eindeutige Evidenz dafür, dass V1-Konditionale - im Kontrast zu wenn-Konditionalen - unintegriert sind, denn wären sie integriert/eingebettet bzw. Gliedsätze, müssten sie als elliptische Antworten auftreten können. Zusätzliche Bestätigung liefert das schon von Altmann (1981: 27) beobachtete Faktum, dass V2-Argumentsätze, die ebenso als (relativ) unintegriert gelten (Reis 1997), mit kanonischen dass-Komplementen in gleicher Weise kontrastieren:

[Was hättest du gern geglaubt?]

a. Dass Hans Millionär wäre.

b. *Hans wäre Millionär.

Letzteres Faktum schlägt von vornherein den Erklärungsversuch von Iatridou \& Embick (1994) aus dem Feld, die Fälle wie (52) auf prinzipielle Unfokussiertheit von V1-Konditionalen zurückführen, denn subordinierte V2-Sätze sind so gut wie immer im Fokus. (Zur Widerlegung der Unfokussiertheitsannahme für V1-Konditionale s. u. 4.4). ${ }^{41}$ Von daher nehmen wir die Unfähigkeit zu Bezugssatzellipsen als klares Indiz für Unintegriertheit von konditionalem V1, zumindest in dem Sinn wie abhängige V2-Sätze unintegriert sind. Weitere Fakten verstärken diesen Eindruck.

\subsection{Bindung und Prinzip-C-Effekte}

Generell ist Bindung zwischen Pronomen und einem quantifizierenden Ausdruck möglich, wenn der linksperiphere NS vom Matrixsatz lizenziert und satzintern rekonstruierbar ist. Frey (2004: 228) präsentiert einen Kontrast im Bindungsverhalten bei linksperipherem wenn-Satz mit so- vs. dann-eingeleiteter Apodosis: Der quantifizierende Ausdruck in der so-Apodosis kann das Pronomen im wenn-Satz (54a) nicht binden, im

41. M. Krifka (p. M.) hat als mögliche Erklärung für (52) vorgeschlagen, dass Fragen bzw. Antworten ein explizites anaphorisches Element benötigten, was von wenn $=$,im Falle dass' geliefert würde, aber nicht von V1-Sätzen. Dies wäre wohl auf den dass- vs. V2Fall (53) übertragbar, ist u. E. aber nicht zielführend, da z. B. warum-Fragen anaphernlose Antworten sehr wohl erlauben. 
Kontrast zur dann-Apodosis (54b). Frey führt das darauf zurück, dass linksperiphere wenn-Sätze im dann-Fall satzintern lizenziert sind (bloße Linksversetzung), aber im so-Fall basisgeneriert sind und unintegriert auftreten.
a. *[Wenn seine ${ }_{i}$ Großmutter glücklich ist $]$, so ist jeder ${ }_{i}$ Lingu- ist glücklich.
b. [Wenn seine ${ }_{i}$ Großmutter glücklich ist $]_{\mathbf{j}}$, dann ist jeder ${ }_{i}$ Lin- guist $t_{\mathbf{j}}$ glücklich.

Nimmt man dies zum Maßstab, verhalten sich linksperiphere V1-Sätze in beiden Fällen unintegriert (wobei der Effekt bei dann u. E. schwächer ist als bei so, vgl. (54'b); Das noch akzeptablere dann-Beispiel (54'c) verdanken wir einem anonymen Gutachter):

(54') a. *[Ist seine ${ }_{i}$ Großmutter glücklich], so ist auch jeder ${ }_{i}$ Linguist glücklich.

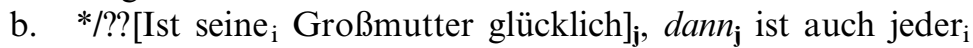
Linguist glücklich.

c. ?/??[Ist seine ${ }_{i}$ Theorie erst mal widerlegt $]_{\mathbf{j}}$, dann $n_{\mathbf{j}}$ macht fast jeder ${ }_{i}$ Linguist gerne weitere Konzessionen.

Das Bindungsverhalten linksperipherer wenn- und V1-Sätze in unmittelbar präfiniter Position unterscheidet sich ebenfalls: Dabei verhält sich der wenn-Satz, wie man es von lizenzierten Gliedsätzen erwartet, d.h. Bindung ist möglich $(55 \mathrm{a}, \mathrm{b})$, und der V1-Satz, wie man es eher von unintegrierten bzw. parataktischen Gefügen erwartet, d. h. Bindung erfolgt nicht (55c). Auch hier mildert Konjunktiv als Dependenzzeichen die Effekte - vorangestellt (55d) wie nachgestellt (55e).

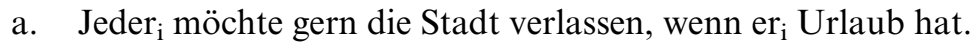
b. Wenn $\mathrm{er}_{\mathrm{i}}$ Urlaub hat, möchte jeder ${ }_{i}$ gern die Stadt ver- lassen.
c. *Hat er ${ }_{i}$ Urlaub, möchte jeder ${ }_{i}$ gern die Stadt verlassen.
d. ?/??Hätte er $_{\mathrm{i}}$ Urlaub, würde jeder $_{\mathrm{i}}$ gern die Stadt verlassen.
e. ?Jeder ${ }_{i}$ würde gern die Stadt verlassen, hätte $e_{i}$ Urlaub.

Dass nachgestellte V1-Sätze ebenso unintegriert sind (worauf bereits die in Abschnitt 4.1.2 diskutierten Daten verweisen) wie initiale V1-Sätze (55c), zeigen auch Daten zu Prinzip-C-Effekten: Nachgestellte wennSätze werden vom Subjekt im Bezugssatz c-kommandiert (56a), nachgestellte V1-Sätze (56b) nicht. Konjunktiv schwächt diesen Gegensatz hier nicht ab: Strukturell ist V1 somit nicht unterhalb oder an IP adjungiert, 
sondern oberhalb. Das Ausbleiben des Prinzip-C-Effekts bei initialem wenn-Satz (57a) spricht gegen eine Topikalisierungsanalyse des wenn-Satzes - analog zum Englischen, vgl. Bhatt \& Pancheva (2006: 649), die das als ein Argument pro linksperiphere Basisgenerierung werten. Analoges gilt für initiale V1-Sätze wie (57b).

a. ${ }^{*} \mathrm{Sie}_{\mathrm{i}}$ ruft nach Hans, wenn Maria ${ }_{\mathrm{i}}$ hungrig ist.

b. Sie $_{i}$ würde nach Hans rufen, wäre Maria ${ }_{i}$ hungrig.

a. Wenn Maria ${ }_{i}$ hungrig ist, ruft $\operatorname{sie}_{i}$ nach Hans.

b. Ist Maria ${ }_{i}$ hungrig, ruft $\operatorname{sie}_{i}$ nach Hans.

Bindungsdaten und Prinzip-C-Effekte weisen demnach auf Unintegriertheit und Basisgenerierung initialer und finaler V1-Sätze hin. ( $\mathrm{Zu}$ weiteren Überlegungen hierzu s. u. Abschnitt 6.)

\subsection{Auftreten von Korrelaten und skopusfähigen Ausdrücken}

Nur Gliedsätze erlauben das Auftreten von Korrelaten, zu denen sie in ein attributives, also wiederum Gliedsatz-Verhältnis treten, insofern ist möglicher Korrelatbezug ein hinreichendes Kriterium für Gliedsatzstatus (Reis 1997: 132), vgl. das entsprechende Verhalten \pm integrierter weilSätze (58). Wenn-Sätze erlauben vorausgehendes Korrelat dann im Bezugssatz (59), was ihren Gliedsatzstatus unterstreicht, V1-Sätze tun das nicht (59'); (59'a) ist allenfalls mit temporaler Interpretation von dann möglich. Konjunktiv verbessert die Akzeptabilität bei Nachstellung, nicht aber bei Kontaktstellung des V1-Satzes zu dann, die absolut ausgeschlossen ist (59'b).

(58) a. Peter muss (deshalb) zu Hause bleiben, weil das Kind krank ist.

b. Peter muss (*deshalb) zu Hause bleiben, weil das Kind ist krank.

(59) a. Ich bin/wäre dann glücklich, wenn ich etwas erreicht habe/ hätte.

b. Dann wenn ich etwas erreicht habe/hätte, bin/wäre ich glücklich.

(59') a. Ich ??bin/?wäre dann glücklich, habe/hätte ich was erreicht.

b. *Dann habe/hätte ich was erreicht, bin/wäre ich glücklich.

Ähnlich wie Korrelate verhalten sich i.e.S. skopusfähige Ausdrücke, seien es Adverbien wie immer, oft, oder Fokuspartikeln wie sogar, nur, 
die eine fokussierbare XP-Konstituente in ihrem Skopus fordern. Wie (60) zeigt, sind wenn-Sätze mögliche Fokuskonstituenten im Skopus solcher Ausdrücke, während V1-Sätze das (eher) nicht sind (60'). Wieder zeigt sich dabei, dass der Effekt bei Nachstellung schwächer ist und sich durch Konjunktiv II weiter abschwächen lässt (60'a, b) ${ }^{42}$ wogegen Kontaktstellung stets zu Ungrammatikalität führt.

(60) a. Es hat sogar/nur/immer Heringssalat gegeben, [wenn PAUL kam].

b. Sogar/Nur/Immer [wenn DU kommst], gibt es Heringssalat.

$\left(60^{\prime}\right)$ a. ??Es hat sogar/nur/immer Heringssalat gegeben, [kam PAUL].

a'. ?Es hätte sogar/nur/immer Heringssalat gegeben, [wäre PAUL gekommen].

b. *Sogar ${ }^{*}$ Nur $/ *$ Immer [kommst DU], gibt es Heringssalat.

Die natürliche Erklärung für die Akzeptabilitätsmuster sowohl bei Korrelaten wie skopusfähigen Ausdrücken ist, dass nur wenn-Sätze eine Strukturstelle in der Apodosis belegen, aber nicht V1-Sätze. Das scheint die Hypothese, dass V1-Konditionale unintegriert sind, weiter zu bestätigen. Zu bedenken ist allerdings, dass die mehr oder minder große Akzeptabilität von Distanzfällen wie (59'a), (60'a) die mehr oder minder große Akzeptabilität der Nachstellung von V1-Sätzen spiegelt, und auch für die strikt ungrammatischen Adjazenzfälle (59'c), (60'c) scheint die Interferenz eines unabhängigen Faktors - generelles Adjazenzverbot skopusfähiger Elemente an uneingeleitete, d.h. V1- und V2-Sätze - zumindest nicht ausgeschlossen. ${ }^{43}$ Andererseits bestätigen die bereits in Abschnitt 4.1.2 aufgeführten Skopusdaten zur Satznegation (45) so klar unintegriertes Verhalten von V1-Sätzen (47), dass auch die analoge Deutung der weiteren Skopusdaten in $\left(59^{\prime}\right)-\left(60^{\prime}\right)$ im Sinne von (H1) u. E. durchaus plausibel ist.

Skopusdaten mit Fokuspartikeln wie (60') sind nach Iatridou \& Embick (1994: $197 \mathrm{f}$.) ein weiterer Hinweis, dass die V1-Protasis generell als Träger thematischer Information fungiere und V1-Sätze entsprechend,

42. Nach Iatridou \& Embick (1994: 196 f.) sind mit (60'a) vergleichbare deutsche V1-Beispiele mit Konjunktiv völlig ungrammatisch, was unseren Intuitionen nach zu stark ist.

43. V1-Sätze erlauben keine einleitende Fokuspartikel, und V2-Sätze nur dann, wenn die Vorfeldkonstituente deren eigentlichen Bereich darstellt. In keiner der gängigen Fokuspartikel-Theorien wird das ohne Stipulation erfasst, was aber am (weit über V1-Konditionale hinausreichenden) Faktum nichts ändert. - Fälle wie Er sagte nur [morgen kommt Hans] (Iatridou \& Embick 1994: 197) stellen das nicht in Frage, da nur (im Mittelfeld) und V2-Satz (im Nachfeld) strukturell nicht adjazent sind. 
anders als wenn-Sätze, nicht fokussierbar seien. Diese rein informationsstrukturelle Deutung (die Bhatt \& Pancheva 2006: 658f. weitgehend übernehmen) wäre natürlich auch mit Einbettungsstatus von V1-Konditionalen verträglich. Sie ist aber unhaltbar, wie sich bereits daran zeigt, dass V1-Konditionale in jeder Stellung Fokuspartikeln samt zugehöriger Fokuskonstituente enthalten können (61). Dass diese als Fokusexponent einer eigenen Fokus-Hintergrund-Gliederung gelten darf, wird der nächste Abschnitt bestätigen. Darüber hinaus sind V1-Konditionale u. E. keineswegs auf thematische, d.h. diskurs-alte Information beschränkt, s. (62). Insofern ist u. E. der Deutungsansatz von Iatridou \& Embick auf ganzer Linie zurückzuweisen.

(61) a. Kommt nur PAUL zum Essen, gibt es nur HEringssalat

b. Hätte er mir nicht sogar geDROHT, wäre ich RUhig geblieben.

c. Ich wäre RUhig geblieben, hätte er mir nicht sogar mit der PolizEI gedroht.

(62) a. A: Wohin fährst Du im Urlaub? B: Das hängt davon ab. Besteht Maja die Fahrprüfung, die muss sie nämlich noch machen, machen wir eine Deutschlandtour.

b. A: Was ist dein größter Wunsch? B: Naja, würd ich endlich mal im Lotto gewinnen, wärs eine Weltreise. A: Du spielst Lotto?? Das hätte ich nie gedacht.

\subsection{Fokus-Hintergrund-Gliederung}

Auch hier geht es grundlegend nur um konditionale V1-Gefüge mit integrierten wenn-Alternanten, also hypothetische Konditionale (zu \pm Integriertheit anderer Subtypen s. o. Abschnitt 2.6). ${ }^{44}$ Integrierte bzw. Gliedsatzgefüge weisen prinzipiell nur eine Fokus-Hintergrund-Gliederung auf, d.h. sie können mit nur einem Fokus und entsprechend mit nur einer hauptakzentuierten Konstituente, dem sog. Fokusexponenten, auskommen. (Dass sie oft in mehrere Intonationsphrasen zerlegbar sind, ist eine andere Sache, s. o. Fn. 19.) Trägt also innerhalb eines komplexen Satzes ein Ausdruck im Nebensatz den Hauptakzent oder kann er bei Hauptakzent im Bezugssatz unbetont bleiben, dann hat dieser Nebensatz

44. Progrediente Intonation bei V1-Sätzen verweist entgegen Polikarpow (1996: 157) nicht notwendig auf Einbettung in den Folgesatz (s. Truckenbrodt 2005: 279). Auch Günthner (1999: 215) zeigt, dass bei Einbettung zusätzlich zu progredienter Intonation keine eigenständige Intonationskontur der einzelnen Syntagmen vorliegt, wogegen unintegrierte wenn-Sätze (s. auch o. 2.6) progrediente Betonung plus durch Pause abgetrennte eigenständige Intonationskontur aufweisen. 
Gliedsatzstatus. Für wenn-Sätze trifft beides zu (63), folglich sind sie Gliedsätze, d. h. sie belegen eine Strukturstelle in ihrem Bezugssatz.

Bei V1-Sätzen dagegen scheint es, als ob weder das Eine noch das Andere geht, vgl. (63'a, b); vielmehr müssen sowohl der V1-Satz als auch der Bezugssatz einen Hauptakzent enthalten (63c). ${ }^{45}$ In diesem Sinne weisen beide Sätze notwendig eine jeweils eigene Fokus-HintergrundGliederung auf, womit sich ,[...] ein V1-Gefüge [...] hinsichtlich der Betonung/Fokussierung (zwei FHGs) eher wie ein parataktisches Gefüge [verhält]" (Reis 2000: 217). Bei finalem V1 interveniert wieder der Nachstellungseffekt, den der Konjunktiv mildern kann (64).
a. Wenn ich MillioNÄR wäre, würde ich es tun.
b. Wenn ich Millionär wäre, würde ich BENTley fahren.
c. Ich würde es tun, wenn ich MillioNÄR wäre.
d. Ich würde BENTley fahren, wenn ich Millionär wäre.
a. ??Wäre ich MillioNÄR, würde ich es tun.
b. ??Wäre ich Millionär, würde ich es TUN.
c. Wäre ich MillioNÄR, würde ich es TUN.
a. ??Ich würde es tun, wäre ich MillioNÄR.
b. ?Ich würde es TUN, wäre ich MillioNÄR.

(63) - (64) zeigt erneut, dass die in 4.4 skizzierte Deutung von Iatridou \& Embick (1994: 198) fehlgeht. Zwar ist richtig, dass Fälle mit Hauptakzent im V1-Satz wie (63a') abweichend sind, aber die Begründung (V1 ist thematisch und deshalb nicht betonbar) ist es nicht, insofern Iatridou \& Embick nicht Daten wie (63'b, c) in Betracht ziehen, die klar zeigen, dass das Fehlen zweier separater Fokus-Hintergrundstrukturen bei V1Sätzen den Mangel ausmacht. Da echt eingebettete Sätze niemals eine separate Fokus-Hintergrundstruktur erfordern (Reis 1997), ist das wiederum Evidenz für den Unintegriertheitsstatus von V1-Konditionalen, also für (H1).

\subsection{Fazit}

In 4.1-4.5 hat sich gezeigt, dass wenn- und V1-Sätze in Hinblick auf die diagnostischen Kriterien für \pm Integriertheit bzw. \pm Einbettungsstatus verschieden sind: Wenn-Sätze verhalten sich integriert, V1-Sätze uninte-

45. Intuitiv scheint der prosodische Unterschied zu analogen wenn-Gefügen nicht groß. Das spricht aber nicht gegen die Unintegriertheit von V1-Gefügen, sondern dafür, auch die Struktur der konditionalen wenn-Gefüge im Gegenwartsdeutschen (Gwd.) einmal näher unter die Lupe zu nehmen. Hierzu bräuchte man u. a. auch mehr Studien über die Prosodie der Teilsatzgrenzen, analog zu Truckenbrodt (2005), und darauf basierende experimentelle Untersuchungen. 
griert. Zwar ergeben nicht alle festgestellten Unterschiede einschlägige Argumente (s. die Stellungspräferenzen in 4.1), und auch die Datenlage ist nicht immer so klar, wie man sich wünschen würde. Aber zum einen gibt es für diese Unklarheiten durchaus plausible Erklärungen (so etwa für die Daten in (48)-(49)), zum andern sind die Daten bzgl. Bezugssatzellipse, Bindung, Fokus-Hintergrund-Gliederung, so- vs. dann-Verteilung, Negationsskopus eindeutig genug, um (H1), und damit (H), hinreichend zu stützen. Hinzuweisen ist darauf, dass nicht nur links-, sondern auch rechtsperiphere V1-Konditionale unintegriert sind, wie VP-Topikalisierung, Negationsskopus und Prinzip-C-Effekte zeigen (wobei Konjunktiv generell den negativen Nachstellungseffekt mildert). Von daher ließe sich $(\mathrm{H})$ auf V1-Sätze generell verallgemeinern, ${ }^{46}$ auch wenn unsere Argumentation nach wie vor linksperiphere V1-Sätze fokussiert.

Ergebnis von Abschnitt 4 ist also, dass die V1-Protasis nicht, wie traditionell angenommen, in ihren Bezugssatz eingebettet ist, sondern, im Einklang mit $(\mathrm{H})$ und $(\mathrm{H} 1)$, mit diesem quasi-parataktisch verknüpft bzw. ihm im linksperipheren Fall unintegriert vorgeschaltet ist. Dieses Ergebnis hat als direkte Konsequenz, dass (H2) gelten muss: Die Apodosis in deklarativen V1-Konditionalgefügen ist entweder ein V2-Satz mit rechtfertigbarer Vorfeld-Ellipse oder aber ein V1-Deklarativ. Im nächsten Abschnitt überprüfen wir, wie es sich damit empirisch verhält.

\section{Zu (H2): Die Apodosis als V1- vs. (elliptischer) V2-Deklarativ}

\subsection{Kann die Apodosis ein elliptischer V2-Deklarativ sein? ${ }^{47}$}

Dass Adverbialsätze V2-Deklarativen unintegriert vorausgehen können, ist von den sog. ,V3'-Fällen her bekannt (s. auch o. Abschnitt 2.6). Will

46. Gegen diese Verallgemeinerung führt ein Gutachter die Alternation zwischen als ob-/ -wenn- mit alsV1-Fällen (Als ob/wenn er der Chef sei, ... vs. Als sei er der Chef, ..., vgl. HdK 2003: 618) an; diese V1-Sätze seien klar integriert. Auch wenn man akzeptiert, dass hier V1-Sätze vorliegen, ist das u. E. bestreitbar: Als ob/wenn- und entsprechend auch alsV1-Sätze sind schon semantisch extrapropositional (vgl. HdK 2003), was bei als oblals wenn-Sätzen, zumindest bei Gebrauch als adverbiale Angaben, mit prosodischer Unintegriertheit korrespondiert, entsprechend u. E. auch bei der alsV1-Alternante. Dass der Befund bei Gebrauch als adverbiale Ergänzungen bei allen Alternanten eher auf Integration deutet, hat offenbar mit deren ,Komplement'-Status zu tun; bzgl. des fehlenden Unterschieds zwischen wenn/ob- und V1-Variante könnte man darauf verweisen, dass, anders als die eingeleiteten Varianten, als V1-Sätze obligatorisch Konjunktiv aufweisen, und das begünstigt, wie hier passim zu sehen, stärker ,integratives ${ }^{6}$ Verhalten. Vor allem aber bleibt die Rolle von als unberücksichtigt: Egal ob als Präposition ist (wie der Gutachter vorschlägt) oder Konjunktion oder etwas Drittes, ist als der eigentliche Verknüpfer des alsV1-Satzes mit dem Bezugssatz, und damit für Auslösung von \pm Integration verantwortlich. Insofern ist dieser Fall für unsere Argumentation unerheblich.

47. Wir schulden beiden Gutachtern Dank, die berechtigterweise auf der Überprüfung der Ellipse-Hypothese insistiert haben. 
man dies für Gefüge mit initialen - und wie in Abschnitt 4 gezeigt: unintegrierten - V1-NS nutzbar machen, ist die Apodosis als V2-Deklarativ mit Vorfeld-Ellipse eines geeigneten Elements zu analysieren. Erstrangiger Kandidat für letzteres ist das resumptive so, das schon in wennGefügen für Unintegriertheit des vorausgehenden Konditionals sorgt (s. o. 4.3). $\mathrm{Zu}$ überprüfen ist nun, ob so die für die Ellipsehypothese notwendigen Voraussetzungen erfüllt: (i) Alle initialen V1-Sätze lassen Wiederaufnahme mit so zu; (ii) so- vs. Ø-Anschluss bewirkt keinen signifikanten Interpretationsunterschied der betreffenden Gefüge.

Was (i) betrifft, kann so offenbar bei allen Untertypen von V1-Nebensätzen resumptiv vorkommen; eindeutig unakzeptable V1-so-Fälle haben wir nicht gefunden. Was (ii) betrifft, gibt es nach Redder (1987) für wennGefüge einen Unterschied zwischen dann- und so-Fortsetzung, der darauf schließen lässt, dass so nicht bedeutungsleer ist: Während so explikativ sei, d. h. das in der wenn-Satz-Proposition thematisierte Hörerwissen über eine Sache wird in der so-eingeleiteten Apodosis „qualitativ verändert“, „modelliert“, leiste dann „im Unterschied zu so [...] eine lineare Fortentwicklung des hörerseitigen Verstehens und Wissens. Es wird stufenlos erweitert." (Redder 1987: 321 f.; ähnlich Eggs 2004.) Dieser Unterschied erklärt nach Eisenberg (1999: 336) ,warum so vornehmlich bei epistemischer, dann vornehmlich bei konditionaler und temporaler Lesart [von wenn-Sätzen] auftritt.“ Das mag quantitativ richtig sein, es schlägt sich allerdings u. E. bei klar epistemischen und konditionalen Fällen nicht in einem belastbaren Akzeptabilitätsunterschied zwischen so- und dann-Fortsetzung nieder. Nur im temporalen Fall ergibt sich ein distinktiver Effekt, vgl. (65)-(67): Während für (65) mit $ø$-Anschluss die temporale Lesart nahe liegt, ohne die konditionale Lesart auszuschließen (je verbunden mit \pm notwendig einheitlicher Betrachtzeit bzw. nichtdeiktischer vs. deiktischer Perfekt-Lesart, s. o. 2.1), und (66) wohl beides zulässt, forciert so für (67) die konditionale Lesart.

(65) a. Wenn Karl heute Abend kommt, erzähle ich von den Plänen.

b. Wenn er die Aufgabe erledigt hat, können wir baden gehen.

(66) a. Wenn Karl heute Abend kommt, dann erzähle ich von den Plänen.

b. Wenn er die Aufgabe erledigt hat, dann können wir baden gehen.

(67) a. Wenn Karl heute Abend kommt, so erzähle ich von den Plänen.

b. Wenn er die Aufgabe erledigt hat, so können wir baden gehen. 
So ist also nicht völlig bedeutungsleer, auch wenn dies nur in wenigen Konstellationen halbwegs klar zu greifen ist ((65)-(67) exemplifiziert die einzigen, die wir bisher gefunden haben). Auf den ersten Blick spricht das gegen die $s o$-Ellipse-These für V1-Gefüge. Auf den zweiten Blick ist es aber mit ihr verträglich, da ja der Austausch von wenn- mit V1-Sätzen auf hypothetisch-konditionale Fälle beschränkt ist (s. Abschnitt 2), und V1-Gestalt der Protasis in diagnostischen Konstellationen à la (65) schon per se die konditionale Interpretation befördert, s. o. (7'), hier wiederholt als (68). So fügt also nichts zur Bedeutung von V1-Gefügen hinzu, was nicht schon in deren Bedeutung enthalten wäre, von daher könnte es also auch ohne Bedeutungsverlust entfallen.
a. Kommt Karl heute Abend, erzähle ich von den Plänen.
b. Hat er die Aufgabe erledigt, werden wir baden gehen.

Von diesen Überlegungen noch nicht abgedeckt sind die konfrontativen V1-Fälle. Da sie stets so erlauben, erfüllen sie (i), und da es keinerlei interpretativen Unterschied zwischen $\varnothing$ - und so-Anschluss-Fällen zu geben scheint, ist wohl auch (ii) erfüllbar. Allerdings bliebe zu klären, (i) wie der fehlende Unterschied im konfrontativen Fall aus der o. a. Bedeutung von so herzuleiten ist (es liegt ja wohl das gleiche so wie in den anderen V1-Fällen vor), (ii) was den auffälligen Unterschied zum soVorkommen in den eingeleiteten Pendants bedingt (die seltenen konfrontativen wenn-Fälle verlangen so, s. o. (17'), die während-Fälle schließen es überwiegend aus, s. u. 5.2.3).

Insgesamt scheint also die Annahme einer so-Ellipse in deklarativen V1-Gefügen verteidigbar, und damit auch die Interpretation der Apodosis als V2-Deklarativ. Wie wir unten sehen werden, gibt es auch diachrone Anhaltspunkte für diese Ausprägung von (H2). Wenn wir es trotzdem nicht dabei bewenden lassen, dann deshalb weil es zum einen kein wirklich zwingendes empirisches Argument für die so-Ellipsenhypothese gibt (so wie es etwa für die angenommene Ellipse bei Topic Drop vorliegt), und uns zum andern gegenüber Annahmen von völlig fakultativen Ellipsen konkreten Materials (wie auch dem alternativem Ansatz eines Null-Elements im Vorfeld) grundsätzlich eine gewisse Skepsis am Platz scheint; sie hat sich auch in anderen Fällen - etwa bei der Analyse von selbständigen V1-Deklarativen als, eigentlichen' V2-Deklarativen nicht bewährt (s. dazu Önnerfors 1997: Kap. 4, sowie Sternefeld 2006: $431 \mathrm{f}$.). Wir untersuchen deshalb im Folgenden, ob sich nicht auch eine ellipsenfreie Analyse der Apodosis deklarativer V1-Gefüge, d.h. ihre Analyse als V1-Deklarativ, zumindest gleich gut verteidigen lässt. 
5.2. Kann die Apodosis ein V1-Deklarativ sein?

\subsubsection{Komplexe V1-Deklarative und Narrativität}

Ein unmittelbar nahe liegendes Argument gegen die Analyse der Apodosis als V1-Deklarativ ist das Faktum, dass bei Voranstellung die Apodosis stets V2-Form hat, vgl. (69):

(69) a. Ich werde verrückt, sollte ich mir das Zeug noch länger anhören müssen.

b. Peter wäre gekommen, hätte er dazu die Möglichkeit gehabt.

Dieses Argument ist jedoch bei genauerer Betrachtung nicht zwingend:

Seit Önnerfors (1997) ist unstrittig, dass es im Deutschen genuine V1Deklarative gibt, die selbständig auftreten können. Dabei sind mehrere Typen mit assertiver Grundfunktion nach ihren pragmatischen Zusatzeffekten zu unterscheiden; für uns wichtig ist jedoch nur der einzig produktive ,narrative' Typ, vgl. (70), sowie zu Vergleichszwecken der nachgestellte ,inhaltlich-begründende‘ Typ, vgl. (71) (s. Reis 2000: 215 f., z. T. nach Önnerfors 1997).

a. Kommt ein Mann in die Kneipe.

b. Hab ich ihr ganz frech noch en Kuss gegeben.

(71) Sein Tod bewegt viele, hatte doch seine Ära den Wiederaufstieg begründet.

Der typische ,narrative' Effekt manifestiert sich darin, dass V1-Deklarative nur in erzählenden, aber nicht in argumentativen, d.h. den Wahrheitsanspruch fokussierenden Kontexten vorkommen, die für V2-Deklarative typisch sind. Die für uns zentrale Beobachtung ist nun folgende: Sobald potentiell narrative V1-Deklarative linksperipher durch NS erweitert werden, verschwindet dieser narrative Effekt, vgl. (72), - was heißt, dass man mit (72) all das anfangen kann, was man mit V2-Deklarativen anfangen kann (Fragen beantworten, Begründen, Urteilen, Widersprechen, etc.), aber nicht mit V1-Deklarativen (s. Reis 2000). Das bestätigt im Wesentlichen Önnerfors' Herleitung des zentralen narrativen Effekts, die wesentlich von Erststellung des Prädikats Gebrauch macht (Önnerfors 1997: 71 ff.).

(72) a. Wie sie sich umschaut, kommt ein Mann in die Kneipe.

b. Als sie sich umdrehte, hab ich ihr ganz frech noch en Kuss gegeben. 
Mit anderen Worten, der narrative Effekt kommt nur bei Erststellung eines V1-Deklarativs zustande. Das wird auch von dem inhaltlich-begründenden V1-Typ (71) bestätigt, der klar nicht-narrative, eher argumentative Geltung hat. Daraus ergeben sich zwei in unserem Zusammenhang wichtige Folgerungen: (i) Nichtinitiale V1-Deklarative sind nichtnarrativ. Ergo ist fehlende Narrativität per se kein Argument gegen V1Deklarativstatus von Zweitkonnekten. (ii) Sollen initiale Deklarative nichtnarrativ sein, müssen sie V2-Gestalt haben. Da Gefüge mit konditionaler Interpretation stets argumentativ, also nichtnarrativ sind, gilt das auch für sie. Ergo ist das Faktum, dass eine vorangestellte deklarative Apodosis stets V2-Form aufweist, auch in V1-Gefügen wie (69), ebenfalls per se kein Argument gegen ihren Status als V1-Deklarativ in Nachstellung.

\subsubsection{Das Vorfeld als Integrationsposition: linksperiphere Adverbiale bestimmten Typs}

Um Argumente für/gegen den V1-Status der Apodosis in V1-Gefügen gewinnen zu können, ist es notwendig, den Status des Vorfelds als Integrationsposition zu sichern. Betrachten wir dazu Fälle wie (73)-(75), alles Deklarativsätze, die Adverbiale bestimmten Typs in drei Stellungsmöglichkeiten zeigen: dem V2-Satz links vorgeschaltet (a), im Vorfeld (b), im Mittelfeld (c).
a. Offen gesagt, ich hab keine Zeit für so was.
b. Offen gesagt hab ich keine Zeit für so was.
c. Ich hab, offen gesagt, keine Zeit für so was.
a. Jede Wette, der wird morgen kommen.
b. ?Jede Wette wird der morgen kommen.
c. Der wird, jede Wette, morgen kommen.
a. Aber klar: Ich werde das erledigen.
b. Klar werde ich das erledigen.
c. Ich werde das, ganz klar, erledigen.

Die betreffenden Ausdrücke sind im Einzelnen sehr verschieden (einiges dazu u. a. in Pittner 1999), wobei zumindest (73) eine offene Klasse repräsentiert. Sie haben aber für unsere Zwecke relevante Gemeinsamkeiten: Semantisch haben sie gemeinsam, dass sie nicht zur eigentlichen Proposition des Satzes gehören, sondern diese aus Sprecherperspektive kommentieren. Weiter teilen sie syntaktische Gemeinsamkeiten, auf die vor allem Meinunger (s. Frey 2006, Meinunger 2006) hingewiesen hat: (i) Die betreffenden Ausdrücke treten im Mittelfeld nur als intonatorisch abge- 
setzte Einschübe auf, d.h. sie sind genau genommen Mittelfeld-unfähig (s. jeweils (c)), damit zusammenhängend: (ii) Ihr eigentlicher Ort ist außerhalb ihres Bezugssatzes (s. jeweils (a)), von dem sie intonatorisch abgesetzt sind, d. h. sie sind unintegriert.

Dieser Befund macht die Tatsache, dass sie trotzdem im Vorfeld vorkommen (s. jeweils (b)), besonders brisant. Für Meinunger wie Frey liegt die Brisanz darin, dass das Vorfeld hier nicht wie üblich vom Mittelfeld aus besetzt wird, was Frey veranlasst, dafür Basis-Generierung als weiteren Weg der Vorfeldbesetzung anzunehmen, während Meinungers Analyse den eventuell denkbaren historischen Weg von außerhalb des Satzes nach innen synchron nachspielen will.

Wie auch immer - für uns ist ein anderes Faktum brisant: Wenn diese Ausdrücke im Vorfeld vorkommen, sind sie stets intonatorisch integriert, d. h. unintegrierte Realisierungen wie in (76) sind ausgeschlossen.
a. Offen gesagt $(* \#)$ hab ich keine Zeit für so was.
b. ?Jede Wette $(* \#)$ wird der morgen kommen.
c. ?Kein Wunder $\left({ }^{*} \#\right)$ sieht der heute blass aus.
d. Klar $(* \#)$ werde ich das erledigen.
(\# indiziert intonatorische Absetzung bzw. je separate FHGs)

Dies zeigt deutlich, dass das Vorfeld eine obligatorische Integrationsposition ist: Intonatorische Absetzung (und damit einhergehende separate Fokussierung) einer Vorfeldkonstituente ist ausgeschlossen. Im Umkehrschluss heißt das: Prosodisch unintegrierte linksperiphere XPs stehen nicht im Vorfeld. Das gibt uns ein recht gut handhabbares Kriterium für die linke Peripherie an die Hand, das wir in den folgenden Abschnitten nutzen.

\subsubsection{Linksperiphere Adverbialsätze in Deklarativen}

Auch Adverbialsätze treten im Mittelfeld nur prosodisch abgesetzt auf. Stellt man sie ins Vorfeld eines deklarativen Gesamtsatzes bzw. neutral gesagt: direkt vors Verb, verhält sich der Großteil jedoch, wie man es von V2-Deklarativgefügen erwartet: Sie sind prosodisch integriert, also in die Vorfeldposition eingebettet (77), und wenn sie prosodisch unintegriert linksperipher stehen, ist das Vorfeld durch eine andere XP-Konstituente besetzt (78)-(79).

(77) a. Als Peter kam, war schon MITtag. / Als PETer kam, war schon Mittag.

b. Während es regnet, PENne ich. / Während es REGnet, penne ich. 
c. Weil es Frost gab, wurde geHEIZT. / Weil es FROST gab, wurde geheizt.

d. Um zu verHANdeln, reist er nach Rom. / Um zu verhandeln, reist er nach ROM.

e. Wenn er KÄMe, wärs gut. / Wenn er käme, wärs GUT.

(78) a. Wenn ich unterBREchen darf*(\#) das ESsen ist fertig.

b. Um die Sache ABzuschließen *(\#) PAUL reist nach Rom.

c. Ob es dir PASST oder nicht*(\#) er steigt AUS.

d. Wer auch immer das VORschlägt * \#) ich lehne AB.

(79) a. Wenn das mein Hund wäre (*\#) bekäme er KEInen Zucker

b. Wenn das MEIN Hund wäre *(\#) er bekäme KEInen Zucker.

(78) belegt dabei semantische Konstellationen von Erst- und Zweitkonnekt, die obligatorisch zur unintegrierten, V3 ${ }^{6}$-Stellung führen, (79) einen (bereits bekannten) fakultativen Fall. Genau welche semantischen Konstellationen die integrierte Vorfeld- vs. unintegrierte ,V3'-Stellung induzieren, lassen wir hier beiseite. ${ }^{48}$ Es genügt festzuhalten, dass sich in den Fällen (77)-(79) das prosodische Kriterium von Abschnitt 5.2.2 hundertprozentig bewährt.

Was tun wir aber dann mit Fällen wie (80)-(81)?

(80) a. Während PEter JUbelte, war sein BRUder eher entTÄUSCHT.

b. Obwohl ich mir das endgültige Urteil noch VORbehalte, neige ich zur MILde.

c. Da die HEIzungsröhren geplatzt sind, hat es FROST gegeben.

(81) a. Wenn man sich's mal geNAU überlegt, machen DIE es ja genau so.

b. Wenn du MEIne Meinung hören willst, STEIgen die Aktien bald.

c. Wenn ich es OFfen sagen darf, halte ich das für einen SCHWINdel.

48. S.o. 2.6. Man beachte, dass sich die, V3'-Konstruktion prosodisch wie syntaktisch (s. o. 4.3 zur so- vs. dann-Konstruktion) von der - diesbezüglich integrierten - Linksversetzungskonstruktion i.e. S. unterscheidet. (S. dazu auch Pittner 1999: 200 ff.). 
d. Wenn ich auch nicht ALles verstehe, bin ich insgesamt doch sehr zuFRIEden.

e. Wieviel er auch verDIENT, ist er doch NIE zufrieden.

(Beispiele a, b aus Vandergriff 1997, c, e aus König \& Van der Auwera 1988)

Für die betreffenden Adverbialsätze wird in der Literatur mehr oder minder explizit behauptet, dass sie stets unintegriert in Satzgefüge eingehen. ${ }^{49}$ Wenn das stimmt, können sie in (80)-(81) nicht im Vorfeld stehen, sondern nur unintegriert außerhalb des Bezugssatzes. Die Frage ist natürlich, $o b$ das stimmt, und das ist insbesondere für linksperiphere Fälle nirgends genau empirisch untersucht. Intuitiv scheint uns in diesen Fällen prosodische Unintegriertheit allerdings recht klar gegeben. ${ }^{50}$ Zusätzlich kann man zumindest bei (80a), (81) auf illokutionäre (bzw. genereller pragmatische) Unabhängigkeit des Adverbialsatzes plädieren - was indirekt ein syntaktisches Kriterium ist, insofern eigenständige Illokutionen an je separate CPs gebunden sind, während eingebettete CPs sich in die Illokution des Matrixsatzes einfügen müssten.

Damit stellt sich auch für eingeleitete Adverbialsätze bestimmten Typs die Frage, welcher Art ihr unintegriert folgender deklarativer Bezugssatz ist - V1 oder V2 mit Vorfeld-Ellipse? Für die Fälle in (81) ist letztere Option nicht auszuschließen, da alle - (81e) u. E. allerdings mit Mühe ein Resumptivpronomen zulassen: eher dann bei (81a), eher bzw. nur so bei $(81 b-e)$. Für die Fälle in (80) trifft das allerdings nicht zu, vgl. (82), so dass mindestens für diese Fälle in signifikantem Umfang ${ }^{51}$ gilt: $i h r$ Bezugssatz ist ein V1-Deklarativ! Dann ist aber auch für V1-Gefüge als grundsätzlich möglich anzuerkennen, dass der jeweilige Bezugssatz ein V1-Deklarativ ist.

49. S. Brandt (1990: 80 ff.) für $d a$, adversatives während, d.h. (80), Pittner (1999: 360 f.) implizit für (81d, e), König \& van der Auwera (1988: 128) für (81c); Vandergriff (1997: 264) für (81a, b). Für die Fälle in (81) gibt es jeweils ein - eo ipso unintegriertes ,V3-Pendant; angesichts von (80) ist das aber wohl nicht deutungsrelevant.

50. Zwar gäbe es auch da das mögliche Gegenargument, dass Sätze, als lange Konstituenten, zu zusätzlichen prosodischen Gliederungen, ,Akzentphrasen' führen, die nicht mit separaten Fokus-Hintergrund-Gliederungen gleichzusetzen sind (s. o. Fn. 19). So weit man das informell mit möglichst kurzen Sätzen testen kann, hält das Gegenargument aber nicht Stich.

51. Für $d a$ ist die prosodische Integriertheit umstritten, s. Brandt (1990) vs. HdK (2003); für obwohl-Sätze ist generell zwischen \pm integrierten Typen zu unterscheiden. Für adversative während-Gefüge scheint resumptives so besser zu werden, sobald die o. a. semantischen Zusatzbedingungen für konfrontative V1-Gefüge erfüllt sind (vgl. Während Öl früher zu billig war, (?l??so) ist es heute zu teuer). Dass trotzdem eine beträchtliche Gruppe nicht elliptisch zu deutender Fälle bleibt, ist jedoch nicht zu bezweifeln. 
(82) a. Während PEter JUbelte, $\left({ }^{*}\right.$ so, ${ }^{*}$ da, ${ }^{*}$ dann $)$ war sein BRUder eher entTÄUSCHT.

b. Obwohl ich mir das endgültige Urteil noch VORbehalte, $(? *$ so, $*$ da, *dann) neige ich zur MILde.

c. Da die HEIzungsröhren geplatzt sind, $\left({ }^{*}\right.$ so, ${ }^{*}$ da, ${ }^{*}$ dann $)$ hat es FROST gegeben.

\subsubsection{Adverbialsätze vor nichtdeklarativen V1-Sätzen}

Von Interesse sind auch die möglichen Vorkommen von Adverbialsätzen - bzw. von Nebensätzen allgemein - vor nichtdeklarativen V1-Sätzen (s. dazu auch Pittner 1999: 302 f.). Es zeigt sich, dass nicht nur Imperative (für die man die Ausnutzung der markierten V2-Variante postulieren könnte) solche Vorkommen zulassen (83), sondern auch V1-Interrogative (84). Dass V1-Exklamative hier zurückhaltend sind, ist wohl deren besonderem interpretativen Effekt geschuldet, aber es gibt wohl auch da vereinzelte Fälle wie (85).

(83) a. Wenn du ins Borchardts gehst, bring Appetit und Geld mit.

b. Damit dir nichts passiert, nimm lieber Chinin mit.

c. Bevor du weggehst, spül bitte noch das Geschirr.

d. ?Während du arbeitest, lass dich lieber nicht stören.

e. Da du ja alles besser weißt, sei bitte auch jetzt spielfreudig.

(84) a. Wenn du nochmal auf die Welt kämst, würdest du (denn) alles genauso machen?

Wenn wir es so sehen, entkleiden wir die Prophetie wirklich ihres Wunders? ([M. Frisch] nach Pittner 1999: 302)

b. Als er hereinkam, haben ihn (denn) wirklich alle frenetisch begrüßt?

c. Seit du in Paris lebst, hat sich (denn) da vieles für dich verändert?

d. Bevor du weggehst, spülst du (denn) noch das Geschirr?

e. Da du ja alles kannst, könntest du (denn) auch 'nen Handstand machen?

f. Dass Peter kommt, war das (denn) wirklich nicht zu ahnen?

g. Ob Peter kommt, könnte man das (denn) nicht bei seiner Frau herauskriegen?

(85) a. Als wir uns neulich trafen, war DAS ein Hallo!

b. Und wenn er so herzlich lachte, war DAS eine Freude!

Mit Sicherheit gibt es hier erhebliche, auch je satztypspezifische semantische Restriktionen. Da es dazu jedoch keinerlei Vorarbeiten gibt, möch- 
ten wir darüber nicht spekulieren, sondern nur das hier Wesentliche hervorheben: (i) Es gibt linksperiphere Vorkommen von NS vor zweifelsfreien V1-Sätzen (84-85); (ii) diese Vorkommen sind nicht auf eventuell stets unintegrierte NS wie (84e) (s. auch (83e)) beschränkt, sondern betreffen auch zweifelsfrei einbettungsfähige Adverbialsätze, die in (84a-d) auch zweifelsfrei Teil der Frageproposition sind; (iii) diese Möglichkeit gibt es für Subjekt- und Objektsätze nicht bzw. nur in Form einer speziellen Resumptivkonstruktion ( $84 \mathrm{f}-\mathrm{g}$ ); (iv) sämtliche linksperipheren Nebensätze in (83)-(85) sind prosodisch unintegriert, wobei die Bezugssätze in (84)-(85) zweifelsfrei V1-Sätze sind.

Gegeben (i)-(iv), sollte es nicht verwundern, dass auch V1-Deklarative mit linksperipheren Adverbialsätzen - zu denen V1-Konditionale gehören - unintegriert (und ohne Resumptivelement) auftreten können und diese trotzdem semantisch in die Satzproposition integriert sind. Insofern sind die gerade skizzierten Fakten zusätzliche Evidenz dafür, dass (H2) in der zweiten Auslegung grundsätzlich möglich ist.

\subsubsection{Diachrone Evidenz}

Konditionale V1-Sätze sind bis in die Anfänge der Überlieferung zurückzuverfolgen; dabei weist das Gesamtgefüge ein Stellungsmuster auf, das den bereits im Althochdeutschen (Ahd.) gut etablierten V2-Constraint verletzt (Axel 2007). Nach Axel entspricht das dem ursprünglichen Stellungsmuster von Adverbialsätzen allgemein: Gleich ob eingeleitet (und V-End) oder uneingeleitet (und V1), traten sie ahd. links vom anderweitig besetzten Vorfeld auf (86a), also unintegriert, so dass in beiden Fällen ,V3‘ resultierte. Dieses Oberflächenmuster behalten Adverbialsätze noch im Mittelhochdeutschen (Mhd.) bei, entsprechend auch konditionale V1-Sätze (86b).

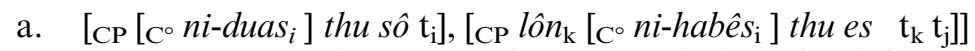
NEG tust du so Lohn NEG erhalten du dafür

,Verhältst du dich nicht so, keinen Lohn bekommst du dafür ${ }^{6}$

b. [CP [CP wil er icht darwiedder sprechen],

(Otfrid II 20,7 (ca. 870)) wird er nicht dagegen sprechen, [CP ich will es ware machen ...]] ich will es wahr machen

(Prosalanzelot 36,2 (ca. 13. Jh.)) (Axel 2002, 2004)

Dass die konditionale V1-Protasis unintegriert war, wird insbesondere durch Belege gestützt, in denen der V1-Satz links vor einem eingebetteten 
Satz auftreten konnte, der als Bezugssatz fungiert, vgl. (87) (= Axel \& Wöllstein 2008: 11, Bsp. (24)). ${ }^{52}$

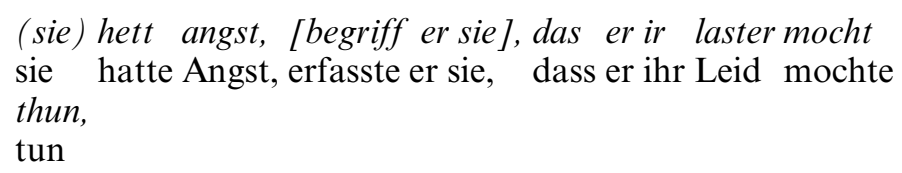
thun,

tun

,Sie hatte Angst, dass er ihr Leid antun würde, wenn er sie erfasste.

(Prosalancelot 52,19 (ca. 13.Jh.))

Axel \& Wöllstein (2008) schlagen Axel $(2002,2004)$ folgend für Adverbialsätze wie (86) -(87) eine Analyse als basisgenerierte Strukturen vor, die an ihren Bezugssatz links-adjungiert sind.

Im Gegenwartsdeutschen (Gwd.) besetzt die Hauptmasse ${ }^{53}$ eingeleiteter linksperipherer Adverbialsätze die Vorfeldposition ihres deklarativen Bezugssatzes. Wie Axel $(2002,2004)$ zeigt, setzt der entsprechende Wandel von Adjunktion zu Einbettung ab dem späten Mhd. ein. Dabei driftet aber die Entwicklung von V1- und eingeleiteten Adverbialsätzen signifikant auseinander: Nur eingeleitete Adverbialsätze (inklusive wenn-Konditionale) erscheinen im Frühneuhochdeutschen (Fnhd.) und frühen Nhd. zunehmend in der Vorfeldposition; bei V1-Konditionalen wird dagegen das Muster (86) im späteren Fnhd. nicht durch das Einbettungsmuster zurückgedrängt, sondern durch das korrelative Muster mit soeingeleiteter Apodosis - ein Muster, das sich noch im Gwd. unintegriert verhält (s. o. 4.3). Erst nach 1650 sind unmittelbar präfinite V1-Konditionale in den Korpora belegt, also ca. 250 Jahre nach dem Auftreten eingeleiteter Adverbialsätze in unmittelbar präfiniter Position (Axel \& Wöllstein 2008: 18). Da die Ausbreitung unmittelbar präfiniter Stellung von Adverbialsätzen im Fnhd. der wichtigste Oberflächenreflex des Aufkommens struktureller Einbettung ist (s. Axel 2007), bedeutet diese erhebliche zeitliche Verzögerung, dass V1-Konditionale diesen Wandel nicht mitmachten, sondern die weit später belegte unmittelbar präfinite Stellung anders zu erklären ist: Nicht der Status der V1-Konditionale als unintegrierte Sätze wandelte sich, sondern die Struktur(optionen) der deklarativen Apodosis. Die dafür nahe liegenden Wandelhypothesen sind diachrone Entsprechungen der beiden Ausprägungen von (H2):

Einerseits könnte Aufkommen der so-Ellipse postuliert werden, die für die Zunahme der unintegrierten ,V2'-Oberflächenstruktur für V1-Gefüge

52. Seit dem Fnhd. wurde dieses Muster zurückgedrängt; im Gegenwartsdeutschen ist die Initialstellung der V1-Protasis bei eingebettetem VE-Bezugssatz nicht mehr möglich (s. Axel \& Wöllstein 2008: 16 und die dort angegebene Literatur).

53. Noch im Gwd. gibt es linksperipher unintegrierte eingeleitete Adverbialsätze (s. 5.2.3 f.). Deren diachrone Entwicklung ist bisher ununtersucht. 
verantwortlich ist. ${ }^{54}$ Andererseits könnte sich aber auch der Status der deklarativen Apodosis zu V1 geändert haben, wofür Axel \& Wöllstein (2008) folgendes Szenario skizzieren: Während die o. a. Ausweitung des korrelativen so-Musters die Fortdauer des unintegrierten Adjunkt-Status für V1-Konditionale sicherte, entwickelte und verbreitete sich ab dem 16. Jh. ein V1-Muster für Deklarative, das nicht nur den narrativen Typ betrifft („späte Spitzenstellung im Aussagesatz“, Behaghel 1932: 27-29): So gibt es V1-Deklarative mit Modalpartikel doch (88), wie sie auch im Gwd. in argumentativen Kontexten auftreten, ebenso nun auch kaumV2-Sätze mit V1-Apodosis (89a) und Belege aus der Urkundensprache, von Maurer (1926: 204) als V1-Sätze beschrieben, die eine starke Verbindung zwischen Hauptsätzen im Diskurs kennzeichnen (89b); dabei wird der vorangehende Satz als subordiniert zum folgenden V1-Satz interpretiert.

... Und ob gleich der Ko̊nig beschlossen hat/ ... den meisten Theil voran\#zuschicken/ werden doch so viel Schiffe zurǘckbleiben/dabey man allen Difficultằten wird begegnen kờnnen. Sind doch alle Fabeln voll Götter/welche Jungfern geraubet haben.

(Weise: Jugendlust 1648, 143 20-25) $[(88)=$ Axel \& Wöllstein 2008: 19, Bsp. (37)]

(89) a. das volk het kaum ihr wunsch verricht, verlor das schiff sich aus dem gsicht

(Fischart, gl. schiff 1577, 527; zitiert nach Grimms DWb, Bd. 5: 357)

b. Am dinstagk bin ich ken Aldem Lessen kuemmen vnd mich dem erzbischoff lassen ansagen. Hatt er mich lassen entphan ...

(Brandenburgisches Dokument (1521a); zitiert nach Maurer 1926: 204, übersetzt entsprechend Maurers Kommentar)

$[(89 \mathrm{a}, \mathrm{b})=$ Axel \& Wöllstein 2008: 19,

Bsp. (38)-(39)]

Auf dem Hintergrund dieser Entwicklungen lässt sich die weitere im 17. Jh. einsetzende Neuerung, der Anstieg der, V1-Apodosis' (d. h. der unmittelbar präfiniten Stellung von V1-Konditionalen) vs. der so-Apodosis, plausibel als das Aufkommen einer neuen V1-Struktur (ohne SpecC-Position) für die deklarative Apodosis von V1-Konditionalen analysieren (Axel \& Wöllstein 2008: 19). Dafür dass sich diese V1-V1-Struktur bis heute ohne weitere Reanalyse halten konnte, gibt es einen zumindest suggestiven Erklärungsansatz: Aufgrund der Oberflächengleichheit mit

54. Darauf hat uns einer unserer Gutachter aufmerksam gemacht. 
Sätzen im Vorfeld einbettenden V2-Strukturen gab es keine störenden Oberflächenunterschiede zwischen dem Stellungsverhalten eingeleiteter und uneingeleiteter Adverbialsätze zu beseitigen.

Obwohl uns diese zweite Deutungsoption wegen ihrer Korrelierbarkeit mit unabhängigen syntaktischen Entwicklungen attraktiver scheint, ist auch die erste nicht unplausibel. Ob ihre nähere sprachgeschichtliche Untersuchung zu einer Entscheidung führen würde, muss hier dahingestellt bleiben, kann es aber auch, da $(\mathrm{H})$ ohnehin mit beiden Ausprägungen von $(\mathrm{H} 2)$ verträglich ist.

\subsection{Fazit}

Wie in 5.1 gezeigt, ist die Analyse der Bezugssätze in deklarativen V1Gefügen als V2-Deklarative mit Vorfeld-Ellipse von so grundsätzlich empirisch verteidigbar. Wie in 5.2 gezeigt, gilt das aber auch für die Analyse der betreffenden Bezugssätze als V1-Deklarative, insofern es unabhängige Evidenz für die Existenz von unintegrierten (insbesondere auch deklarativen) V1-V1-Gefügen im Deutschen gibt. Weiter gibt es diachrone Evidenz sowohl für die besondere Rolle der Entwicklung der so-Apodosis als auch der V1-Deklarative für die Entwicklung der V1-Gefüge, was beide Analyseoptionen zusätzlich rechtfertigt, auch wenn uns die V1Deklarativ-Hypothese vorerst diachron zwingender erscheint. Damit ist aber (H2) in jedem Fall gerechtfertigt, und das heißt, im Verein mit den Ergebnissen der vorangegangenen Abschnitte: auch $(\mathrm{H})$ ist insgesamt hinreichend gerechtfertigt. Damit ist unser zentrales deskriptives Ziel erreicht.

\section{Zur Präzisierung von (H): Die syntaktische Struktur konditionaler V1-Gefüge}

Auch nach Abschluss des Beweisgangs für $(\mathrm{H})$ ist noch eine entscheidende Frage offen: Welche Struktur genau ist es, die den (quasi-)parataktischen Eigenschaften konditionaler V1-Gefüge, d. h. der syntaktischen (und prosodischen) Unintegriertheit der V1-Protasis vis-à-vis der Apodosis, entspricht? Dafür kommen u. E. hauptsächlich vier Möglichkeiten in Betracht (von uns an der Option einer deklarativen V1-Apodosis illustriert):

(90) [CP1 [CP2 Regnet es] [CP3 bleiben wir zu Hause $]]$ 
Asymmetrische Konnexion (Abschnitt 6.2)

[KonP [SpecKon [CPRegnet es]] [Kon' [Kon ${ }^{\circ}$ ] [bleiben wir zu Hause]]] Split-CP-Modell (Abschnitt 6.3)

[CP Regnet es [C ${ }^{\prime}{ }_{\text {FinP }}$ [SpecFinP [Fin' ${ }_{\text {Fin }}{ }^{\circ}$ bleiben] [IP wir [VP $\mathrm{Zu}$ Hause]]]]]]]

Adjunktionsanalyse (Abschnitt 6.4)

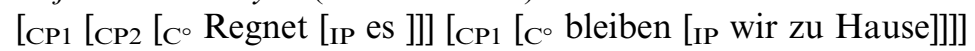

Obwohl die klassische Adjunktionsanalyse theorieintern wenig Sympathien genießt (Kayne 1994, ${ }^{55}$ Rizzi 2004), zeigen synchrone und diachrone Arbeiten, dass aus empirischen Gründen mit der Einbindung von Adverbialpositionen in die syntaktische Struktur via satzperiphere Adjunktion zu rechnen ist (s. u. 6.4). Wir präferieren diese Analyse ebenfalls und rechtfertigen dies im Folgenden, hauptsächlich in Abwägung gegenüber der Split-CP-Analyse (6.3). Die in (90) und (91) illustrierten Analysen werden wir aus empirischen Gründen verwerfen, und deshalb nur kurz würdigen $(6.1,6.2)$. Einen möglichen Einwand gegen die Adjunktionsanalyse - das Fehlen iterierter Adjunktion - behandeln wir in 6.5.

\subsection{CP-Rekursion}

Culicover \& Jackendoff (2005 [1997, 1999]) schlagen die von ihnen sog. CP-Rekursionsanalyse, ${ }^{56}$ eine parataktische Analyse par excellence, für die Analyse von komparativen Korrelativgefügen (= KK) (94a) und [adverbial-]asymmetrischer Koordination (= AAK) (94b) vor.
a. The more you eat, the less you want. ,If/As you eat more, you want less.' [IP/CP1 [CP2 The more you eat] [CP3 the less you want.]]
b. Mary listens to the Grateful Dead, (and) she gets depressed. ,If Mary listens to Grateful Dead, she gets depressed.' [IP/CP1 [CP2 Mary listens to the Grateful Dead] [CP3 (and) she gets depressed.]]

(Culicover \& Jackendoff 2005: 502, 509)

55. Technisch gesehen hat Kayne (1994) nicht die Adjunktion, sondern die Spezifikatoren abgeschafft, die nunmehr adjungierte Konstituenten sind; allerdings wiederum nur eine pro Projektion (wir danken einem unserer Gutachter für diese Klärung). Insofern findet sich bei ihm nicht das klassische Adjunktionsverständnis.

56. Wie einer unserer Gutachter mit Recht anmerkt, hat diese Analyse mit der unter diesem Namen geläufigeren Analyse von V2-Phänomenen im Germanischen (s. etwa Iatridou \& Kroch 1992) strukturell nichts zu tun. 
Kennzeichnend für beide ist ihres Erachtens ein Syntax-Semantik-Mismatch: Interpretativ besteht eine semantische Abhängigkeit des Initialsatzes vom Folgesatz, also ein subordinationstypisches, dabei quasi-konditionales Verhältnis; syntaktisch sehen sie jedoch klare Indizien für ein parataktisches Verhältnis der Teilsätze, was sie zur Annahme der Struktur (90) mit kopfloser CP1 für KK und AAK veranlasst. Da V1-Konditionalgefüge analoge Eigenschaften aufweisen, scheint die CP-Rekursionsanalyse - die nach Culicover \& Jackendoff sprachübergreifend für Phänomene dieser Art gelten soll - auf den ersten Blick eine interessante Analyseoption.

Auf den zweiten Blick allerdings nicht mehr: Von vornherein unerklärlich wäre unter Annahme von CP-Rekursion, dass (nur) die Apodosis die Hauptsatz-typische pragmatische Variabilität - Satzmodusvarianz, Vorkommen von Einstellungs- und sonstigen kontextbezogenen Ausdrücken - aufweist. Vor allem aber verhalten sich die V1-Gefüge interpretativ anders: Zum einen ist die konditionale Interpretation nicht linearisierungsgebunden, da sie bei möglicher Nach- wie Medialstellung erhalten bleibt. Zum andern haben zumindest AAK die konditionale Interpretation stets neben einer lediglich koordinativen (s. o. (94b)); V1-Gefüge dagegen haben (neben der adversativen-konfrontativen) nur die hypothetisch konditionale Interpretation, die an grammatische Mittel wie Verbstellung und Unintegriertheit der Konnekte gebunden ist - was heißt, dass sie keine konditionale Lesart ermöglichen, sondern eine konditionale Semantik haben (vgl. Abschnitt 2.3). Entsprechend liegt auch kein Semantik-Syntax-Mismatch vor. Von daher schließen wir CP-Rekursion i.S. v. Culicover \& Jackendoff (2005: 520) für die Analyse von V1-Gefügen aus: V1-Gefüge verhalten sich nicht i. e. S. ,parataktisch bzw. ,quasi-koordiniert'.

\subsection{Asymmetrische Konnexion}

Für die Analyse komplexer Sätze, deren Glieder einander nicht subkategorisieren, schlägt Wöllstein (2008) das sog. Konnexionsmodell vor: Formal ist KonP eine asymmetrische, binär verzweigende, von einem funktionalen Kopf projizierte Struktur (im Einklang mit Kaynes 1984 ,binary branching conjecture $[\mathrm{BBC}]$ ), deren Konnekte in Spezifikator- und Komplementposition des Kon-Kopfes auftreten (struktur- und oberflächenäquivalent zur CP-Struktur), s. o. (91). ${ }^{57}$

57. (91), (96) entspricht den BBC-konformen asymmetrischen Modellen von Munn (1987) und Johannessen (1998) für die Satzkoordination. (Munns spätere Modifikationen seiner 1987er Strukturannahmen sind für das Deutsche ohne Belang.) 
Die diesem Modell zugrunde liegende Idee ist, dass Matrix-Adverbialsatzgefüge und Satzkoordinationen semantisch mittels eines einheitlichen Interpretationsverfahrens verknüpft sind, das eine semantische Dependenzrelation (notwendige Kausalrelation zwischen Bedingung und Folge) zwischen den Konnekten etabliert. ${ }^{58}$ Diese asymmetrische Relation wird syntaktisch durch strukturelle Independenz des externen (Erst-) Konnekts vs. strukturelle Dependenz des internen (Zweit-)Konnekts abgebildet, insofern die syntaktische Komplementposition eine von einem funktionalen Kopf strukturell dependente Position ist.

Dieses Modell hat einen für die Analyse unserer V1-Gefüge attraktiven Grundzug: Gliedsatzstatus/Einbettung der V1-Protasis sind im Konnexionsmodell strukturell explizit ausgeschlossen, ergo ist die Protasis kein Vorfeldelement, und die Apodosis kann ebenfalls V1 sein. Entsprechend bilden Erst- und Zweitkonnekt deklarativer V1-Gefüge die quasiparataktische Struktur (95) - passgenau zu den strukturellen Implikationen unserer zentralen Hypothese $(\mathrm{H})$.

$$
\begin{aligned}
& \text { [KonP [SpecKon [CP1 Kommt Maria/Protasis]] [Kon’ [Kon` } \varnothing]\left[\mathrm{CP}_{2}\right. \text { geht } \\
& \text { Hans/Apodosis]]] }
\end{aligned}
$$

Es ergeben sich allerdings zwei Probleme: Das erste betrifft die Unterscheidbarkeit \pm integrierter Adverbialsätze. Zwar bildet im Konnexionsmodell die V1-Protasis das externe, semantisch und strukturell independente Konnekt, s. (96a), die jedoch wenn-Protasis das interne, semantisch und strukturell dependente Konnekt, s. (96b).
a. [KonP [SpecKon [CP1 Erreicht $\mathrm{er}_{\mathrm{n}}$ was $]$ [Kon' Kon $\left.^{\circ} \varnothing\right][\mathrm{CP2}$ ist

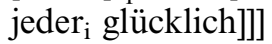
b. [KonP [SpecKon [CP1 Jeder ${ }_{\mathrm{i}}$ ist $\mathrm{t}_{\mathrm{k}}$ glücklich]] [Kon' [Kon $\left.{ }^{\circ} \varnothing\right][\mathrm{CP} 2$ wenn er $_{i}$ was erreicht $\left.\left.]_{k}\right]\right]$

Aber sowohl das externe wie das interne Konnekt in (96) bilden unintegrierte Satzstrukturen, die nur durch \pm Rekonstruierbarkeit in ihr externes Konnekt unterscheidbar sind, und daraus ist keine adäquate Repräsentation des - nur konfigurational zu fassenden - Integriertheitsunterschieds abzuleiten. Von daher kann das Modell in vorliegender Form wesentliche von \pm Integriertheit abhängige Verhaltensunterschiede, so die o. a. Bindungs- und FHG-Unterschiede, nicht erfassen. Für integrierte,

58. Eine solche Interpretation liegt bei Konstruktionen unterschiedlichsten Typs vor, jedoch nur für nichtsubkategorisierte Satzgefüge, unabhängig davon, ob sie durch koordinierende oder adverbialsatzeinleitende Konnektoren verknüpft werden, oder wie V1+V1Gefüge konnektorlos sind. 
im Konnexionsmodell syntaktisch independente Satzstrukturen bleibt die Annahme einer CP-Struktur mit Integrationspositionen für Adverbialsätze somit die adäquatere.

Das zweite Problem betrifft die für das Modell grundlegende semantische Dependenzrelation, die auf einem kontrafaktisch kausalen Schlussverfahren i. S. v. Lewis (1981) $)^{59}$ basiert. Konnektorlose Konnexionen bilden diese Defaultrelation unmodifiziert ab. Demnach müsste Lewis' kontrafaktische Kausalrelation auch Sätzen wie (95) unmodifiziert zugrunde liegen bzw. daraus müsste die spezifische Semantik der V1-Gefüge folgen (Wöllstein 2008: 82). Aber ist das der Fall? Die V1-Semantik spezifiziert ja keine Kausalrelation zwischen den in den Teilsätzen ausgedrückten Sachverhalten, sondern eine davon verschiedene Relation, die hypothetisch-konditionale. Solange nicht klar gezeigt werden kann, wie syntaktisch independente konnektorlose Konnexionen auf dem angenommenen semantischen Default operieren und welche modifizierende Funktion Verbstellung (V1 vs. V2 vs. VE) dabei hat, kann das Konnexionsmodell auch die V1-spezifische Semantik nicht adäquat abbilden. Auch diese Analyseoption scheidet also für V1-Gefüge aus.

\subsection{Split-CP-Analyse}

Bekanntlich stehen innerhalb des Split-CP-Modells von Rizzi (1997) mehrere Spezifikatorpositionen links vom Finitum $\left(\right.$ Fin $\left.^{\circ}\right)$ zur Verfügung, ${ }^{60}$ vgl. etwa den diesem Ansatz verpflichteten Vorschlag von Frey (2005a, b, 2006) zur Struktur der linken Satzperipherie im Deutschen:

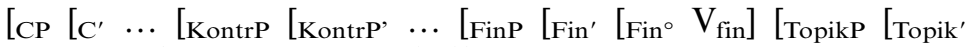

$$
\begin{aligned}
& \text {...][]]]]]] (Frey 2005a: } 2.3 \text { (27)) }
\end{aligned}
$$

$\mathrm{Zu}$ fragen ist, ob diese Vermehrung präfiniter XP-Positionen die adäquate Erfassung unserer V1-Gefüge bzw. generell von Strukturen mit unintegrierter Erstkonstituente erlaubt.

Auf jeden Fall gut in diesem Modell zu repräsentieren sind integrierte Linksversetzungskonstruktionen (LVK), egal ob man Bewegung der LVKonstituente in die oberste Spec-Position annimmt (so etwa Grewendorf

59. Lewis' kontrafaktische Kausalrelation teilt mit der Implikationsrelation A $\rightarrow$ B wesentliche Eigenschaften: (Wahrheit von) A nicht ohne (Wahrheit von) B, vgl. Wöllstein (2008: 54 ff.).

60. Hier sei vor allem auf Arbeiten von Cinque (1999), (2006) verwiesen: In seinem ,functional specifier approach' wird im Zusammenhang mit Adverbi(al)en - im Schwerpunkt satzinterne und Nicht-Sätze - die Position vertreten, sog. Adjunkte seien integrale Bestandteile des Satzes, die zu dessen funktionaler Ausstattung zählen. 
2002) oder Basisgenerierung in dieser Position plus Koindizierung mit dem (allein) nach SpecFinP bewegten Resumptivpronomen, wie Frey es tut, s. (98).

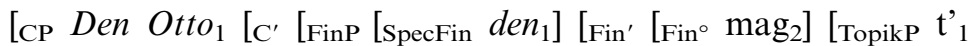

$$
\begin{aligned}
& \text { [jeder } \left.\left.\mathrm{t}_{1} \mathrm{t}_{2}\right] \text { ] }\right] \text { ]]] }
\end{aligned}
$$

Der Vorteil dieser Analyse gegenüber der außerhalb des Split-CP-Modells allein möglichen Adjunktionsanalyse ist die i. e. S. satzinterne Verortung der LV-Konstituente, die deren satzinterne Lizenziertheit bzgl. Kasus und Thetarolle wie auch ihr Bindungsverhalten adäquat zu erfassen erlaubt. Anders gesagt, die Intuition, dass bei Linksversetzungen wie (98) „doppelte Vorfeldbesetzung“" vorliegt (Altmann 1981: $162 \mathrm{f}$.), ist adäquat abgebildet (Frey 2005a: 167).

Wie aber lassen sich unintegrierte Erstkonstituenten ins Split-CP-Modell einfügen? Auf dem Hintergrund der LVK ist das am besten an der sog. Hanging Topic (=HT)-Konstruktion zu diskutieren, die sich von der LVK in wesentlichen Hinsichten unterscheidet: Sie weist keine progrediente Intonation und nur fakultativ Kasuskongruenz auf (99a vs. 99a'), ebenso anderes Bindungs- und Prinzip-C-Verhalten (99b, c vs. 99b', c'), - alles Anzeichen, dass „die HT-Phrase eine selbstständige, syntaktisch nicht in den Folgesatz integrierte Einheit darstellt" (Frey 2005a: 170).
a. Den/*Der Hans, $\rightarrow$ den mag jeder.
a'. Den/Der Hans, $\downarrow$ jeder mag ihn.
b. Seinen ${ }_{i}$ Doktorvater, den verehrt jeder ${ }_{i}$ Linguist.

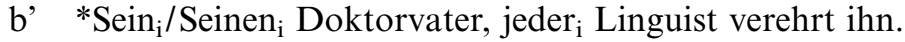
c. *Den neuen Artikel von Peter $_{i}$, den will er $_{\mathrm{i}}$ in LI veröffent- lichen.
c'. Der neue/den neuen Artikel von Peter $_{i}, e_{i}$ will ihn in LI veröffentlichen.

Dieser Unterschied im Deutschen lässt sich jedoch nicht adäquat mittels der vom Split-CP-System bereitgestellten linksperipheren Spec-Positionen darstellen, auch wenn man diese eventuell noch weiter differenziert: Wird die HT-Phrase in einer dieser Positionen, also satzintern, basisgeneriert (s. etwa Grohmann 2003), sind die o. a. Unterschiede zur LVK die ja klar auf fehlende satzinterne Lizenzierung der HT-Phrase hindeuten - nicht bzw. nur ad hoc erklärbar. Aber auch die Aufgabe des Grundgedankens, dass satzinterne Konstituenten stets satzintern lizenziert sein müssen - was Frey (2006) u. a. für die in 5.2.2 diskutierten Adverbiale wie kein Wunder, offen gesagt vorschlägt und mit Basisgene- 
rierung der betreffenden Elemente im Vorfeld $=$ SpecCP korreliert - , hilft nicht weiter: Wie in 5.2.2 gezeigt, müssen selbst satzintern unlizenzierte XPs dieser Art in Vorfeldposition prosodisch integriert sein; unintegrierte Realisierung ist strikt ungrammatisch. Mit anderen Worten, die Positionen vor $\mathrm{Fin}^{\circ}$ (im CP/IP-Modell vor $\mathrm{C}^{\circ}$ ) sind Integrationspositionen, in denen prosodisch unintegrierte linksperiphere XPs nicht stehen. Damit aber ist eine Analyse von Konstruktionen jeder Art mit unintegrierter Erstkonstituente innerhalb des Split-CP-Systems ausgeschlossen - seien es HT-Konstruktionen, ${ }^{61}$ seien es die hier interessierenden konditionalen V1-Gefüge. Der sich bietende Ausweg wäre natürlich Lokalisierung unintegrierter Erstkonstituenten außerhalb des C-Systems via Adjunktion - wie es u. a. Cinque für ,extrasententiale Einheiten' vorgeschlagen hat. ${ }^{62} \mathrm{Da}$ aber phrasale Adjunktion im Split-CP-Modell nicht vorgesehen ist, auch nicht an Nichtargumente (Rizzi 1997: 325), ist dieser Ausweg nicht gangbar. Folglich scheidet auch eine reine Split-CP-Analyse für V1-Gefüge aus.

\subsection{Adjunktionsanalyse}

Die Orientierung der jüngeren Theorieansätze an Ökonomieannahmen für phrasale Bewegung und die Suche nach möglichst restriktiven Modellen der Phrasenstruktur hat weithin dazu geführt, phrasale Adjunktion generell auszuschließen (Kayne 1994), dies nicht nur als Resultat von Bewegung, sondern bald auch, wie im Split-CP-Modell umgesetzt, als basisgenerierte Struktur (Rizzi 2004). Die wichtigste Konsequenz ist der generelle Ausschluss einer Adjunktionsanalyse von Adverbialpositionen zugunsten einer Theorie, die Adverbiale, von entsprechenden funktionalen Köpfen lizenziert, auf Spezifikatorpositionen beschränkt. Das zentrale Problem ist aber, dass gerade im Adverbialbereich neben eingebet-

61. Gegenpositionen zu satzinternen HTs werden aber nicht nur für das Deutsche vertreten: Für Haegeman (2008) etwa haben Ausdrücke, die u.a. in oben beschriebener Weise syntaktisch unabhängig vom Bezugssatz sind, den Status von ,orphans' und sind Einheiten des Diskurses bzw. einer Diskursgrammatik (ebenso Cinque 1997: 98, s. insbesondere Frey \& Shaer 2004: 491). Entgegen diesen Analysen, die HTs strukturell außerhalb des C-Systems ansiedeln, wurden im Anschluss an Rizzi (1997) u. a. von Benincà und Poletto (s. zusammenfassend Benincà \& Poletto (2004)) satzinterne Topikpositionen innerhalb des italienischen C-Systems vorgeschlagen, die zwischen HT und LVK unterscheiden. Wir gehen dem nicht nach, da eine Adaption für die V1-Konditionale ausgeschlossen ist: Erstens ist die Topikposition keine Strukturposition für V1-Konditionale und zweitens wäre eine universale funktionale Projektion wie z.B. ,condition' im C-System mit Unintegriertheitsmerkmal erst zu etablieren.

62. Frey selbst schlägt (2005b: 94) vor, dass die HT-Phrase Teil einer, independent discourse unit' sei, strukturell unabhängig vom Bezugssatz, buchstabiert diesen Vorschlag aber nicht weiter aus. 
teten auch vielfach syntaktisch-prosodisch unintegrierte Satzgefüge auftreten. Es muss also eine strukturelle Basis für die Repräsentation von Unintegriertheit zur Verfügung stehen. Eben diese bietet die Adjunktionsanalyse, ${ }^{63}$ und sie wird auch als solche genutzt. ${ }^{64}$ Zwei diesbezüglich für uns interessante Vorschläge sind folgende:

Bei ihrer Untersuchung \pm integrierter Nebensätze am rechten Satzrand hat Reis (1997) eine Dreiteilung vorgeschlagen und syntaktisch breit gerechtfertigt: (i) Integrierte eingeleitete NS (z. B. wenn- und dass-Komplementsätze) stehen im Nachfeld, wo sie direkt von V lizenziert und damit auch unmittelbar in die Verbprojektion eingebettet sind (100a). ${ }^{65}$ (ii) Absolut unintegrierte NS (u. a. weiterführende Relativ-, so dass-, wogegen-, (epistemische) weil-Sätze), die u. a. durch separate FHG und pragmatische Selbständigkeit ausgezeichnet sind, stehen in ,Schlussstellung', d.h. sind an ihre Bezugs-CP rechts-adjungiert (100c). Es gibt aber auch einen Zwischen-Fall: (iii) relativ (un)integrierte NS, die mit (i) FHG-Integriertheit und Bindungsverhalten teilen, mit (ii) die sonstigen syntaktischen Restriktionen (z. B. keine VF-Stellung, Mit-Topikalisierung, Extraktion oder Korrelate) und entsprechend ,dazwischen “ - in sog. Nachstellung, was VP-Adjunktion entspricht - angesiedelt sind (100b); hierzu zählen nach Reis nicht nur argumentrealisierende V2-Sätze, sondern auch die adverbialen ,freien` dass-Sätze.

$$
\begin{array}{lll}
\text { a. +integriert: } & {\left[\mathrm{CP} 1 \ldots\left[\mathrm{vP} \mathrm{V}^{\circ}[\mathrm{CP} 2 \ldots]\right]\right]} & \text { Nachfeld } \\
\text { b. rel. (un)integriert: }[\mathrm{CP} 1 \ldots[\mathrm{VP}[\mathrm{vP} \ldots][\mathrm{CP} 2 \ldots]]] & \text { Nachstellung } \\
\text { c. }- \text { integriert: } & {[\mathrm{CP} 1[\mathrm{CP} 1 \ldots[\mathrm{VP} \ldots]][\mathrm{CP} 2 \ldots]]} & \text { Schlussstellung }
\end{array}
$$

Aufgrund der in Abschnitt 4 präsentierten Fakten ist klar, wie die - bei Reis nicht behandelten - V1-Nebensätze einzuordnen sind: sie verhalten sich sowohl rechts- wie linksperipher ,absolut unintegriert'. Was diesen Unterschied zu den ebenfalls uneingeleiteten, aber relativ (un)integrier-

63. Für Merkmale der Adjunktion als strukturbildende Operation vgl. zusammenfassend Chomsky (2004: $117 \mathrm{f}$.).

64. Für basisgenerierte Adjunktion (nicht nur) von Adverbialsätzen im Idg. argumentiert etwa Kiparsky (1995: 157f.), zu Adjunktion von Adverbial- an Argumentsätze im Ahd. und Aengl. s. Axel (2007: 231). Auch McCloskey (2004: 9) oder Chomsky (2004) gehen von basisgenerierten Adjunkten (Adverbial- bzw. Relativsätze) aus. $\mathrm{Zu}$ unintegrierten eingeleiteten Adverbialsätzen s. Haegemans zahlreiche Arbeiten (u. a. von 2003, 2005, 2008) zum Englischen, zum Deutschen Reis (1997), Pittner (1999) und, diachron, Axel (2007).

65. Vgl. auch Bhatt \& Pancheva (2006: 647), die für nachgestellte if-Sätze via PrinzipC-Effekte zeigen, dass keine CP-Adjunktion vorliegt: Satzfinale if-Sätze werden c-kommandiert. Gleiches gilt für wenn-Sätze, s. (56a). Zur (kontroversen) Konzeption eines V-lizenzierten Nachfelds s. u.a. Haider (1995) vs. Müller (1995) und die Beiträge in Beerman et al. (1997). 
ten V2-NS bedingt, ist hier nicht zu klären. Bemerkenswert bleibt, dass alle uneingeleiteten Nebensätze sich ,uneingebettet' verhalten, was mittelbar auch die These von deren lediglich semantisch lizenziertem Substitutscharakter (s. o. ( $\mathrm{SH})$ ) stützt.

Haegeman, die in zahlreichen Arbeiten unintegrierte (periphere) eingeleitete Adverbialsätze, initiale wie finale, sprachübergreifend behandelt hat, stellt vergleichbare pragmatische und syntaktische Kontraste zwischen integrierten vs. unintegrierten Nebensätzen fest, ${ }^{66}$ die vergleichbare Strukturzuweisungen motivieren: ${ }^{67}$ Kanonische, d.h. integrierte Adverbialsätze werden auf IP-Ebene des Bezugssatzes unterhalb des Subjekts eingebettet. Unintegrierte Adverbialsätze weisen eine satzexterne Adjunktionsstruktur auf: 68

[CP1 [CP2 adverbial clause] [CP1 associated clause (=Bezugssatz)] (Haegeman 2005: 71)

Wir nehmen, im Einklang mit den Restriktionen für (basisgenerierte) Adjunktion in Chomsky (2004), genau dasselbe für unsere V1-Gefüge an: V1-Protasis in Erststellung ist linksperipher an die Wurzelprojektion der Apodosis adjungiert (102a) und in Letztstellung rechtsperipher (102b). In beiden Positionen ist sie dort basisgeneriert und satzintern nicht rekonstruierbar.
a. [CP1 [CP2 V1-Protasis] [ $\mathrm{CP}_{\mathrm{CP}}\left[\mathrm{C}^{\circ}\right.$ Apodosis $\left.\left.]\right]\right]$

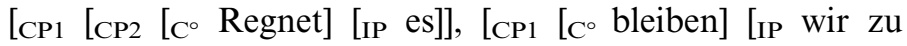 Hause.]]]
b. $\left[\mathrm{CP} 1\left[\mathrm{CP} 1\left[\mathrm{SpecC}\right.\right.\right.$ Wir [ $\mathrm{C}^{\circ}$ würden] [IP $\mathrm{Zu}$ Hause bleiben]]], [CP2 [C ${ }^{\circ}$ würde] [IP es regnen.]]]

66. S. vor allem Haegeman (1985, 2008 [1991], 2005 [2002], 2003, 2006), wo sie auf entsprechende Effekte im Englischen bzgl. Negationsskopus, FHG, Prosodie, aber auch bzgl. parasitärer Lücken verweist (Haegeman 2005: 66-71). Pragmatisch scheinen linksperiphere unintegrierte NS mehr als rechtsperiphere auf die Bereitstellung eines temporalen oder Voraussetzungsrahmens für die Interpretation des Bezugssatzes abgestellt (s. auch die in Abschnitt 2 und 3 diskutierten Funktionen unintegrierter wenn-Sätze), aber gleich unabhängig von diesem.

67. Das betrifft auch die interne Struktur \pm integrierter Adverbialsätze: Beide tragen nach Haegeman (2005: 77) ein ,Sub'-Merkmal, das die semantische Unterordnung gewährleistet, unterscheiden sich aber oberhalb der Fin-Projektion: Nur unintegrierte Sätze besitzen gemäß ihren pragmatischen ,Hauptsatz'-Eigenschaften eine eigene Satztyp (=C-) Projektion.

68. Nach Haegeman (2008: 589 f.) sind dagegen unintegrierte (periphere) Adverbialsätze ,orphans', d. h. außerhalb der syntaktischen Struktur zu repräsentieren. 
Damit sind die zentralen Eigenschaften der V1-Gefüge abbildbar: Unintegriertheit und die damit verbundenen Eigenschaften resultieren aus der satzexternen Adjunktion der V1-Protasis, ebenso die Identifikation der unintegriert verbundenen Sätze als Neben- vs. Bezugssatz, die gleichzeitig als Aufhänger der semantischen Interpretation fungiert. Gleiches gilt für die weiteren syntaktischen und prosodischen Effekte von Unintegriertheit initialer V1-Sätze: Ihre basisgenerierte, satzexterne Adjunktion entspricht dem fehlenden Gliedsatzstatus, erklärt die Bindungsdaten, die Prinzip-C-Effekte, Skopusdaten und die separate Fokus-HintergrundGliederung. Auch nicht-initiale V1-Sätze verhalten sich (absolut) unintegriert, wie aus Daten zur VP-Topikalisierung (4.1.2: (48)-(49)), Bindungsdaten und Prinzip-C-Effekten (4.3: (55)-(56)) hervorgeht. Dabei zeigte sich, dass nachgestellte wenn-Sätze, anders als V1-Sätze, vom Subjekt des Bezugssatzes c-kommandiert werden. Selbst IP-Adjunktion würde die Prinzip-C-Effekte nicht abbilden können.

Nachzutragen ist, dass Adjunktion an Argumente (s. McCloskey 2004 fürs Englische) auch im Gwd. möglich sind, vgl. (103), aber nur für satzintern lizenzierte Konstituenten. Insofern wird unsere Analyse durch den Kontrast zwischen möglicher Adjunktion von wenn-Sätzen (103a) vs. unmöglicher Adjunktion von V1-Sätzen an dass-Komplemente (103b, c) erneut bestätigt. ${ }^{69}$

(103) a. Ich habe befürchtet, [CP1 [CP2 wenn das stimmt], [CP1 dass du nachgeben musst]].

b. ??/*Ich habe befürchtet, [CP1 [CP1 dass du nachgeben müsstest], [CP2 stimmte das]].

c. *Ich habe befürchtet, [CP1 [CP2 stimmte das], [CP1 dass du nachgeben müsstest]].

Die CP-Adjunktionsanalyse wird also den empirischen Eigenschaften unintegrierter V1-Gefüge gerecht, gleich ob die Protasis initial oder final steht. Zwei ergänzende Überlegungen sind allerdings notwendig: (i) Da es auch integrierte Herausstellungsstrukturen nach links gibt, so insbesondere die o. a. LVK (die auch Sätze umfasst), ist diese Adjunktionsanalyse mit einem Modell der linken Satzperipherie zu koppeln, das die satzinterne Erfassung der LVK erlaubt. (ii) Um der Möglichkeit von V1-

69. Der wenn-Satz in (103a) ist (analog zu Fällen wie: Ich weiß, wenn das stimmt, was du tun musst) als an den dass-Satz adjungiert aufzufassen und dabei - im Einklang mit dem oben Festgestellten - unintegriert. Hinsichtlich (103b, c) könnte deutlich erkennbarer Konjunktiv den Effekt mildern (vgl. ?/?? Ich fürchte, dass du nachgeben müsstest, würde das stimmen). (Auf die Notwendigkeit dieser Präzisierungen hat uns einer der Gutachter aufmerksam gemacht.) 
Status der Apodosis gerecht zu werden, muss dieses Modell auch den Unterschied zwischen V2- und V1-Deklarativen als signifikant ausweisen können. Für (i) liefert der in 6.3 skizzierte Vorschlag von Frey (2006) einen geeigneten Ansatzpunkt. Wie (ii) in einem Split-CP-Modell empirisch sinnvoll zu gewährleisten ist, bleibt noch zu klären. ${ }^{70}$

\subsection{Nachbemerkung: Mehrfache Modifikation und Adjunktion}

Im Zusammenhang mit der Adjunktionsanalyse liegt die Frage nahe, wie es sich strukturell mit Mehrfachmodifikation durch Konditionalsätze, also iterierter Adjunktion, verhält.

Linksperiphere Mehrfachmodifikation durch wenn-Konditionale ist illustriert in (104). Dabei hat die unmittelbar eingebettete CP2, die Apodosis des modifizierenden Konditionals, die unmittelbar modifizierende Funktion fürs Gesamtgefüge: Wir bleiben nicht zu Hause, wenn es regnet, sondern wenn es beim Regen auch donnert. Interessanterweise ist im modifizierenden Konditional nur die Abfolge Apodosis > Protasis möglich. Das gilt auch für jeden weiteren wenn-Satz, der einen übergeordneten wenn-Satz modifiziert, und den durch diesen modifizierten Satz gegebenen Bedingungsraum weiter einschränkt, vgl. etwa [[Wenn es donnert [wenn es regnet [wenn es Nacht ist]]] [bleiben wir zu Hause]]; allerdings sind solche Sätze fast nicht mehr zu verarbeiten.

(104) $[\mathrm{CP} 1[\mathrm{SpecC} 1[\mathrm{CP} 2$ Wenn es donnert, [CP3 wenn es regnet, $]]]$ [C, bleiben [IP wir zu Hause.]]]

Prinzipiell können auch unintegrierte V1-Konditionale rekursiv modifizieren, s. (105a), bei gleicher Bedeutung wie (104). Aber geht das auch, wenn der Bezugssatz selbst ein V1-Konditional ist wie in (105b, c), also mehrfache Adjunktion an die Apodosis vorläge? (Da indikativische V1Protasis normalerweise nicht nachgestellt wie in (105b) vorkommt, ist (105c) mit vorangestellter Protasis hinzugefügt.)

(105) a. [CP1 [СР2 Donnert es, [CP3 wenn es regnet,]] [CP1 [C bleiben [ip wir zu Hause.]]]]

b. [CP1 [CP2 Donnert es,] [CP3 regnet es,]] [CP1 [C bleiben [IP wir zu Hause.]]]]

70. Es geht darum, Beschränkungen für die Aktualisierung/Besetzung der diversen präfiniten Spec-Positionen zu formulieren, die nicht nur den V2-Constraint fürs Deutsche gewährleisten, sondern V1-Sätze als echte Alternativstruktur (also nicht als V2-Satz mit PF-leerem Operator im Vorfeld) ausweisen. Für eine einsichtsvolle Diskussion dieses Punkts vgl. Sternefeld (2006: 431 f.). 
c. [CP1 [CP2 [CP3 Regnet es,] donnert es,] [CP1 [C, bleiben [IP wir $\mathrm{zu}$ Hause.]]]]

Abgesehen davon, dass die Interpretation für (105b, c) schwer fällt, scheint sie nicht der in (104) zu entsprechen, vielmehr ist die präferierte Interpretation in beiden Fällen eine parataktische (tendenziell disjunktive) Verknüpfung von $\mathrm{CP} 3$ und $\mathrm{CP} 2:^{71}$ Wenn es regnet oder wenn es donnert, bleiben wir zu Hause, aber auch, wenn nur eins davon zutrifft. Auf den ersten Blick widerspricht das der Adjunktionsanalyse von 6.4 Adjunktion sollte im Prinzip iterierbar sein. Auf den zweiten Blick allerdings nicht: U.E. wird die konditionale Interpretation iterierter V1-Nebensätze durch das parataktische prosodische Muster von V1-Konditionalgefügen blockiert: In zweigliedrigen Gefügen endet die Protasis mit hohem Grenzton (steigendes Muster), verbunden mit einer Pause, die Apodosis mit tiefem Grenzton (fallendes Muster) (106a). Im Fall der zweifachen Adjunktion (106b) sollte u. E. CP2, als Apodosis von CP3, fallendes Tonmuster haben, um als solche erkennbar zu sein, als (Ende der) Protasis zu CP1 muss sie jedoch steigendes Muster, wieder gefolgt von einer Pause, aufweisen. Die ,Rettung' aus diesem Dilemma besteht in Anpassung der Interpretation an die Prosodie; was zu einer nichtkonditionalen, parataktischen Interpretation von CP3-CP2 führt. Inwiefern diese nicht einer und-, sondern einer, inklusiven oder 6 -Interpretation zu entsprechen scheint, vgl. (105b, c), müssen wir hier offen lassen.

(106) a. [CP1 [CP2 Donnert es, $\uparrow]$ \# [CP1 bleiben [IP wir zu Hause. $\downarrow]]]$ b. [CP1 [CP2 [CP3 Regnet es, $\uparrow]$ \# [CP2 donnert es, $\uparrow]]$ \# [CP1 bleiben [IP wir zu Hause. $\downarrow$ ]]]

Allerdings scheint Iterierung nicht grundsätzlich die konditionale Interpretation zu blockieren, vgl. den folgenden Fall mit medialer Protasis im modifizierenden Konditional (107): ${ }^{72}$

(107) [ [CP1 [CP2 Stünde/Steht, [CP3 wollte/will ich das Lokal betreten] ein Türsteher am Eingang], [CP1 würde [IP ich...]]]

Iterierte Modifikation durch V1-Konditionale ist somit grundsätzlich möglich. Erfolgt diese durch Adjunktion, sei es rechts oder links, beschränken allerdings die prosodischen Bedingungen konditionaler V1-

71. Wir danken Christian Fortmann für diesen Hinweis.

72. Diesen Hinweis mitsamt dem Datum verdanken wir einem unserer Gutachter. 
Gefüge die Interpretation entsprechend. ${ }^{73}$ Dass diese letzten Beobachtungen mehr Fragen aufwerfen als Lösungen bereitstellen, ist evident; da sie jedoch unsere Hauptergebnisse nicht zu tangieren scheinen, wollen wir es dabei belassen.

\subsection{Fazit}

Die Adjunktionsanalyse für V1-Gefüge ist den anderen Optionen überlegen, vor allem dadurch, dass sie eine strukturelle Basis für die Abbildung von \pm Integriertheit verfügbar macht. Darüber hinaus ist sie anders als die CP-Rekursions-Analyse standardmäßig derivierbar, anders als das Konnexionsmodell kann sie strukturell zwischen integrierten, relativ (un-) integrierten und absolut unintegrierten Nebensätzen unterscheiden, und anders als im Split-CP-Modell lassen sich syntaktische und prosodische Unintegriertheit gleichermaßen abbilden. Die Iterierbarkeit konditionaler Modifikation (durch wenn- wie V1-Gefüge) bedarf weiterer Untersuchungen.

\section{Schlussbemerkung}

Ziel der vorgehenden Argumentation war zu zeigen, dass die Unintegriertheitshypothese $(\mathrm{H})$ für konditionale V1-Gefüge eine ernst zu nehmende These ist, die der traditionellen Einbettungshypothese vieles voraushat. Die Argumentation vollzog sich in drei Schritten: Nachweis, (i) dass V1und wenn-Gefüge semantisch verschiedene Distribution haben $(=\mathrm{H} 3)$ (Abschnitte 2, 3) - was zumindest gegen die traditionelle Gleichbehandlung ihrer Struktur spricht -, (ii) dass sie auch syntaktisch verschiedene Distribution haben, die für V1-Gefüge auf unintegrierte, ,quasi-parataktische' Struktur verweist $(=\mathrm{H} 1)$ (Abschnitt 4), (iii) dass die durch (ii) forcierte Annahme, dass es sich bei der nachgestellten Apodosis in V1Gefügen entweder um einen V2-Deklarativ mit Vorfeld-Ellipse oder einen V1-Deklarativ handelt $(=\mathrm{H} 2)$ in beiden Ausprägungen verteidigbar ist (Abschnitt 5). Durch Nachweis von $(\mathrm{H} 1)-(\mathrm{H} 2)$ ist $(\mathrm{H})$ direkt bestätigt. Abschnitt 6 enthält einen Präzisierungsvorschlag für $(\mathrm{H})$ in Form einer Adjunktionsanalyse für V1-Gefüge, der durch Vergleich mit verfügbaren Analysealternativen gerechtfertigt wird.

Wie eingangs deutlich gemacht, war die Argumentation für $(\mathrm{H})$ nicht nur Selbstzweck, sondern auch weiterer Schritt auf die Substitutshypo-

73. Ob Medialstellung wie in (107) von der (106b) entsprechenden prosodischen Beschränkung erfasst wird, darüber möchten wir hier nicht spekulieren; es scheint aber so, als ob nur ein einmaliges steigendes Muster vorliegt und die CP3 nur mit einer Grenzpause abgesetzt ist und nicht mit einem ansteigenden Tonmuster endet: Stünde \# [CP3 wollte ich das Lokal betreten] \# ein Türsteher am Eingang,] $\uparrow$ würde ich ... $\downarrow$. 
these ( $\mathrm{SH})$ hin, dass unselbständige V-in-C-Sätze niemals ,geborene' Nebensätze sind, sondern semantisch lizenzierte Substitute für V-End-Sätze bestimmten Typs, mit entsprechend ,markierter' Syntax. Der Nachweis von (H3), in Verbindung mit (H1), hat (SH) auch für V1-Sätze - als semantisch restringierte und entsprechend lizenzierte Substitute für wenn-Sätze bestimmten Typs - bestätigt: V1-Nebensätze haben offenbar eine Bedeutung, die Substitution für/durch wenn-Sätze auf Fälle beschränkt, in denen (a) die Wahrheit des Konsequens von der Wahrheit des Antecedens abhängt und (b) der Wahrheitswert des V1-Antecedens in der thematisierten Welt prinzipiell offen ist. Die Parallelen zur Semantik der V1-Entscheidungsinterrogative (Abschnitt 3) lassen dabei auf die mögliche Spezifikation einer einheitlichen Strukturbedeutung für V1Sätze im Deutschen hoffen.

Es ist uns bewusst, dass damit zur Grammatik von V1-Gefügen längst noch nicht alles Notwendige gesagt oder getan ist. Die unseres Erachtens wichtigsten Desiderata sind folgende: Zum einen die Einordnung unserer Analyse dieser Gefüge in eine begründete Gesamtanalyse der linken Satzperipherie im Deutschen, zum andern die experimentelle Absicherung der zentralen prosodischen Evidenz, schließlich die gründliche Beschäftigung mit empirischen Problemen bzw. Rätseln, die uns die ganze Untersuchung durch begleitet haben, ohne eine uns wirklich befriedigende Lösung zu finden; dazu gehört u.a. das semantische Verhältnis der adversativ-konfrontativen zu konditionalen V1-Gefügen, insbesondere aber der große Einfluss von Indikativ vs. Konjunktiv auf das mehr oder minder klar, integrative' Verhalten von V1-Konditionalen.

Eingereicht: 15. 8. 2008

Überarbeitete Fassung eingereicht:

18. September 2009

Deutsches Seminar

Eberhard-Karls-Universität Tübingen mer@uni-tuebingen.de angelika.woellstein@uni-tuebingen.de

\section{Literatur}

Altmann, Hans (1981). Formen der ,Herausstellung im Deutschen: Rechtsversetzung, Linksversetzung, freies Thema und verwandte Konstruktionen. Tübingen: Niemeyer.

Anderson, Alan R. (1951). A Note on subjunctive and counterfactual conditionals. Analysis 11: $35-38$.

Adger, David \& Joseph Quer (2001). The Syntax and semantics of unselected embedded questions. Language 77: 107-133.

Auer, Peter (2000). Pre- and Post-Positioning of Wenn-Clauses in Spoken and Written German. In Cause - Condition - Concession - Contrast. Cognitive and Discourse Perspectives, Elizabeth Couper-Kuhlen \& Bernd Kortmann (eds.), Berlin, New York: Mouton de Gruxter.

Axel, Katrin (2002). Zur diachronen Entwicklung der syntaktischen Integration linksperipherer Adverbialsätze im Deutschen. Beiträge zur Geschichte der deutschen Sprache und Literatur 124: 1-43. 
Axel, Katrin (2004). The syntactic integration of preposed adverbial clauses on the German left periphery: A diachronic perspective. In The Syntax and Semantics of the Left Periphery, Horst Lohnstein \& Susanne Trissler (eds.), 23-58. Berlin, New York: Mouton de Gruyter.

Axel, Katrin (2007). Studies on Old High German Syntax. Left Sentence Periphery, Verb Placement and Verb-Second. Amsterdam, Philadelphia: John Benjamins.

Axel, Katrin \& Angelika Wöllstein (2008). German verb-first conditionals as unintegrated clauses. A case study in converging synchronic and diachronic evidence. In The Fruits of Empirical Linguistics II, Susanne Winkler \& Sam Featherston (eds.), 1-37. Berlin, New York: Mouton de Gruyter.

Beermann, Dorothee, David LeBlanc \& Henk van Riemsdijk (eds.) (1997). Rightward Movement. Amsterdam, Philadelphia: John Benjamins.

Behaghel, Otto (1928). Deutsche Syntax. Eine geschichtliche Darstellung. Bd. III: Die Satzgebilde. Heidelberg: Winter.

Behaghel, Otto (1932). Deutsche Syntax. Eine geschichtliche Darstellung. Bd. IV: Wortstellung, Periodenbau. Heidelberg: Winter.

Benincà, Paola \& Cecilia Poletto (2004). Topic, focus and V2: Defining the CP sublayers. In The Structure of $C P$ and IP. The Cartography of Syntactic Structures, Luigi Rizzi (ed.), 52-75. Oxford: Oxford University Press.

Bhatt, Rajesh \& Roumyana Pancheva (2006). Conditionals. In The Blackwell Companion to Syntax, Martin Everaert \& Henk R. van Riemsdijk (eds.), 638-687. Oxford: Blackwell.

Bolinger, Dwight (1978). Yes/no questions are not alternative questions. In Questions, Henry Hiz (ed.), 87-105. Dordrecht: Reidel.

Brandt, Margareta (1990). Weiterführende Nebensätze. Zu ihrer Syntax, Semantik und Pragmatik. Stockholm: Almqvist \& Wiksell.

Chomsky, Noam (2004). Beyond explanatory adequacy. In Structures and Beyond: The Cartography of Syntactic Structures. Vol. 3, Adriana Belletti (ed.), 104-131. Oxford: Oxford University Press.

Cinque, Guglielmo (1997 [1983]). 'Topic' constructions in some European languages and 'connectedness'. Reprinted in Materials on Left Dislocation, Elena Anagnostopoulou, Henk van Riemsdijk \& Frans Zwarts (eds.), 93-118. Amsterdam, Philadelphia: John Benjamins.

Cinque, Guglielmo (1999). Adverbs and Functional Heads: A Cross-Linguistic Perspective. Oxford Studies in Comparative Syntax. Oxford: Oxford University Press.

Cinque, Guglielmo (2006). Restructuring and Functional Heads. The Cartography of Syntactic Structures. Oxford Studies in Comparative Syntax. Oxford: Oxford University Press.

Culicover, Peter \& Ray Jackendoff (1997). Semantic subordination despite syntactic coordination. Linguistic Inquiry 28: 195-217. [Wieder in: Peter Culicover \& Ray Jackendoff (2005): Kap. 13. 473-499.]

Culicover, Peter \& Ray Jackendoff (1999). The view from the periphery: The English comparative correlative. Linguistic Inquiry 30: 543-571. [Wieder in: Peter Culicover \& Ray Jackendoff (2005): Kap. 14. 500-529.]

Culicover, Peter \& Ray Jackendoff (2005). Simpler Syntax. Oxford: Oxford University Press.

Dancygier, Barbara (1998). Conditionals and Prediction. Time, Knowledge and Causation in Conditional Constructions. Cambridge: Cambridge University Press.

Eckardt, Regine (2007). The syntax and pragmatics of embedded yes/no questions. In On Information Structure, Meaning, and Form, Kerstin Schwabe \& Susanne Winkler (eds.), 447-466. Amsterdam, Philadelphia: John Benjamins.

Eggs, Ekkehard (2004). Zwischen Kausalität und Konditionalität. In Brücken schlagen: Grundlagen der Konnektorensemantik, Hardarik Blühdorn, Eva Breindl \& Ulrich Hermann Waßner (eds.), 333-372. Berlin, New York: Mouton de Gruyter. 
Eisenberg, Peter (1999). Grundriss der deutschen Grammatik. Bd. 2: Der Satz. Stuttgart: Metzler.

Fabricius-Hansen, Cathrine (1980). Sogenannte ergänzende wenn-Sätze. Ein Beispiel semantisch-syntaktischer Argumentation. In Festschrift für Gunnar Bech, Mogens Dyhr, Karl Hyldgaard-Jensen \& Jørgen Olsen (eds.), 160-188. Kopenhagen: Institut for germansk filologi.

Fabricius-Hansen, Cathrine (1997). Der Konjunktiv als Problem des Deutschen als Fremdsprache. Germanistische Linguistik 136: 13-36.

Fabricius-Hansen, Cathrine \& Kjell Johann Sæbø (1983). Über das Chamäleon wenn und seine Umwelt. Linguistische Berichte 83: 1-35.

Fabricius-Hansen, Cathrine \& Kjell Johann Sæbø (2004). In a mediative mood: The Semantics of the German reportive subjunctive. Natural Language Semantics 12: 213-257.

Fintel, Kai von (1999). The presuppositions of subjunctive conditionals. In MIT Working Papers in Linguistics 25, Uli Sauerland \& Orin Percus (eds.), 29-44.

Frank, Nicola (1998). Präferenzprädikate und abhängige Verbzweitsätze. Magisterarbeit, Tübingen. (Arbeitspapiere des SFB 340 Stuttgart-Tübingen. Bericht Nr. 128).

Frey, Werner (2004). Notes on the syntax and pragmatics of German Left Dislocation. In The Syntax and Semantics of the Left Periphery, Horst Lohnstein \& Susanne Trissler (eds.), 203-234. Berlin, New York: Mouton de Gruyter.

Frey, Werner (2005a). Zur Syntax der linken Peripherie im Deutschen. In Deutsche Syntax: Empirie und Theorie. Symposium Göteborg 13.-15. Mai 2004, Franz Josef d'Avis (ed.), 147-171. Göteborg: Acta Universitatis Gothoburgensis.

Frey, Werner (2005b). Pragmatic properties of certain German and English left peripheral constructions. Linguistics 43(1): 89-129.

Frey, Werner (2006). Contrast and movement to the German prefield. In The Architecture of Focus, Valéria Mólnár \& Susanne Winkler (eds.), 235-264. Berlin, New York: Mouton de Gruyter.

Frey, Werner \& Benjamin Shaer (2004). 'Integrated' and 'non-integrated' left-peripheral elements in German and English. In Proceedings of the Dislocated Elements Workshop, ZAS Berlin, November 2003, Werner Frey, Benjamin Shaer \& Claudia Maienborn (eds.), 465-502. Berlin: ZAS (ZAS Papers in Linguistics, 35).

Glas, Reinhold (1984). Sollen im heutigen Deutsch. Bedeutung und Gebrauch in der Schriftsprache. Tübingen: Narr.

Green, Georgia M. (1980). Some wherefores of inversion. Language 56: 582-602.

Greenberg, Joseph H. (1963). Some universals of grammar with particular reference to the order of meaningful elements. In Universals of Language, Joseph Greenberg (ed.), 73113. Cambridge, MA: MIT Press.

Grewendorf, Günther (2002). Left dislocation as movement. In Georgetown University Working Papers in Theoretical Linguistics. Vol. 2, Simon Mauck \& Jenny Mittelstaedt (eds.), 31-81.

Grohmann, Kleanthes K. (2003). Successive cyclicity under (anti-)local considerations. Syn$\operatorname{tax}$ 6: $260-312$.

Günthner, Susanne (1999). Wenn-Sätze im Vor-Vorfeld. Deutsche Sprache 3: 209-235.

Haegeman, Liliane (1985). Subordinating conjunctions and X-bar syntax. Studia Germanica Gandensia 2: 1-42.

Haegeman, Liliane (2008 [1991]). Parenthetical adverbials: The radical orphanage approach. In Dislocated Elements in Discourse. Syntactic, Semantic, and Pragmatic Perspectives, Benjamin Shaer, Philippa Cook, Werner Frey \& Claudia Maienborn (eds.), 580-611. London: Routledge.

Haegeman, Liliane (2005 [2002]). The syntax of adverbial clauses and its consequences for topicalization. Paper presented at Linguistique des Langues Romanes. Hommage à Liliane Tasmowski. [Unveröff. Ms. Université Charles de Gaulle, Lille III]. 
Haegeman, Liliane (2003). Conditional clauses: External and internal syntax. Mind and Language 18: 317-339.

Haegeman, Liliane (2006). Conditionals, factives, and the left periphery. Lingua 116: $1651-1669$.

Haider, Hubert (1995). Downright down to the right. In On Extraction and Extraposition in German, Uli Lutz \& Jürgen Pafel (eds.), 245-271. Amsterdam, Philadelphia: John Benjamins.

Haiman, John (1983). Paratactic if-clauses. Journal of Pragmatics 7: 263-281.

Haiman, John (1986). Constraints on the form and meaning of the protasis. In On Conditionals, Elizabeth Closs Traugott, Alice Ter Meulen, Judy Snitzer Reilly \& Charles A. Ferguson (eds.), 215-227. Cambridge: Cambridge University Press.

Hermodsson, Lars (1977). „Wenn Goethe sagt ... “ Zum ,resumptiven“ oder ,formal-konditionalen wenn. Moderna Språk 71: 227-238.

Hilpert, Martin (i. E.). What can synchronic gradience tell us about reanalysis? Verb-first conditionals in written German and Swedish. [Erscheint in: Grammaticalization and Grammar, Kristin Davidse, Hubert Cuyckens \& Jean Ch. Verstraete (eds.). Amsterdam, Philadelphia: John Benjamins.]

HdK (2003) = Pasch, Renate, Ursula Brauße, Eva Breindl \& Ulrich H. Waßner (2003). Handbuch der deutschen Konnektoren. Linguistische Grundlagen der Beschreibung und syntaktische Merkmale der deutschen Satzverknüpfer (Konjunktionen, Satzadverbien und Partikeln). Berlin, New York: Mouton de Gruyter.

Iatridou, Sabine (2000). The grammatical ingredients of counterfactuality. Linguistic Inquiry 31: $231-270$.

Iatridou, Sabine \& David Embick (1994). Conditional inversion. In Proceedings of NELS 24. Merce González (ed.), 189-203. Amherst: Graduate Linguistics Student Association.

Iatridou, Sabine \& Anthony Kroch (1992). The licensing of CP-recursion and its relevance to the Germanic verb-second phenomenon. Working Papers in Scandinavian Syntax 50: $1-24$.

Johannessen, Janne-Bondi (1998). Coordination. Oxford: Oxford University Press.

Kayne, Richard S. (1984). Connectedness and Binary Branching. Dordrecht: Foris.

Kayne, Richard S. (1994). The Antisymmetry of Syntax. Cambridge, MA: MIT Press.

Kiparsky, Paul (1995). Indoeuropean origins of Germanic syntax. In Clause Structure and Language Change, Adrian Battye \& Ian G. Roberts (eds.), 140-169. Oxford: Oxford University Press.

Kaufmann, Gerhard (1972). Das konjunktivische Bedingungsgefüge im heutigen Deutsch. Tübingen: Narr.

König, Ekkehard (1986). Conditionals, concessive conditionals and concessives: Areas of contrast, overlap and neutralization. In On Conditionals, Elizabeth Closs Traugott, Alice Ter Meulen, Judy Snitzer Reilly \& Charles A. Ferguson (eds.), 229-246. Cambridge: Cambridge University Press.

König, Ekkehard (1992). From discourse to syntax: The case of concessive conditionals. In Who Climbs the Grammar Tree, Rosemarie Tracy (ed.), 423-434. Tübingen: Niemeyer.

König, Ekkehard \& Jan van der Auwera (1988). Clause integration in German and Dutch conditionals, concessive conditionals and concessives. In Clause Combining in Grammar and Discourse, John Haiman \& Sandra A. Thompson (eds.), 101-134. Amsterdam, Philadelphia: John Benjamins.

Köpcke, Klaus-Michael \& Klaus-Uwe Panther (1989). On correlations between word order and pragmatic function of conditional sentences in German. Journal of Pragmatics 13: $685-711$.

Lasersohn, Peter (1996). Adnominal conditionals. In Proceedings of SALT VI, Teresa Galloway \& Justin Spence (eds.), 154-166. Ithaca: Cornell University Press.

Lewis, David (1981 [1978]). Kausalität. In Kausalität. Neue Texte, Günter Posch (ed.), 102126. Stuttgart: Reclam. 
Maurer, Friedrich (1926). Untersuchungen über die deutsche Verbstellung in ihrer geschichtlichen Entwicklung. Heidelberg: Winter.

Metschkowa-Atanassowa, Sdrawka (1983). Temporale und konditionale „wenn“-Sätze. Untersuchungen zu ihrer Abgrenzung und Typologie. Düsseldorf: Schwann-Bagel.

McCloskey, John (2004). Questions and questioning in local English, Manuskript, University of California, Santa Cruz.

Meinunger, André (2006). Interface Restrictions on V2. The Linguistic Review 23: 127-160.

Munn, Alan (1987). Coordinate structure and X-bar theory. McGill Working Papers in Linguistics 4: $121-140$.

Müller, Gereon (1995). On extraposition and successive cyclicity. In On Extraction and Extraposition in German, Uli Lutz \& Jürgen Pafel (eds.), 213-244. Amsterdam, Philadelphia: John Benjamins.

Nieuwint, Pieter (1989). Should in conditional protases. Linguistics 27: 305-318.

Öhl, Peter (2007). Unselected embedded interrogatives in German and English. S-Selection as dependency formation. Linguistische Berichte 212: 403-437.

Önnerfors, Olaf (1997). Verberst-Deklarativsätze. Grammatik und Pragmatik. Stockholm: Almqvist \& Wiksell.

Pittner, Karin (1999). Adverbiale im Deutschen. Untersuchungen zu ihrer Stellung und Interpretation. Tübingen: Stauffenburg.

Polikarpow, Alexander (1996). Zum Problem der asyndetischen Subordination in der Syntax der gesprochenen deutschen Sprache. Deutsche Sprache 24: 154-168.

Redder, Angelika (1987). Wenn ... so. Zur Korrelatfunktion von so. In Sprache und Pragmatik. Lunder Symposium 1986, Inger Rosengren (ed.), 315-326. Stockholm: Almqvist \& Wiksell.

Reich, Ingo (2009). Asymmetrische Koordination im Deutschen. Tübingen: Stauffenburg.

Reis, Marga (1997). Zum syntaktischen Status unselbständiger Verbzweit-Sätze. In Sprache im Fokus. Festschrift für Heinz Vater zum 65. Geburtstag, Christa Dürscheid, Karl-Heinz Ramers \& Monika Schwarz (eds.), 121-144. Tübingen: Niemeyer.

Reis, Marga (2000). Anmerkungen zu Verb-erst-Sätzen im Deutschen. In Deutsche Grammatik in Theorie und Praxis, Rolf Thieroff, Matthias Tamrat, Nanna Fuhrhop \& Oliver Teuber (eds.), 215-227. Tübingen: Niemeyer.

Rizzi, Luigi (1997). The fine-structure of the left periphery. In Elements of Grammar: Handbook of Generative Syntax, Liliane Haegeman (ed.), 281-337. Dordrecht: Kluwer.

Rizzi, Luigi (2004). On the cartography of syntactic structures. In The Structure of CP and IP: The Cartography of Syntactic Structures, Vol. 2, Luigi Rizzi (ed.), 3-15. Oxford: Oxford University Press.

Rosengren, Inger (1993). Imperativsatz und „Wunschsatz“ - zu ihrer Grammatik und Pragmatik. In Satz und Illokution, Bd. 2, Inger Rosengren (ed.), 1-47. Tübingen: Niemeyer.

Schwarz, Bernhard (1998). Reduced conditionals in German: Event quantification and definiteness. Natural Language Semantics 6: 271-301.

Sternefeld, Wolfgang (2006). Syntax. Eine morphologisch motivierte generative Beschreibung des Deutschen. 2 Bde. Tübingen: Stauffenburg.

Traugott, Elizabeth Closs (1985). Conditional markers. In Iconicity in Syntax, John Haiman (ed.), 289-307. Amsterdam, Philadelphia: John Benjamins.

Truckenbrodt, Hubert (2004). Zur Strukturbedeutung von Interrogativsätzen. Linguistische Berichte 199: 313-350.

Truckenbrodt, Hubert (2005). A short report on intonation phrase boundaries in German. Linguistische Berichte 203: 273-296.

Truckenbrodt, Hubert (2006). On the semantic motivation of syntactic verb movement to $\mathrm{C}$ in German. Theoretical Linguistics 32: 257-306.

Uhmann, Susanne (1991). Fokusphonologie. Eine Analyse deutscher Intonationskonturen im Rahmen der nicht-linearen Phonologie. Tübingen: Niemeyer. 
Van den Nest, Daan (i. E.) Should conditionals be emergent. Asyndetic subordination in German and English as a challenge to grammaticalization research. [Erscheint in: Grammaticalization and Grammar, Kristin Davidse, Hubert Cuyckens \& Jean Ch. Verstraete (eds.). Amsterdam, Philadelphia: John Benjamins.]

Vandergriff, Ilona (1997). Two-domain conditionals: Verb-first, integration, politeness. In Insights in Germanic Linguistics II, Irmengard Rauch \& Gerald F. Carr (eds.), 257274. Berlin, New York: Mouton de Gruyter.

Welke, Klaus (1965). Untersuchungen zum System der Modalverben in der deutschen Sprache der Gegenwart. Ein Beitrag zur Erforschung funktionaler und syntaktischer Beziehungen. Berlin: Akademie-Verlag.

Wöllstein, Angelika (2008). Konzepte der Satzkonnexion. Tübingen: Stauffenberg.

Zaefferer, Dietmar (1987). Satztypen, Satzarten, Satzmodi - Was Konditionale (auch) mit Interrogativen zu tun haben. In Satzmodus zwischen Grammatik und Pragmatik. Referate anläßlich der 8. Jahrestagung der Deutschen Gesellschaft für Sprachwissenschaft. Heidelberg 1986, Jörg Meibauer (ed.), 259-285. Tübingen: Niemeyer.

Zifonun, Gisela, Ludger Hoffmann, Bruno Strecker \& Joachim Ballweg (1997). Grammatik der deutschen Sprache. 3 Bde. Berlin, New York: Mouton de Gruyter. 